\title{
THE IMPACT OF SECONDARY LYMPHEDEMA AFTER HEAD AND NECK CANCER TREATMENT ON SYMPTOMS, FUNCTIONAL STATUS, AND QUALITY OF LIFE
}

\author{
By \\ JIE DENG \\ Dissertation \\ Submitted to the Faculty of the \\ Graduate School of Vanderbilt University \\ in partial fulfillment of the requirements \\ for the degree of \\ DOCTOR OF PHILOSOPHY
}

in

Nursing Science

August, 2010

Nashville, Tennessee

\author{
Approved: \\ Professor Sheila H. Ridner \\ Professor Mary S. Dietrich \\ Professor Barbara A. Murphy \\ Professor Kenneth A. Wallston \\ Professor Nancy Wells
}


Copyright (C) 2010 by Jie Deng All Rights Reserved 
Dedicated to individuals with head and neck cancer 


\section{ACKNOWLEDGMENTS}

This is a great opportunity for me to express my appreciation to all of those who supported me during my dissertation study.

First and foremost, I would like to express my deepest appreciation to my exceptional mentor and committee chair, Dr. Sheila H. Ridner. I greatly appreciate that she let me work with her in her two research studies during my PhD program, which stimulated my idea to conduct this study as well as being a very significant experience for me to learn about how to manage and conduct research studies as a principle investigator. She has been a true model for me to be a great student, teacher, scholar, and scientist. Without her guidance, support, assistance, and encouragement, I would not have completed my dissertation study. I also want to give my sincerest thanks to the excellent members of my dissertation committee: Drs. Mary S. Dietrich, Barbara A. Murphy, Kenneth A. Wallston, and Nancy Wells. I feel so fortunate to have had each of them to work with me given their wide range of knowledge. Each of them has supported and guided me from unique and different angles for my dissertation. It has been a great honor and a true joy to learn from each of them.

Second, I would like to give my special thanks to Drs. Robert Sinard and Anthony Cmelak who both conducted endoscopic examination to assess internal lymphedema in my study. They provided tremendous support during data collection. I would like to specifically thank Dr. Stanley Rockson who has been my external mentor for lymphedema and allowed me to work with him and his research team at Stanford University. This enhanced my knowledge in lymphatic diseases and research. 
I especially appreciate Dr. Mary Jo Gilmer who has been continually supportive during my PhD program. I am highly appreciative of Dr. Larry Lancaster who has been supportive of editing my manuscripts and dissertation as well as providing me with insightful understanding my findings from a physiological perspective. I greatly appreciate Dr. Stewart Bond for his on-going support, guidance, help, and encouragement. I want to give my special thanks to my co-workers of the School of Nursing, including Candace Bonner, Joey O’Dell, and Nancy Kidd for their constant support and encouragement.

I would like to extend my appreciation to the Oncology Nursing Society and Vanderbilt Graduate School for financial support of this project.

The greatest thank I would to give is to my family. I thank my parents for their eternal love, encouragement, and support. I thank my brother and sister for their encouragement and support. Finally, I want to express my upmost appreciation to my husband, Dr. Xuguang Sun, for his endless love, support, inspiration, and encouragement. He has always been my best friend in my life. Without his support, I would not have reached the end of this process. I would like to express my thanks to my daughter, Fangyi, and my son, Michael. I want to thank them for being such wonderful and happy kids every day throughout this process. 


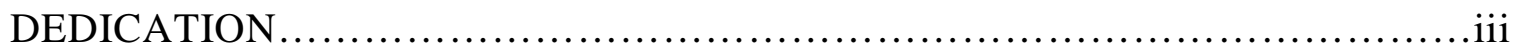

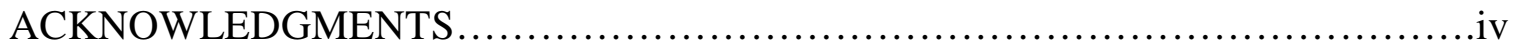

LIST OF TABLES............................................................viii

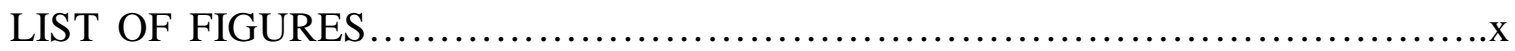

Chapter

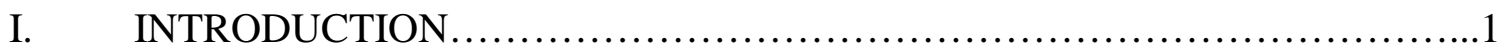

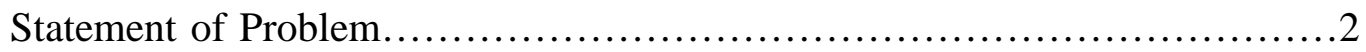

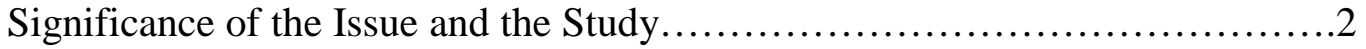

Significance to Society..............................................

Significance to Healthcare..............................................

Significance to Science of Nursing.....................................12

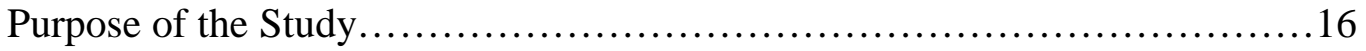

Research Questions..................................................16

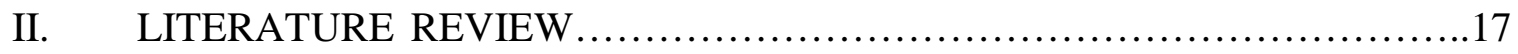

History of the Problem of Interest..........................................17

Theoretical Literature Review............................................19

Methodological Literature Review........................................24

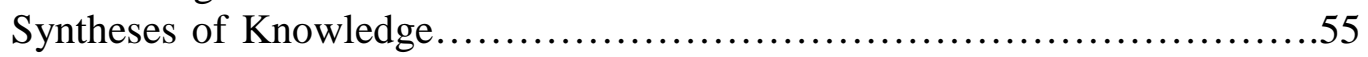

Research Hypotheses..................................................... 57

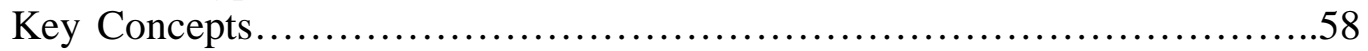

Theoretical Framework for the Study.....................................60

III. METHODOLOGY .........................................................63

Research Design and Assumptions.......................................63

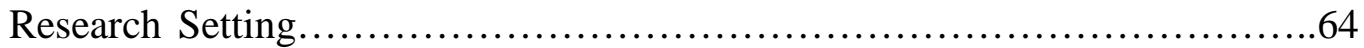

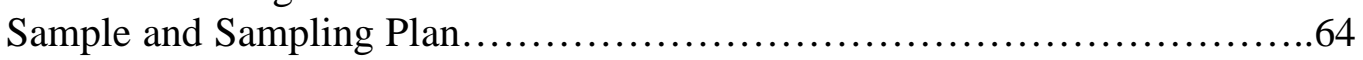

Nature and Size of Sample..........................................64

Criteria for Sample Selection........................................65

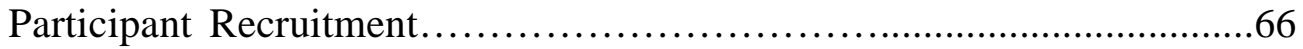

Human Subjects Protection............................................66 
Data Collection Methods..............................................68

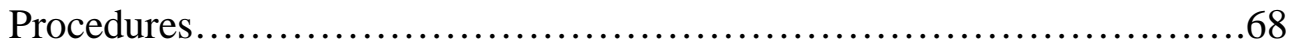

Instruments......................................................68

Credibility, Rigor, and Validity ..................................78

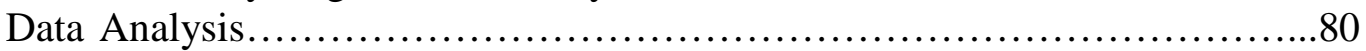

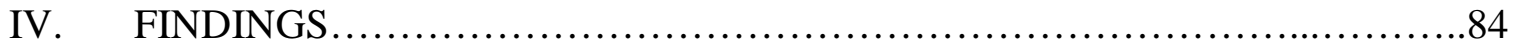

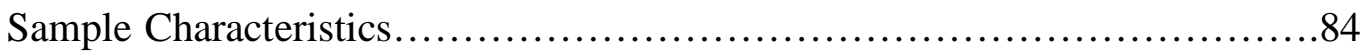

Findings Related to Study Aims.........................................91

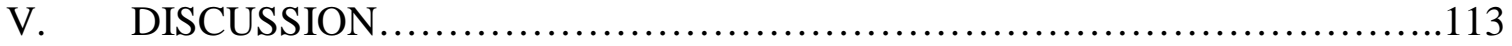

Sample Characteristics...............................................113

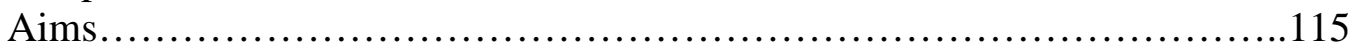

Study Strengths and Limitations.........................................131

Implications .................................................... 134

Recommendations for Future Research...............................137

Appendix

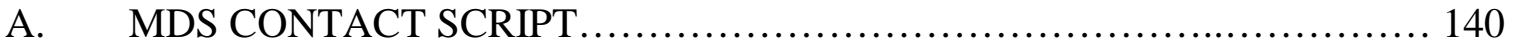

B. PATIENTS CONTACT CRIPT ............................................ 141

C. SCREENING FORM..........................................................142

D. DEMOGRAPHIC AND BACKGROUND INFORMATION FORM...........143

E. HEAD AND NECK CANCER DISEASE \& TREATMENT INFORMATION FORM................................................144

F. PATTERSON'S SCALE FOR EDEMA IN LARYNX AND

PHARYNX................................................................145

G. LYMPHEDEMA DISEASE \& TREATMENT INFORMATION FORM.......146

H. VANDERBILT HEAD AND NECK SYMPTOM SURVEY (VHNSS).........147

I. HOSPITAL ANXIETY AND DEPRESSION SCALE (HADS)..................149

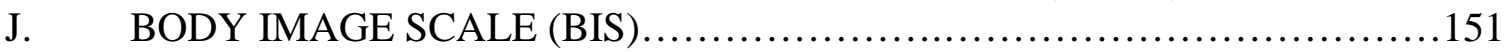

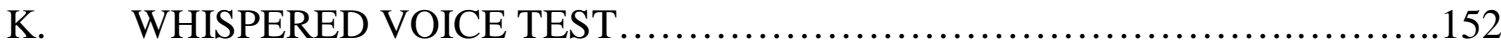

L. TRISMUS GRADING CRITERIA .......................................153

M. CERVICAL RANGE OF MOTION (CROM) …............................154

N. FACT-H\&N (VERSION 4)....................................................... 155

O. QUALITY OF LIFE SCALE (LINEAR ANALOG SELF

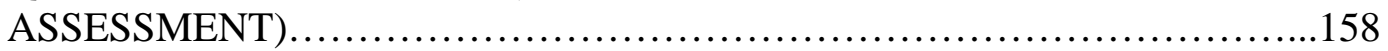

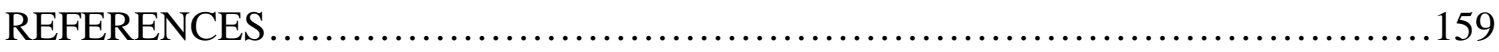




\section{LIST OF TABLES}

Table

1. An Estimate the Cost for Initial Treatment for One Head and Neck Cancer Patient with Secondary Lymphedema.................................

2. Conceptual Models \& Theories Related to the Problem of Interest...............20

3. NCI Lymphedema of the Head and Neck Grading Scale......................25

4. NCI Lymphedema-related Fibrosis Scale...................................26

5. ACS Lymphedema of the Head and Neck Staging Criteria.......................27

6. Clinical Classification of Lymphedema..................................28

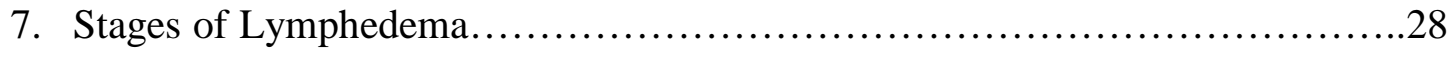

8. Symptom and Functional Impairment Studies...............................33

9. Common Instruments Used to Measure Psychological Effects in Cancer Survivors..................................................40

10. Common Quality of Life Instruments for Head and Neck Cancer...............43

11. Tuning Fork Test Results.............................................. 74

12. Data Resources and Data Collection Methods................................77

13. Demographic Characteristics.......................................... 86

14. Health Behavior Characteristics....................................... 87

15. Head and Neck Cancer Disease and Treatment Characteristics.................88

16. Internal Consistency and Sample Scores on the Instruments...................90

17. Prevalence of Secondary Lymphedema..................................91

18. Internal Lymphedema Data.........................................92

19. Location and Extent of Internal Lymphedema.............................92 
20. External Lymphedema Data........................................93

21. Associations between Severity of Lymphedema (LE) and VHNSS Scores........................................................95

22. Associations between Severity of Lymphedema (LE) and BIS/HADS Scores....

23. Functional Status Data...................................................99

24. Associations of Severity of Lymphedema (LE) with Hearing Test..............100

25. Associations of Severity of Lymphedema (LE) with Trismus...................101

26. Associations of Severity of Lymphedema (LE) with CROM..................102

27. Associations between Severity of Lymphedema (LE) and Signs

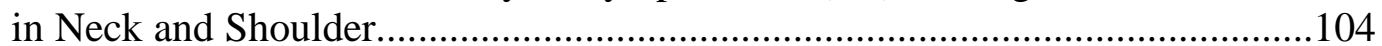

28. Associations of Severity of Lymphedema (LE) and FACT-H\&N.............107

29. Associations between Severity of Lymphedema (LE) and LASA .............108

30. Logistic Regression of Possible Factors on Any Lymphedema...............110

31. Logistic Regression of Possible Factors on Combined lymphedema.............112 


\section{LIST OF FIGURES}

Figure

Page

1. The Theory of Unpleasant Symptoms.................................61 


\section{CHAPTER I}

\section{INTRODUCTION}

Lymphedema is an accumulation of lymphatic fluid and proteins in the interstitial spaces (Rockson, 2001). Lymphedema may be either primary or secondary. Primary lymphedema is a rare, inherited condition in which lymph nodes and lymph vessels are abnormal or absent (National Cancer Institute [NCI], 2007a). Secondary lymphedema is usually the consequence of cancer treatment, of blocking the lymphatic pathways by tumors (Foldi, Foldi, Strobenreuther, \& Kubik, 2006), trauma, large or circumferential wounds, or burns (Hettrick, Nof, Ward, \& Echernach, 2004; Rockson \& Rivera, 2008). Secondary lymphedema is the most common form of lymphedema in developed countries (Foldi et al., 2006). The most common cause of secondary lymphedema in the United States is cancer therapy (Dos, Gorska-Dos, \& Szuba, 2005; Lymphoedema Framework, 2006). As a result of lymph node dissection, radiation, and chemotherapy, many cancer patients develop secondary lymphedema after their cancer treatment, such as those with breast, ovarian, melanoma, and head and neck cancer (Foldi et al., 2006; Ridner, 2008). Once an individual develops either primary or secondary lymphedema, they face burdensome life-long self-care and often experience physical, psychological, and social difficulties. For example, they may have to change their vocations, and family income may suffer (Lewis \& Morgan, 2008; Radina \& Armer, 2001). Their families or significant others may also be impacted by the changes lymphedema causes in the affected person (Lymphoedema Framework, 2006; Rockson \& Rivera, 2008; Sneddon \& 
Lewis, 2007). Thus, lymphedema is a significant societal issue for patients, their families, and society.

\section{Statement of Problem}

The problem of interest is secondary lymphedema related to head and neck cancer treatment. European literature provides evidence that head and neck cancer patients may have a higher risk and a higher prevalence of secondary lymphedema from surgery, radiotherapy, and chemoradiation therapy than other cancer patients (Micke et al., 2003). However, limited research studies exist regarding secondary lymphedema related to treatment of head and neck cancer patients, especially its symptoms, signs (measurement), affects on body functions, influences on quality of life, and possible risk factors. There is a need (1) to examine the significance of the problem of interest to society, healthcare, and science of nursing; (2) to determine the state of science; and (3) to conduct a research study that will further our knowledge and fill in gaps in the current literature (e.g., symptoms, functional status, and quality of life related to secondary lymphedema in head and neck cancer patients).

Significance of the Issue and the Study

\section{Significance to Society}

Incidence of Head and Neck Cancer and Related Secondary Lymphedema

In the United States, although the overall incidence of head and neck cancer has slightly decreased in the past two decades, the incidence of tongue and tonsillar cancer 
has increased, especially in young adults (Argiris, Karamouzis, Raben, \& Ferris, 2008). It was estimated that 48,010 Americans developed head and neck cancer and 11,260 deaths from oral cavity, pharynx, and larynx cancer occurred in 2009 (American Cancer Society, [ACS], 2009). Early detection and multi-modality therapy have led to improvement in survival rates, leaving many head and neck cancer patients at risk for experiencing secondary complications from their cancer treatment (Bentzen et al., 2003; ONS Research Agenda, 2009-2013), such as secondary lymphedema. In the European literature, the prevalence of secondary lymphedema after head and neck cancer, whether with combined or single treatment, varies between 12\% and 54\% (Buntzel, Glatzel, Mucke, Micke, \& Bruns, 2007; Dietz et al., 1998; Schiefke et al., 2009; Wolff et al., 2009). The prevalence and the incidence of secondary lymphedema related to head and neck cancer treatment in the United States are unknown and unpublished at this time. The data from a observation study the PI conducted over 7 clinic days at the VanderbiltIngram Cancer Center, Tennessee, USA, show that approximately 25\% (11/43) head and neck cancer patients greater than 3 months post-treatment have secondary external lymphedema. There are more than a half million head and neck cancer survivors in the United States (Head and Neck Cancer, 2008; Jemal et al., 2007; Oishi, 2007). If head and neck cancer patients in the United States experience lymphedema at rates similar to their European counterparts, 60,000 to 270,000 of them could have lymphedema. Risk Factors for Head and Neck Cancer and Related Secondary Lymphedema Behaviors common to many members of society appear to place individuals directly at risk for developing head and neck cancer and indirectly at risk for developing secondary lymphedema. Specifically, smoking and alcohol use are identified as 
independent risk factors (Hashibe et al., 2007; Itano \& Taoka, 2005; NCI, 2007b).

Several studies report that the combined consumption of cigarette smoke and alcohol increases risk of head and neck cancer by over 30 -fold (ACS, 2008). Although the prevalence of cigarette smoking among adults 18 and older has decreased over the last 30 years, $20.8 \%$ of adults and $23 \%$ of high school students continue to smoke (ACS, 2008). In fact, smoking rates are higher in southern states than the rest of the nation, such as $26 \%$ of Tennessee adults and $27 \%$ of Kentucky adults smoke compared to $20.8 \%$ nationally. The trend is also present among two states’ youth: $27.6 \%$ Tennessee high school students and 28\% Kentucky high school students smoke compared to $23 \%$ nationally (ACS, 2008).

Compared to quitting completely, some of these smokers switched to using smokeless tobacco, which they assume to be a risk-free alternative, but this does not reduce the risk of head and neck cancer (American Academic of Otolaryngology-Head and Neck Surgery [AAO-HNS], 2008). A sexually transmitted virus, the human papillomavirus (HPV), also places certain individuals at risk for developing head and neck cancer (Mouth Cancer Foundation [MCF], 2008; NCI, 2007b). Currently, 5-year survival rate for head and neck cancer is between 59.8\% and 63.6\% (NCI, 2007c). Head and neck cancer is curable if detected early (AAO-HNS, 2008; Werner \& Davis, 2004). Significant societal changes in smoking and alcohol use or abuse and sexual behavioral may be needed to reduce the incidence of head and neck cancer in the United States.

Risk factors for development of secondary lymphedema related to head and neck cancer are unclear as the exact mechanism for development of secondary lymphedema in head and neck cancer patients has not been clarified. This lack of knowledge makes it 
difficult to develop risk reduction strategies or prevention regimens for these patients. Some pathophysiological processes related to cancer treatment may precipitate lymphedema. Head and neck cancer treatment (i.e., surgery, radiation, and/or chemotherapy) disrupts lymphatic structures (e.g., surgical lymphadenectomy and injury of lymphatic vessels), and leads to an increased accumulation of lymphatic fluid in interstitial space. The retention of lymphatic fluid activates inflammatory/immune responses and results in skin tissue fibrosis and adipose deposition (Tabibiazar et al., 2006). Skin tissue fibrosis further aggravates lymphatic function. Thus, lymphatic damage renders the lymphatic system unable to transport normal amounts of fluid and protein from the normal capillary filtration, which is the primary reason that lymphedema occurs after cancer treatment (Foldi et al., 2006). Because of this pathophysiological process, head and neck cancer patients are at high risk for developing secondary lymphedema (Dennert \& Horneber, 2007; Dos et al., 2005; Lymphoedema Framework, 2006; Murphy, Gilbert, \& Ridner, 2007a; Ridner, 2008).

\section{Cost to Patients and Society}

Financial costs. Secondary lymphedema may result in added healthcare costs to patients, including treatment costs (such as rehabilitation treatment and compression bandages) and financial loss related to lymphedema influences on their ability to do their jobs. One cohort study demonstrated significantly higher costs among the women in the breast-cancer-related lymphedema group compared with the breast cancer group without lymphedema; and the estimated difference in the two-year medical costs ranged from \$14,877-\$23,167 based on insurance data (Shih et al., 2009). Currently, secondary lymphedema is most commonly associated with breast cancer treatment. Insurance 
companies do not fully cover lymphedema treatment in breast cancer patients; therefore, these data may underestimate the cost of lymphedema in breast cancer patients. That is, the insurance reimbursement is still an issue for some breast cancer patients with secondary lymphedema. Lymphedema is a less well-known phenomenon in head and neck cancer, and therefore the reimbursement issues are likely greater. Some head and neck cancer patients pay for their lymphedema treatment and compression garment fees themselves.

Head and neck cancer patients need to be referred for lymphedema treatment and rehabilitation in order to relieve the symptoms and improve compromised body functions related to secondary lymphedema (Foldi et al., 2006). In general, this therapy includes education of postural techniques, head/neck massage, head/neck exercise, and application of compression mask/garment/bandages on the head/neck (Foldi et al., 2006; Lymphoedema Framework, 2006). No actual data regarding the cost of head and neck lymphedema treatment are available in the literature. The data from one rehabilitation center located in Middle Tennessee, USA, show a reasonable estimate of the cost for initial treatment. The initial treatment includes the first evaluation fee, daily treatment fee (about 14 days), weekly treatment fee (about one to two months), and cost of material for treatment. Thus, the cost of the initial treatment for one head and neck cancer patient with secondary lymphedema is estimated from \$ 7,676 to \$ 9,284 (see Table 1) (A.M. Flores, personal communication, September 16, 2008).

This estimate does not include the custom garment fee. These garments vary in price. Over-the-counter and customized lymphedema garments range from approximately \$50 to \$300 (About Lymphedema Sleeves/Garments, 2008). Additionally, the cost of 
materials for self-management for one head and neck cancer patient with secondary lymphedema after the initial treatment is approximately $\$ 220$ per year (A.M. Flores, personal communication, September 16, 2008).

Table 1

An Estimate of the Cost for Initial Treatment for One Head and Neck Cancer Patient with Secondary Lymphedema

\begin{tabular}{lc}
\hline Initial Treatment & Cost $(\$)$ \\
\hline $1^{\text {ST }}$ Evaluation & 350 \\
Daily Treatment $\times 14$ Days & $5,628(402 \times 14$ Days $)$ \\
Weekly Treatment $\times 1-2$ Months & $1,608(402 \times 4$, for 1 Month), 3216 (402×8, for 2 Months) \\
Cost of Materials for Treatment & 90 \\
Total Cost for Initial Treatment & $7,676-9,284$ \\
\hline
\end{tabular}

In addition to the direct costs incurred from treatment, we could hypothesize that secondary lymphedema in head and neck cancer patients causes moderate or severe alterations in cervical range of motion, swallowing, and speaking functions. Such changes may affect work ability/efficiency for some individuals and family income could be reduced. One study estimated the number of days a patient's usual daily activities were interrupted by either hospitalization or office visits and found a significant difference between the breast cancer patients with lymphedema and breast cancer patients without lymphedema (58.7 days vs. 46.5 days, $\mathrm{p}<$.001) (Shih et al., 2009). Furthermore, some patients have to pay out of pocket for medications they take for their pain and muscle spasm related to moderate or severe head and neck lymphedema. Thus, the issues of potential loss of income and additional costs related to secondary lymphedema in head and neck cancer patients need to be examined. 
Other costs. The treatment of lymphedema not only costs patients money, but also takes up their time and energy, exacting a high psychological expense. Head and neck cancer patients with secondary lymphedema are often instructed to do self-massage daily until their lymphedema is controlled or relieved. They may also have to wear highly visible face and neck compression garments that cause them to avoid many social situations. Thus, they may also lose needed social support systems.

\section{Summary}

Addressing secondary lymphedema related to head and neck cancer is important to society for several reasons. First, approximately $12 \%-54 \%$ of the head and neck cancer population after their cancer treatment may have the condition. Second, this may be a preventable/controllable health problem if risk factors are identified and made known to the general public, as has been done with cigarette smoking and lung cancer. Third, secondary lymphedema related to head and neck cancer creates financial and psychological burdens to both individuals and society. Therefore, research into secondary lymphedema related to head and neck cancer will provide society with evidence-based information to develop better strategies to reduce lymphedema occurrence, manage lymphedema, and decrease expenses related to this condition.

\section{Significance to Healthcare}

\section{Continuum of Care Required}

Patients with locally advanced head and neck cancer are treated with radical neck dissection, large area radiation therapy, and/or concurrent chemoradiation (CCR) (Vokes et al., 2000). These treatments often lead to a damaged lymphatic system and leave 
individuals at risk for developing secondary lymphedema (Foldi et al., 2006;

Lymphoedema Framework, 2006). Head and neck lymphedema not only alters the appearance of patients' most visible body areas (Hammond, 2007; Zimmermann et al., 2005), but also may cause functional impairment, such as speaking, breathing, and swallowing (Bruns et al., 2004; Micke et al., 2003). Severe lymphedema may be lifethreatening (Murphy et al., 2007a). For instance, severe interstitial mucosal swelling of the supraglottic region may cause inspiratory stridor and dyspnea, and require tracheotomy (Micke et al., 2003). Depending upon the severity and location of the swelling, patients may require either outpatient treatment from a lymphedema therapist or hospital treatment from a skilled surgeon.

\section{Treatment Issues}

Secondary lymphedema is often treated by physical decongestive therapy, such as manual lymphatic drainage and wearing a compression garment (Piso et al., 2001). Such treatment should be provided by certified lymphedema therapists (National Lymphedema Network [NLN], 2005a). The therapists can be from a variety of healthcare professions; however, typically physical therapists and advanced practice nurses are eligible for reimbursement under Medicare guidelines (NLN, 2005b). Head and neck lymphedema treatment is likely to be more complex and difficult than breast cancer-related arm lymphedema based on the following reasons. First, head and neck lymphedema includes not only external but also internal lymphedema. External lymphedema is treated through compression devices and manual lymphatic drainage (Piso et al., 2001). Due to the contour and location of the head and neck lymphedema, a general compression bandage is not appropriate for all patients (Coopee, 2008). Many individuals may require 
customized compression garments. Some patients find it difficult to tolerate compression garments on their face and neck. This is also risk for obstructing blood flow to the brain if the garments are too tight. Sometimes they could only wear the compression garments for two hours at a time as compared to breast cancer patients with arm lymphedema who can continue to wear compression sleeves over several hours. This intermittent use of the compression garment might affect the effectiveness of lymphedema treatment. Moreover, literature is lacking about how to manage internal lymphedema. It is also unknown if external lymphedema treatment (e.g., manual lymphatic drainage and compression garment) reduces internal lymphedema.

In addition, some head and neck cancer patients with lymphedema, such as those with hypersensitive carotid sinus and cardiac arrhythmias (Foldi et al., 2006), are not eligible for physical decongestive therapy. If unable to undergo early physical decongestive therapy, head and neck cancer patients with secondary lymphedema are at risk for development of chronic lymphedema and even late fibrosis, such as skin stiffness, tightness, and limited neck range of motion, similar to breast cancer-related arm lymphedema (Davis et al., 2003). Once fibrosis develops, it is much more difficult to treat lymphedema. Secondary lymphedema, as a chronic process, may be refractory to therapy, and requires extensive management of co-morbid conditions such as impaired swallowing and voice alterations (Lymphoedema Framework, 2006). Therefore, secondary lymphedema, especially late-effect lymphedema (occurring 3 to 6 months after cancer treatment), remains a unique treatment challenge when caring for head and neck cancer patients. This challenge warrants future studies to address the issue of 
lymphedema treatment and decrease patients' physical and psychological symptom burden and functional loss.

\section{Access to Knowledgeable Professionals}

Although lymphedema is a progressive chronic condition and a lifelong sideeffect of cancer and cancer therapy, it may be ameliorated by proper management by healthcare professionals (Lymphoedema Framework, 2006). Access to healthcare professionals with lymphatic system and diseases knowledge is critical to manage lymphedema. These trained professionals can be aware of the potential risk factors for lymphedema, identify the patients at risk of lymphedema, assess patients' lymphedema symptoms, document the risks of lymphedema to alert other healthcare professionals, and refer lymphedema patients for appropriate and timely treatment (Lymphoedema Framework, 2006). However, studies have found that breast cancer-related lymphedema patients had a limited access to trained professionals. For example, some breast cancer patients do not have access to qualified professionals who understand lymphedema (Hadamitzky \& Pabst, 2008; Ridner, 2005). Lack of understanding of lymphedema by healthcare professionals and poor information provided to patients affect health-related quality of life in breast cancer patients with lymphedema (Coward, 1999; Morgan, Franks, \& Moffatt, 2005). Breast cancer-related lymphedema is a much more well-known phenomenon than head and neck lymphedema; thus access to educated healthcare professionals may be even a larger issue in head and neck cancer patients with lymphedema. 


\section{Summary}

Managing head and neck lymphedema is a significant issue to healthcare. First, management of secondary lymphedema in head and neck cancer patients requires a multidisciplinary approach and runs the full continuum of services from outpatient clinics to intensive care units. Second, early detection and appropriate treatment may minimize certain patients’ secondary lymphedema and associated symptoms; if disregarded, lymphedema can progress and become difficult to handle (Lymphoedema Framework, 2006; Marrs, 2007). Third, access to well-informed healthcare professionals may be a key aspect to address various challenges in treating and managing head and neck lymphedema. Consistent with one of the goals of Healthy People 2010 (i.e., improving the quality of life and years of healthy living) (Healthy People 2010, 2000), healthcare professionals need to play an active role in lymphedema treatment and management. Well-informed healthcare professionals have knowledge of the patients at risk of lymphedema, relieve their lymphedema associated symptom burden and functional loss, and improve their quality of life.

\section{Significance to Science of Nursing}

Nurses have collaborated with other healthcare professionals to provide patients with the best care since the time of Florence Nightingale (Miracle, 2008). They have participated in directly collecting patients' symptoms and complaints, evaluating their signs and compromised functions, and communicating with and educating patients how to maintain a good quality of life. As the American Nurses Association (ANA) states, 
“The nurse determines the appropriate delegation of tasks consistent with the nurse's obligation to provide optimum patient care” (Code of Ethics for Nurses, 2008).

The National Lymphedema Network (NLN) indicates nurses are key members for helping patients manage lymphedema (NLN, 2005b). As a member of the interdisciplinary healthcare team, a large amount of information has shown that nurses have taken a critical and unique role in managing breast cancer-related secondary lymphedema in clinical settings. Nurses engage in not only assessing secondary lymphedema, but also in educating and guiding breast cancer patients on how to conduct self-monitoring, detect early secondary lymphedema, take appropriate actions to reduce risk factors, and implement management strategies to alleviate the impact of lymphedema (Lymphoedema Framework, 2006; Marrs, 2007).

Besides caring for patients with lymphedema in clinical settings, nurses have engaged in numerous significant studies in the role of principal investigator. Nurses have conducted a great number of studies related to secondary complications of cancer treatment, such as breast cancer-related lymphedema. Their studies have covered a variety of domains, such as symptoms and symptoms cluster, measurements, quality of life, and possible risk factors (Armer \& Whitman, 2002; Coward, 1999; Ridner, 2005). The studies have contributed to clearly describing secondary lymphedema related to breast cancer treatment.

Although studies have examined breast cancer-related lymphedema, little concern has been given to exploring other cancer-related lymphedema, such as head and neck lymphedema. Critical information about how nurses should educate and manage head and neck cancer patients at risk for or with secondary lymphedema is absent at this time. 
Many gaps related to head and neck lymphedema need to be addressed, such as symptoms and symptom burden, functional loss, compromised quality of life, possible risk factors, incidence, and prevalence. These unanswered domains affect nurses and other healthcare professionals who care for head and neck cancer patients with secondary lymphedema, that is, clinical care related to head and neck lymphedema is still an underaddressed issue in current clinical settings. Nurses and other healthcare professionals are poorly equipped with knowledge and skills about caring for secondary lymphedema related to head and neck cancer treatment. Therefore, research into head and neck lymphedema is not only critical to nursing research but also significant to clinical nursing care.

Based on their pathophysiological similarity, we assume that a fair amount of overlap exists between breast cancer-related lymphedema and head/neck cancer-related lymphedema. It may be possible to select and adapt the instruments used in breast cancerrelated lymphedema to gauge the experiences of head and neck cancer patients with lymphedema. Nevertheless, head and neck lymphedema is most likely to have different symptom burden, functional status, quality of life, and possible risk factors from breast cancer-related lymphedema due to their different anatomical sites, treatment regimens, and different cancer types. There is a need to examine and identify the similarities and differences between breast cancer-related lymphedema and head and neck cancer-related lymphedema. The Oncology Nursing Society (ONS) stated the research priorities of oncology nursing during 2009-2013, including research that considered cancer treatmentrelated side-effects and late-effects (ONS Research Agenda, 2009-2013). Thus, 
examining secondary lymphedema related to head and neck cancer treatment is consistent with the research priorities of the ONS.

\section{Summary}

Identified gaps in the literature regarding head and neck cancer patients with secondary lymphedema include lack of evidence on risk factors, deficiency in its symptoms and symptom burden, and poor understanding of its influence on functional loss and quality of life. These gaps not only influence how nurses and other healthcare professionals detect and assess head and neck cancer patients at risk of secondary lymphedema but also affect how they educate and guide patients about how to manage, alleviate, and control symptom burden related to secondary lymphedema.

The study focused on the gaps in the literature and clinical care. It will also provide nurses and other healthcare professionals with empirical evidence to manage secondary lymphedema after cancer treatment. The study will advance the development of oncology nursing, increase the knowledge base of secondary lymphedema for oncology nursing and other healthcare providers' practice, and help oncology nurses recognize and better care for patients with secondary lymphedema after head and neck cancer treatment. Quality oncology nursing care may make a remarkable impact on patient outcomes. Armed with an essential knowledge of secondary lymphedema, nurses and other healthcare providers can be hands-on in patient education, monitor for the occurrence of secondary lymphedema, and become involved in reducing the extent of secondary lymphedema and its negative impact on patients, healthcare, and society (Marrs, 2007). 


\section{Purpose of the Study}

The purpose of the study was to examine the association among the severity of lymphedema, symptoms, functional status, and quality of life in head and neck cancer patients. This study also examined the possible factors contributing to the presence of secondary lymphedema in head and neck cancer patients. The specific aims for the study included:

1. To determine the prevalence of secondary lymphedema in head and neck cancer patients (Aim 1);

2. To examine the associations between the severity of lymphedema in head and neck cancer patients and (a) symptoms; (b) functional status; and (c) quality of life (Aim 2);

3. To examine the possible risk factors contributing to the presence of secondary lymphedema after head and neck cancer treatment by comparing patients with and without secondary lymphedema (e.g., demographic information and head and neck cancer disease information) (Aim 3).

\section{Research Questions}

1. What is the prevalence of external lymphedema, internal lymphedema and combined lymphedema in head and neck cancer patients?

2. What are the associations between severity of lymphedema in head and neck cancer patients and (a) symptoms; (b) functional status; and (c) quality of life?

3. What are the possible factors contributing to the presence of secondary lymphedema in head and neck cancer patients? 


\section{CHAPTER II}

\section{LITERATURE REVIEW}

The section reviews the problem of interest from the perspectives of its origin and history, theoretical frameworks, and methodological approaches used in the literature. Based on the extensive literature review, syntheses of knowledge and research hypotheses are proposed. The key concepts and the theoretical framework for the study are developed.

\section{History of the Problem of Interest}

There are differing historical perspectives about the origin and history of lymphedema. The Merriam-Webster Dictionary (2007) cites the etymology of lymphedema as being from New Latin in 1889 and its definition as edema due to faulty lymphatic drainage. However, Foldi (2001) states that an Italian anatomist, Paulo Mascagni, in the $18^{\text {th }}$ century, had a correct, deep insight into the etiology of lymphedema. Mascagni thought that edema was caused by the obstruction of the lymph nodes, and dilatation of the lymph vessels led to the valves being inadequate to prevent the retrograde flow of lymph (Foldi, 2001). Nevertheless, his views were dismissed at the turn of the $19^{\text {th }}$ century and replaced by a vague concept that lymphedema was related to a defect of the nervous system (Foldi, 2001). It was not until the third decade of the $20^{\text {th }}$ century that the accurate physiological view of lymphedema was reinstated. Drinker and Field, in 1933, correctly explicated and demonstrated that blockage of the lymphatic 
system of an experimental animal led to lymphedema. They established that lymphedema occurs as a consequence of the inability of the lymph system to drain away the lymphatic fluid overload (Foldi, 2001; Mayerson, 1969).

Cancer therapy, as the most common cause of secondary lymphedema in developed countries, might be related to the origin of secondary lymphedema. Although there is lack of clear documentation of the historical origin of secondary lymphedema in head and neck cancer patients, it probably arises with emergence of treatment modalities of head and neck cancer (e.g., surgery and/or radiation therapy). The history of surgical treatment of cervical lymph node metastases began in the 19th century (Ferlito et al., 2007). According to Werner and Davis (2004), in 1880 a Swiss surgeon, Theodor Kocher, advocated lymph node dissection of the submandibular triangle when performing a transcervical approach for the surgical removal of tongue cancer. An American Surgeon, George Washington Crile, performed radical neck dissection in 1906, which was a decisive progress in the treatment of metastatically affected cervical lymph nodes (Werner \& Davis, 2004). Because of lymphatic system damage, radical neck dissection may be associated with development of secondary lymphedema.

Although the first radical neck dissection surgery was done in 1906 and the first article available regarding secondary lymphedema was published in 1936 (Reichent \& Mathes, 1936), the exact mechanism leading to secondary lymphedema has not been totally clarified, and there is a lack of a curative therapy available for secondary lymphedema (Lymphoedema Framework, 2006). Research has centered on mechanisms that result in secondary lymphedema. However, some aspects of secondary lymphedema in head and neck cancer patients have been neglected. The incidence and prevalence of 
secondary lymphedema related to head and neck cancer treatment, its effect on symptom burden, functional loss, risk factors, and effects on quality of life have been unexplored. Therefore, secondary lymphedema related to head and neck cancer treatment is an understudied disease.

\section{Theoretical Literature Review}

Throughout the literature review, four conceptual models/theories have been used to understand secondary lymphedema after cancer treatment: the Biomedical Conceptual Approach (Uzarski et al., 2008), the Structural Model of Post-breast Cancer Lymphedema (Armer, Radina, Porock, \& Culbertson, 2003), the Biopsychosocial Conceptual Approach (Jager, Doller, \& Roth, 2006; Passik, Newman, Brennan, \& Tunkel, 1995), and the Theory of Unpleasant Symptoms (Lenz, Pugh, Milligan, Gift, \& Suppe, 1997). The following table (see Table 2) summarizes the characteristics, strengths, and limitations of the four conceptual models/theories.

Through the above analysis, it is clear that the Biomedical Conceptual Approach has contributed significantly to further our understanding of the pathological reasons that lymphedema occurs and supports various treatment modalities. Specifically, this model has supported lymphedema as a progressive pathologic condition of the lymphatic system with an abnormal accumulation of protein-rich fluid in the interstitial space (Cheville et al., 2003). The lymph accumulation in the interstitial space triggers subsequent inflammation, adipose tissue hypertrophy, and fibrosis. The swelling and later induration of the affected area can lead to disfigurement, as well as decreased function and mobility (Cheville et al., 2003; Warren, Brorson, Borud, \& Slavin, 2007). 
Table 2

Conceptual Models \& Theories Related to the Problem of Interest

\begin{tabular}{|c|c|c|c|}
\hline $\begin{array}{c}\text { Conceptual } \\
\text { Models/ } \\
\text { Theories }\end{array}$ & Characteristics & Strengths & Limitations \\
\hline $\begin{array}{l}\text { Biomedical } \\
\text { Conceptual } \\
\text { Model }\end{array}$ & $\begin{array}{l}\text { The Biomedical } \\
\text { Conceptual Model } \\
\text { focuses on the } \\
\text { physical process of } \\
\text { lymphedema (e.g., } \\
\text { physiology and } \\
\text { pathology). }\end{array}$ & $\begin{array}{l}\text { The Biomedical Conceptual } \\
\text { Model has been extremely } \\
\text { useful throughout history by } \\
\text { establishing the pathological } \\
\text { reasons that lymphedema } \\
\text { occurs, and exploring and } \\
\text { developing different } \\
\text { treatment regimens. }\end{array}$ & $\begin{array}{l}\text { It does not take into } \\
\text { account the role of } \\
\text { psychological or social } \\
\text { factors, individual } \\
\text { differences, and individual } \\
\text { subjectivity. It does not } \\
\text { explain how lymphedema } \\
\text { affects patients' daily life, } \\
\text { mood, other distressful } \\
\text { symptoms, and ignores the } \\
\text { nursing perspectives. }\end{array}$ \\
\hline $\begin{array}{l}\text { Structural } \\
\text { Model of Post- } \\
\text { breast Cancer } \\
\text { Lymphedema }\end{array}$ & $\begin{array}{l}\text { The Structural Model } \\
\text { proposes the inter- } \\
\text { relationships among } \\
\text { lymphedema, coping } \\
\text { effectiveness, } \\
\text { psychosocial } \\
\text { adjustment, functional } \\
\text { health status, and } \\
\text { protective } \\
\text { mechanisms. }\end{array}$ & $\begin{array}{l}\text { The Structural Model views } \\
\text { lymphedema from a global } \\
\text { perspective through depicting } \\
\text { multiple dimensions of post- } \\
\text { breast cancer lymphedema. } \\
\text { The goal of the model is to } \\
\text { identify variables that } \\
\text { influence lymphedema } \\
\text { progression, its impact on } \\
\text { psychosocial outcomes, and } \\
\text { functional health status, } \\
\text { which then can enlighten } \\
\text { subsequent interventions. }\end{array}$ & $\begin{array}{l}\text { The Structural Model was } \\
\text { used in one study, which } \\
\text { did not examine the entire } \\
\text { relationships among its } \\
\text { multiple variables (Armer } \\
\text { et al., 2003). The model } \\
\text { needs to be further tested } \\
\text { on the propositions among } \\
\text { its variables through more } \\
\text { studies. Another issue is } \\
\text { that the model does not } \\
\text { cover the component of } \\
\text { possible risk factors of } \\
\text { leading to lymphedema } \\
\text { occurrence. }\end{array}$ \\
\hline $\begin{array}{l}\text { Biopsycho- } \\
\text { social } \\
\text { Conceptual } \\
\text { Model }\end{array}$ & $\begin{array}{l}\text { The Biopsychosocial } \\
\text { Conceptual Model } \\
\text { implies management } \\
\text { of disease processes } \\
\text { (e.g., secondary } \\
\text { lymphedema) requires } \\
\text { the healthcare team to } \\
\text { address biological, } \\
\text { psychological, and } \\
\text { social influences upon } \\
\text { a patient's functioning. }\end{array}$ & $\begin{array}{l}\text { The Biopsychosocial } \\
\text { Conceptual Model can be a } \\
\text { general framework to } \\
\text { understand the problem of } \\
\text { interest and has potential to } \\
\text { guide this study. That is to } \\
\text { say, secondary lymphedema } \\
\text { may not only affect head and } \\
\text { neck cancer patients' } \\
\text { physical functions but also } \\
\text { influence their psychosocial } \\
\text { well-being and quality of life. }\end{array}$ & $\begin{array}{l}\text { The Biopsychosocial } \\
\text { Conceptual Model is broad } \\
\text { and does not provide a } \\
\text { straightforward, testable } \\
\text { model to explain the } \\
\text { interactions or causal } \\
\text { influences among different } \\
\text { variables. }\end{array}$ \\
\hline $\begin{array}{l}\text { Theory of } \\
\text { Unpleasant } \\
\text { Symptoms } \\
\text { (Lenz et al., } \\
\text { 1997) }\end{array}$ & $\begin{array}{l}\text { The Theory of } \\
\text { Unpleasant Symptoms } \\
\text { has three major } \\
\text { components: the } \\
\text { symptoms, the } \\
\text { influencing factors, } \\
\text { and the consequences } \\
\text { of the symptom } \\
\text { experience. }\end{array}$ & $\begin{array}{l}\text { In comparison to the other } \\
\text { models, the Theory of } \\
\text { Unpleasant Symptoms views } \\
\text { lymphedema from a more } \\
\text { clearly defined perspective, } \\
\text { including the symptoms, the } \\
\text { influencing factors, and } \\
\text { performance. The theory has } \\
\text { been applied to various } \\
\text { symptom studies. }\end{array}$ & $\begin{array}{l}\text { The Theory of Unpleasant } \\
\text { Symptoms lacks the } \\
\text { component of symptom } \\
\text { management strategies. }\end{array}$ \\
\hline
\end{tabular}


However, it does not focus on individual subjective experience (i.e., symptoms) related to the impact of secondary lymphedema, does not consider individual differences, and ignores the influence of the psychological and social factors. In some circumstances, the Biomedical Conceptual Approach limits understanding and examination of secondary lymphedema related issues from a holistic viewpoint (Wade \& Halligan, 2004). For example, the Biomedical Conceptual Approach comprehends and manages secondary lymphedema from the viewpoint of physical factors and neglects the roles of both situational factors (e.g., working environment) and psychological factors (e.g., distressed mood) related to experiencing secondary lymphedema associated symptoms.

The Structural Model of Post-breast Cancer Lymphedema is a conceptual framework proposed in 2002 (Armer \& Whitman, 2002). The model was developed based on the biobehavioral model of cancer, stress, and disease progression (as cited in Armer et al., 2003) and the model of stress and coping (as cited in Armer et al., 2003). The model has three components: the indicators of lymphedema, protective mechanisms, and post-breast cancer psychosocial adjustment and functional health status. Lymphedema is conceptualized as consisting of both objective (e.g., circumferential measurement) and subjective (e.g., coping effectiveness) indicators. The objective assessment reflects the physical aspects of lymphedema, and subjective assessments describe the cognitive/emotional components related to coping with lymphedema. The protective mechanism includes problem solving and social support, which could reduce the progression of lymphedema. Finally, both of the protective mechanisms and the indicators of lymphedema are related to post-breast cancer psychosocial adjustment and functional health status (Armer et al., 2003). Only one study examined one of the three 
components, that is, objective and subjective indicators of lymphedema (Armer et al., 2003). The other components and entire propositions of the model have not been tested or clarified at the current time, which affects its usefulness in research.

The Biopsychosocial Conceptual Approach developed by George Engel may be appropriate to understand the problem of interest, as it indicates that management of disease processes (such as lymphedema) requires addressing biological, psychological, and social domains. This model emphasizes the interaction relationship among the three domains and their contribution to the comprehension and management of a disease. However, it is broad and lacks explanatory components by not explaining the domains of symptoms and interactions among different variables. Thus, it could not guide a study as a concrete theoretical framework.

The Theory of Unpleasant Symptoms was published in 1995 (Lenz, Suppe, Gift, Pugh, \& Milligan, 1995) and updated in 1997 (Lenz et al., 1997). It has three major components: the symptoms, the influencing factors, and the consequences of the symptom experience. Symptoms are the central focus of the theory. Each symptom can be measured separately or in combination with other symptoms (e.g., symptoms cluster). Each symptom has four common domains: intensity (strength or severity), timing (duration and frequency of occurrence), level of distress perceived (degree of discomfort or bothersomeness), and quality. These domains are related to one another. In the Theory of Unpleasant Symptoms, three categories of influencing factors are assumed to affect symptoms: physiologic factors, psychologic factors, and situational factors. Physiologic factors include normal physiological conditions and abnormal pathological status. The psychologic factors contain an individual's emotional reaction to a disease/injury and 
associated knowledge about the symptoms and their possible meaning. Situational factors cover a person's social and physical environment that may affect the individual's experiencing, interpreting, and reporting of symptoms. The three categories of influencing factors may interact with one another and commonly influence the symptom experience. Performance is the final component of the Theory of Unpleasant Symptoms and includes the "outcome" or "effect" of the symptom experience. It contains functional health status and quality of life related to the symptoms. The performance outcomes can have an impact on the symptom experience and the influencing factors.

Based on its components of a symptom, the Theory of Unpleasant Symptoms has been applied to development of a symptom scale, which measures intensity, distress, timing, and quality of the symptom (Fadol et al., 2008). In clinical settings, the Theory of Unpleasant Symptoms can be used to explore symptom relief strategies based on its three major components (Liehr, 2005). Additionally, the Theory of Unpleasant Symptoms has been extensively applied to various symptom experience and management studies. It has been used in not only breast cancer patients with lymphedema (Ridner, 2005) but also in other disease populations with related symptom management, such as postoperative pain (Huth \& Broome, 2007), postpartum fatigue (Rychnovsky, 2007), hemodialysis fatigue (Liu, 2006), and COPD symptoms (Reishtein, 2005). Compared with other models, the Theory of Unpleasant Symptoms may be the best conceptual framework to guide my research study. 


\section{Methodological Literature Review}

In the United States, injury to or removal of regional lymph nodes during surgery or radiation therapy, infection, or tumor growth are the most common conditions that lead to secondary lymphedema (Holcomb, 2006). As healthcare professionals have become aware of the problem of secondary lymphedema related to cancer treatment, more concern has been raised about the availability of methodological approaches that are reliable and valid for use in research and clinical practice with breast cancer patients. Little attention has been given to methodological approaches specific to head and neck cancer patients with secondary lymphedema (Foldi et al., 2006; Lymphoedema Framework, 2006).

The purposes of this section include (1) critically analyzing methodological approaches that have been used to study secondary lymphedema related to head and neck cancer treatment; (2) discussing advantages and disadvantages of methods used in the literature (e.g., efficiency of method, cost of method); and (3) identifying strengths and weaknesses of the methodological approaches used to investigate the problem of interest (e.g., small sample size, poor reliability/validity of instruments). Through this empirical literature review, the state of the science in relation to secondary lymphedema in head and neck cancer patients will be integrated and the implications for improving methodological approaches in this area will be proposed. Moreover, the integration of methodological approaches was used as the knowledge base underpinning the methodological design and measurement instruments chosen for the research study.

Additionally, to be consistent with the key concepts of the research study, the methodological approaches to secondary lymphedema related to head and neck cancer 
treatment are reviewed and analyzed from five domains: (1) signs and measurement; (2) symptoms and effects on body functions; (3) psychological effects, (4) effects on quality of life; and (5) possible risk factors.

\section{Methodological Approaches Used in the Literature}

\section{Signs and Measurement}

The National Cancer Institute updated and published the Common Terminology Criteria for Adverse Events v3.0 (CTCAE v3.0) in 2006 (CTCAE v3.0, 2006). CTACE v3.0 is commonly used as a comprehensive, multimodality grading system for reporting the acute and late-effects of cancer treatment (Trotti et al., 2003). It provides a grading (severity) scale to describe head and neck lymphedema (see Table 3). It also provides a scale to evaluate lymphedema-related fibrosis (see Table 4).

Table 3

NCI Lymphedema of the Head and Neck Grading Scale

\begin{tabular}{ll}
\hline Grade & \multicolumn{1}{c}{ Descriptions } \\
\hline Grade 1 & Localized to dependent areas, no disability or functional impairment \\
Grade 2 & Localized facial or neck edema with functional impairment \\
Grade 3 & Generalized facial or neck edema with functional impairment (e.g., difficulty in turning \\
& neck or opening mouth compared to baseline) \\
Grade 4 & Severe with ulceration or cerebral edema; tracheotomy or feeding tube indicated \\
Grade 5 & Death \\
\hline
\end{tabular}


Table 4

NCI Lymphedema-related Fibrosis Scale

\begin{tabular}{ll}
\hline Grade & \multicolumn{1}{c}{ Descriptions } \\
\hline Grade 1 & $\begin{array}{l}\text { Minimal to moderate redundant soft tissue, unresponsive to elevation or compression, } \\
\text { with moderately firm texture or spongy feel }\end{array}$ \\
Grade 2 & $\begin{array}{l}\text { Marked increase in density and firmness, with or without tethering } \\
\text { Grade } 3\end{array}$ \\
Very marked density and firmness with tethering affecting $\geq 40 \%$ of the edematous area
\end{tabular}

The American Cancer Society also provides a system for grading non-limb lymphedema from Stage 0 to Stage III based on the CTACE v3.0 of the National Cancer Institute (ACS, 2006; Cheville et al., 2003). The four stages provide a basic method of evaluating lymphedema of the head and neck (see Table 5).

The above two scales are interchangeable, e.g., Grade 1=Stage 0, Grade 2=Stage I, and Grade 3=Stage II. Although the two scales have been developed to assess cancer treatment-associated lymphedema, they do not differentiate the measurement of external and internal lymphedema, nor do they contain distance and volume measurement of lymphedema other than edema or swelling that may be related to head and neck cancer patients with lymphedema. In addition, the two scales do not have any skin changes related to secondary lymphedema nor whether elevation (or posture changes) reduces the swelling. 
Table 5

ACS Lymphedema of the Head and Neck Staging Criteria

\begin{tabular}{ll}
\hline Stage & \multicolumn{1}{c}{ Descriptions } \\
\hline Stage 0 & Swelling is local and does not affect regular functioning \\
Stage I & Swelling is local and affects regular functioning \\
Stage II & $\begin{array}{l}\text { General swelling in the face or neck affects regular functioning (e.g., it may make } \\
\text { it more difficult for a person to turn his or her head or open and close her mouth) }\end{array}$ \\
Stage III & $\begin{array}{l}\text { Swelling is severe and may accompany ulcers on the skin or brain swelling; the } \\
\text { ability to eat is severely affected }\end{array}$ \\
\hline
\end{tabular}

Throughout the literature review, no other criteria are available specifically for grading secondary lymphedema after head and neck cancer treatment. Some criteria focus on general lymphedema from pathophysiological domains, e.g., the Clinical Classification of Lymphedema (International Society of Lymphology) (Twycross, Jenns, \& Todd, 2000) (see Table 6) and the Stages of Lymphedema (Foldi, Foldi, \& Kubik, 2003) (see Table 7). The Stages of Lymphedema was developed by Foldi and his colleagues (2003). Although the authors did not state the reliability and validity of the scale, they developed the Stages of Lymphedema based on their experience treating over 100,000 patients suffering from lymphedema. There are three major components in the scale: pathology, signs and symptoms, and diagnosis. Thus, the scale illustrates the entire picture for general secondary lymphedema. Although these criteria are not specific for head and neck lymphedema, they can be used to comprehend the possible pathological process and clinical changes, and help diagnose secondary lymphedema after head and neck cancer treatment. 
Table 6

Clinical Classification of Lymphedema

\begin{tabular}{ll}
\hline Grade & \multicolumn{1}{c}{ Descriptions } \\
\hline Grade 1 & No or minimal fibrosis, i.e., oedema pits on pressure and reduced with limb elevation \\
Grade 2 & Substantial fibrosis clinically, i.e., oedema does not pit and does not reduce with limb elevation \\
Grade 3 & Grade 2 plus elephantine (trophic) changes \\
\hline
\end{tabular}

Table 7

Stages of Lymphedema

\begin{tabular}{|c|c|c|c|}
\hline$\overline{\text { Stage }}$ & Pathology & Signs and Symptoms & Diagnosis \\
\hline $\begin{array}{c}0 \\
\text { Latency }\end{array}$ & $\begin{array}{l}\text { Focal fibrosclerotic } \\
\text { tissue alterations }\end{array}$ & None & $\begin{array}{l}\text { Functional isotope } \\
\text { lymphograpy }\end{array}$ \\
\hline $\begin{array}{l}\text { I } \\
\text { Reversible }\end{array}$ & $\begin{array}{l}\text { High protein edema; } \\
\text { focal fibrosclerotic tissue } \\
\text { alterations }\end{array}$ & $\begin{array}{l}\text { Pitting edema; elevation reduces the } \\
\text { swelling; possibly "pain of } \\
\text { congestion" }\end{array}$ & $\begin{array}{l}\text { Basic diagnostic } \\
\text { procedures }\end{array}$ \\
\hline $\begin{array}{l}\quad \text { II } \\
\text { Spontaneously } \\
\text { Irreversible }\end{array}$ & $\begin{array}{l}\text { Extensive fibrosclerosis, } \\
\text { proliferation of adipose } \\
\text { tissue }\end{array}$ & $\begin{array}{l}\text { Brawny, hard swelling that does not } \\
\text { recede with elevation }\end{array}$ & $\begin{array}{l}\text { Basic diagnostic } \\
\text { procedures }\end{array}$ \\
\hline $\begin{array}{l}\text { III } \\
\text { Elephantiasis }\end{array}$ & $\begin{array}{l}\text { Extensive fibrosclerosis, } \\
\text { proliferation of adipose } \\
\text { tissue }\end{array}$ & Like Stage II; invalidism & $\begin{array}{l}\text { Basic diagnostic } \\
\text { procedures }\end{array}$ \\
\hline
\end{tabular}

Although there are several criteria available to grade the degree of secondary

lymphedema, none of them are evidence-based standards for grading secondary

lymphedema in head and neck cancer population in the current literature review.

Therefore, it is essential to systematically investigate pathophysiological processes and

clinical changes of secondary lymphedema related to head and neck cancer, and further

develop evidence-based staging criteria of secondary lymphedema for head and neck

cancer population in future research. 
In addition, certain head and neck cancer patients may develop secondary lymphedema externally (e.g., face and submental area) (Hammond, 2007; Zimmermann et al., 2005) and internally (e.g., laryngx, pharyngx, and oral cavity) (Bruns et al., 2004; Micke et al., 2003). Thus, the signs and measurement of head and neck cancer patients with secondary lymphedema may include external lymphedema and internal lymphedema.

External lymphedema. Current distance and volume lymphedema measurement systems do not allow for more detailed evaluation of swelling that occurs in head and neck cancer treatment (ACS, 2006; Cheville et al., 2003). This has given rise to an almost complete lack of information on lymphedema incidence after the treatment of head and neck cancer (Cheville et al., 2003). A review of the literature reveals that the following studies explore quantitative measurement for external lymphedema of the head and neck by using a measuring tape.

One study (Zimmermann et al., 2005) employed a self-designed measurement standard to grade 20 head and neck cancer patients' external lymphedema by using a measuring tape. The authors chose four anatomical sites (including tragus, nostrils, corner of the mouth, and tip of the chin) to measure and compare the treatment effects of sodium selenite on postoperative lymphedema. The authors stated that the circumferential distance from the tragus to the tip of the chin best represents the lymphedema. In order to ensure the validity of the lymphedema measurement, they considered the influence of facial size. That is to say, the absolute distance between tragus and tip of the chin was subtracted from the circumferential measurement in each case. Although the authors mentioned the same PI completed all measurements and used the measuring tape in a 
straight line to ensure reproducibility, they did not clearly report intra-rater reliability and if the measurement tool was used in other studies.

In another study (Piso et al., 2001), a clinical evaluation of lymphedema was performed to grade 11 head and neck cancer patients' external lymphedema by distance measurements. The authors measured the distances among seven well-defined anatomic marks (including tragus, mental protuberance, mouth angle, mandibular angle, nasal wing, internal eye corner, and external eye corner). Meanwhile, they also used sonographic assessment of soft-tissue width at the face and neck. They found that although tape measurement seemed to best gauge the degree of lymphedema, sonographic assessment was necessary especially in patients with severe swelling and difficultly detecting the well-defined anatomic marks. Their study indicated good validity of the measurement methods using both types of measurements, but the authors did not clearly describe the reliability of the measurement tool in the article (i.e., intra-rater or inter-rater) or whether the measurement method was employed in other research studies. Piso, Eckardt, Liebermann, and Gehrke (2002) found that sonographic soft tissue width at defined sites of the head and neck was highly reproducible in 21 healthy adults without marking the measurement sites. They suggested that sonographic soft tissue width could be used to measure and quantify the effectiveness of manual lymphatic drainage for head and neck lymphedema by monitoring the course of the skin-to-bone distance. Their study reflected a good reliability and validity for assessing lymphedema.

In addition, a scoring system modified after Foldi and Foldi et al., Micke et al., and Miller et al. was used to measure external lymphedema in two studies (Bruns et al., 2004; Micke et al., 2003). In their study, they indicated content validity based on the 
experts' review but did not report reliability of the scoring system (i.e., neither intra-rater nor inter-rater reliability). Throughout the literature review, volume-based or distancebased technologies measuring external lymphedema of the head and neck have been explored in some studies, but they have not been validated as an evidence-based measurement method to guide clinical assessment due to the small sample sizes of the studies and limited psychometrically validated information of the instruments. Future work is needed to establish validity and reliability regarding volume-based or distancebased measurement of head and neck lymphedema.

Internal lymphedema. It has been recognized that edema may involve mucosal/soft tissue structures visible only on endoscopic examination. The following studies explored internal lymphedema in head and neck cancer patients. Patterson et al. (2007) thought available instruments lack sensitivity to record internal edema that occurs after radiotherapy in specific laryngo-pharyngeal structures. They conducted an exploratory study to develop a rating scale to measure edema in the larynx and pharynx for irradiated head and neck cancer patients. Eleven structures (e.g., posterior pharyngeal wall and epiglottis) and two spaces (i.e., valleculare and pyriform sinus) were identified as the areas sensitive to the development of edema. They viewed 25 nasendolaryngoscopic images using the scale. The interrater reliability for scoring the edema rating scale was noted by the investigator as moderate (weighted kappa, 0.54). The intra-rater reliability was very good (weighted kappa $=0.84$ ). The edema rating scale can be scored with very good test-retest reproducibility and moderate levels of agreement between clinicians. Based on the experts' suggestions, the scale was developed with a 
good content validity. The authors suggested that modifications to the method were needed to increase inter-rater reliability of the rating scale.

In two other studies (Bruns et al., 2004; Micke et al., 2003), interstitial endolaryngeal edema was graded using a scoring system modified after the late-effects of normal tissue and somatic objective management analytic (LENT-SOMA) system. In one study, the late radiation morbidity scoring scheme of Toxicity Criteria of the Radiation Therapy Oncology Group (RTOG)/the European Organization for Research and Treatment for Cancer (EORTC) was used to diagnose the grade of laryngeal lymphedema (Rudat et al., 1999). The LENT-SOMA and RTOG/EORTC scoring systems were developed based on the experts' views, and both had content validity but lacked reported reliability data.

Although some studies have researched and developed some instruments for measuring external and internal lymphedema, these instruments’ psychometric characteristics need to be further examined. Due to limited quantitative measurement components, the applications of these instruments are restricted which affects accurate collection of patients' data and examination of the overall incidence of lymphedema in head and neck cancer patients. Thus, investigators need to be involved in exploring and addressing lymphedema measurement issues through developing validated and reliable rating scales.

Symptoms and Effects on Body Functions

Head and neck cancer-related lymphedema studies. Six studies (Bruns et al., 2004; Eisbruch et al., 2004; Machtay et al., 2004; Micke et al., 2003; Piso et al., 2001; 


\section{Rudat et al., 1999) discussed lymphedema-induced symptoms and function loss in head and neck cancer patients; two studies reported co-existing fibrosis (see Table 8).}

Table 8

Symptom and Functional Impairment Studies

\begin{tabular}{|c|c|c|c|c|c|}
\hline Study & Description & $\begin{array}{l}\text { Cancer } \\
\text { Treatment } \\
\text { Modality }\end{array}$ & $\begin{array}{l}\text { Follow-up } \\
\text { Period }\end{array}$ & $\begin{array}{l}\text { Symptom/Functional } \\
\text { Status Assessment } \\
\text { Methods/Instruments }\end{array}$ & $\begin{array}{c}\text { Results } \\
\text { (Symptoms/ } \\
\text { Functional } \\
\text { Impairments) }\end{array}$ \\
\hline $\begin{array}{l}\text { Piso et } \\
\text { al. } 2001\end{array}$ & $\begin{array}{l}\text { To evaluate } \\
\text { manual lymphatic } \\
\text { drainage and } \\
\text { compression } \\
\text { garments for } \\
\text { postoperative } \\
\text { head-neck } \\
\text { lymphedema after } \\
\text { curative surgery } \\
\text { for orofacial } \\
\text { tumors }(\mathrm{N}=11)\end{array}$ & Surgery alone & $\begin{array}{l}\text { Up to } \\
\text { postoperative } \\
30 \text { days }\end{array}$ & $\begin{array}{l}\text { Self-reported intensity of } \\
\text { tension/pain caused by the } \\
\text { swelling (visual analog } \\
\text { scale of 0-10). } \\
\text { Self-reported disability } \\
\text { with swallowing and } \\
\text { speaking (score, 0-6 } \\
\text { points). Impaired } \\
\text { swallowing and speaking } \\
\text { were quantified as follows: } \\
0=\text { no difficulties; } \\
\text { 1=minimal difficulties; } \\
2=\text { =moderate difficulties; } \\
\text { and 3= severe difficulties. }\end{array}$ & $\begin{array}{l}\text { Feeling of tension in } \\
\text { the face and/or neck, } \\
\text { pain in the } \\
\text { submandibular region; } \\
\text { Impaired swallowing } \\
\text { and speaking }\end{array}$ \\
\hline $\begin{array}{l}\text { Bruns et } \\
\text { al. } 2004\end{array}$ & $\begin{array}{l}\text { To investigate the } \\
\text { impact of selenium } \\
\text { in the treatment of } \\
\text { lymphedema of the } \\
\text { head and neck } \\
\text { region after cancer } \\
\text { treatment ( } \mathrm{N}=36 \text { ) }\end{array}$ & $\begin{array}{l}\text { Radiation } \\
\text { alone or in } \\
\text { combination } \\
\text { with surgery }\end{array}$ & $\begin{array}{l}\text { The median } \\
\text { interval was } 4 \\
\text { months after } \\
\text { the end of } \\
\text { head and neck } \\
\text { cancer } \\
\text { treatment } \\
\text { (range: 2-12 } \\
\text { months) }\end{array}$ & $\begin{array}{l}\text { A scoring system modified } \\
\text { after the LENT-SOMA } \\
\text { criteria for endolaryngeal } \\
\text { lymphedema (i.e., } \\
\text { subjective parameters } \\
\text { assessing breathing from } \\
\text { Grade } 0 \text { to Grade 4) }\end{array}$ & $\begin{array}{l}\text { Interstitial } \\
\text { endolaryngeal } \\
\text { lymphedema } \\
\text { associated with stridor } \\
\text { and dyspnea symptoms }\end{array}$ \\
\hline $\begin{array}{l}\text { Micke et } \\
\text { al. } 2003\end{array}$ & $\begin{array}{l}\text { To investigate the } \\
\text { influence of } \\
\text { selenium in the } \\
\text { treatment of } \\
\text { lymphedema of the } \\
\text { head and }\end{array}$ & $\begin{array}{l}\text { Radiation } \\
\text { alone or by } \\
\text { irradiation } \\
\text { after surgery }\end{array}$ & $\begin{array}{l}\text { The median } \\
\text { interval was } 4 \\
\text { months after } \\
\text { the end of } \\
\text { cancer } \\
\text { treatment }\end{array}$ & $\begin{array}{l}\text { A scoring system modified } \\
\text { after the LENT-SOMA } \\
\text { criteria (i.e., subjective } \\
\text { domain evaluating } \\
\text { breathing from Grade } 0 \text { to } \\
\text { Grade 4) }\end{array}$ & $\begin{array}{l}\text { Laryngeal lymphedema } \\
\text { associated with stridor } \\
\text { and dyspnea }\end{array}$ \\
\hline
\end{tabular}


neck region after cancer treatment

$(\mathrm{N}=36)$

$\begin{array}{ll}\text { Rudat et } & \text { To detect the } \\ \text { al. } 1999 & \text { associations } \\ & \text { between acute and } \\ & \text { late radiation } \\ & \text { effects, tumour } \\ & \text { control and in vitro } \\ & \text { radiosensitivity } \\ & \text { of primary normal } \\ \text { tissue fibroblasts } \\ \text { (N=68) }\end{array}$

$\begin{array}{ll}\text { Machtay } & \text { To determine the } \\ \text { et al. } & \text { feasibility, } \\ 2004 & \text { toxicity, and } \\ & \text { preliminary } \\ & \text { efficacy of a } \\ & \text { regimen of } \\ \text { postoperative } & \text { reirradiation, } \\ \text { chemotherapy and } \\ \text { the radioprotector } \\ \text { amifostine after } \\ \text { salvage head-and- } \\ \text { neck surgery } \\ \text { (N=16) }\end{array}$

$\begin{array}{ll}\text { Eisbruch } & \text { To identify the } \\ \text { et al. } & \text { anatomic } \\ 2004 & \text { structures whose } \\ & \text { damage or }\end{array}$

malfunction cause

late dysphagia and aspiration after

intensive

chemotherapy and

radiotherapy (RT)

for head-and-neck

cancer $(\mathrm{N}=26)$

(range: 2-12

months)

$\begin{array}{lll}\begin{array}{l}\text { Simultaneous } \\ \text { concomitant }\end{array} & \begin{array}{l}\text { The median } \\ \text { follow-up }\end{array} & \begin{array}{l}\text { The author stated that a } \\ \text { tracheotomy had to be }\end{array} \\ \begin{array}{l}\text { boost } \\ \text { radiochemo- }\end{array} & \begin{array}{l}\text { months } 21 \\ \text { performed in five of } 68\end{array} \\ \text { therapy with } & \text { (range: 2.5-81 } & \begin{array}{l}\text { patients (7\%) because of } \\ \text { the }\end{array} \\ \text { carboplatin } & \text { months) } & \begin{array}{l}\text { radiation-induced chronic } \\ \text { larynx lymphedema. }\end{array}\end{array}$

Impaired breathing

function

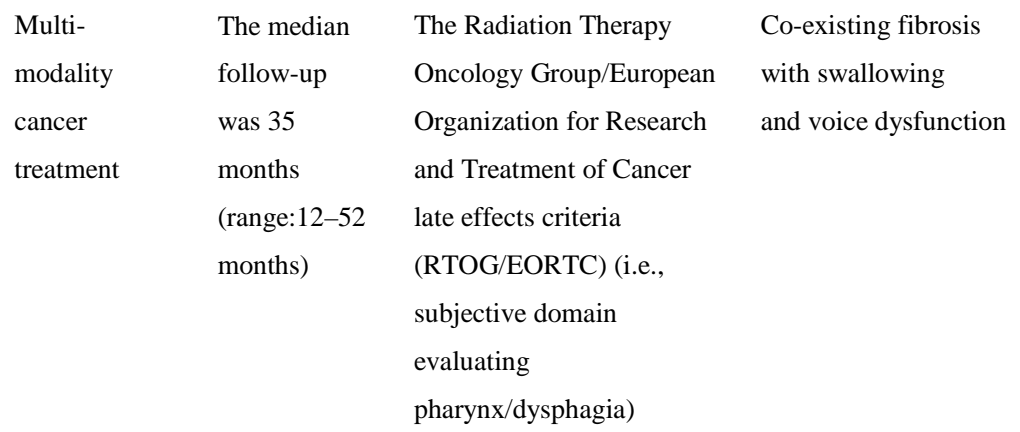

\begin{tabular}{|c|c|c|c|}
\hline $\begin{array}{l}\text { Chemotherapy } \\
\text { and } \\
\text { radiotherapy }\end{array}$ & $\begin{array}{l}\text { The early (1- } \\
3 \text { months) and } \\
\text { late } \\
\text { (6-12 } \\
\text { months) after } \\
\text { cancer } \\
\text { therapy } \\
\text { completion }\end{array}$ & $\begin{array}{l}\text { Evaluation of swallowing } \\
\text { with } \\
\text { videofluoroscopy and } \\
\text { direct endoscopy }\end{array}$ & $\begin{array}{l}\text { Co-existing fibrosis } \\
\text { with impaired } \\
\text { aspiration and } \\
\text { swallowing; Stiffness } \\
\text { of laryngeal and } \\
\text { epiglottic walls due to } \\
\text { lymphedema and } \\
\text { fibrosis; Mucosal and } \\
\text { submucosal fibrosis at } \\
\text { base of tongue or at its } \\
\text { attachment to } \\
\text { pharyngeal } \\
\text { musculature }\end{array}$ \\
\hline
\end{tabular}


Bruns and colleagues (2004) investigated the impact of selenium in the treatment of lymphedema of the head and neck region. Their results suggested a short positive effect of sodium selenite on secondary head and neck lymphedema caused by radiotherapy alone or in combination with surgery. They recruited 36 head and neck cancer patients with persistent, extensive, or progressive lymphedema of the head and neck region, including 20 patients with interstitial endolaryngeal lymphedema and 16 patients with other lymphedemas of the head and neck area. They determined their subjects actually had lymphedema through the following modified clinical grading systems: (1) interstitial endolaryngeal lymphedema was clinically graded using a score adopted from the LENT-SOMA system (as cited in Bruns et al., 2004); (2) the extent of other lymphedemas of the head and neck area was graded using the modified scoring systems of Foldi and Foldi et al. and of Millere et al. (as cited in Bruns et al., 2004). In their study, they reported that 20 head and neck cancer patients with interstitial endolaryngeal lymphedema had stridor and dyspnea symptoms.

Micke and colleagues (2003) also evaluated the impact of selenium in the treatment of lymphedema after radiotherapy. Their results suggested that sodium selenite had a positive on secondary-developing lymphedema caused by radiation therapy alone or by irradiation after surgery. They determined their subjects actually had lymphedema of the head and neck area using the scoring system modified after Foldi and Foldi et al. and Micke et al., and Miller et al. (as cited in Micke et al., 2003). Interstitial endolaryngeal edema was graded using a scoring system modified after the LENTSOMA criteria (as cited in Micke et al., 2003). Indeed, they used several grading systems that might be similar to Bruns' (2004). In their study, they found that 20 patients had 
subjective breathing difficulty symptoms related to interstitial endolaryngeal lymphedema.

A study aimed at the detection of associations between acute and late radiation effects in head and neck cancer patients found that 29 of 68 (43\%) head and neck cancer patients developed chronic laryngeal lymphedema within 12 months of radiation therapy and that it impeded their breathing function (Rudat et al., 1999). The authors stated that laryngeal lymphedema was caused by an impaired lymphatic system due to radiation therapy. In their study, laryngoscopy and CT were employed to examine laryngeal lymphedema and the late radiation morbidity scoring scheme of Toxicity Criteria of the RTOG/EORTC was used to diagnose the grade of lymphedema.

Thus, there are the several common characteristics across the head and neck cancer-related lymphedema studies. (1) Lymphedema was identified after surgery alone, radiotherapy alone, or combined surgery and radiation. (2) The studies examined treatment-associated early and late-effect lymphedema, that is, time spans from less than 30 days to within 12 months after cancer treatment. (3) The studies found head and neck cancer-associated lymphedema caused patients to have unpleasant symptoms (i.e., tension, pain, stridor, dyspnea, and sensory deprivation) and functional impairments (i.e., swallowing, speaking, and breathing).

Fibrosis and lymphedema. If a patient has injury to vital anatomy in the head and neck, fibrosis can often coexistent with local or regional lymphedema, which may also contribute to soft-tissue induration and functional consequences (O'Sullivan \& Levin, 2003). Two studies (Eisbruch et al., 2004; Machtay et al., 2004) identified that lymphedema coexists with fibrosis in head and neck cancer patients. The exact 
mechanism or relationship between lymphedema and tissue fibrosis has not been clarified, but lymphedema patients often develop tissue fibrosis over time (Foldi et al., 2006). The fibrosis might cause head and neck cancer patients with secondary lymphedema to have specific symptoms, such as tightness, stiffness, and limited neck range of motion. For example, stiffness of laryngeal walls caused by lymphedema and fibrosis has been reported to negatively affect both phonation and swallowing (Eisbruch et al., 2004). However, other possible symptoms (e.g., tightness and problems driving) related to fibrosis in head and neck cancer patients with secondary lymphedema have not been examined or reported in the current literature.

Experts' viewpoints. Based on experts' knowledge and clinical experience, the following review articles explicate the possible symptoms that may be experienced by head and neck cancer patients with secondary lymphedema. Hammond (2007) stated that symptoms of head and neck lymphedema not only include external swelling or puffing around the head, face, or neck, but might also include many invisible symptoms patients also experience, such as trouble swallowing and pain when moving the neck and head into certain positions. Murphy et al. (2007a) noted that lymphedema can impair breathing, eating, swallowing and speech, and that the swelling alters the appearance of a patient. Matorin (1994) noted that oral cavity and laryngeal involvement lymphedema could produce dyspnea and feeding difficulties.

Based on the literature review, the relationship between fibrosis and lymphedema, and experts' viewpoints, secondary lymphedema may be associated with numerous symptom issues and functional impairment. However, limited research studies are available that address symptom burden and functional loss related to secondary 
lymphedema in head and neck cancer patients. It is unknown whether secondary lymphedema in head and neck cancer is associated with functional impairment, such as hearing, mouth range of motion, and neck range of motion. If external or internal lymphedema (swelling or fibrosis) affects the anatomical structures of outer or middle ear, it is unclear whether patients develop conductive hearing impairment. If internal lymphedema (swelling or fibrosis) influences patients' inner ear or hearing nerve, it is unknown whether patients have sensorineural hearing impairment. Similarly, if lymphedema (swelling or fibrosis) affects trigeminal nerve or masticatory muscles, patients might have trismus. Lymphedema (swelling or fibrosis) might compromise skin, muscles, or nerves in the neck and shoulder area, thus patients might have decreased neck range of motion and abnormal signs (such as tenderness and postural abnormalities). Nonetheless, all these postulations need to be clarified. Therefore, there is a need to systematically explore and examine symptoms, symptom burden, and functional difficulties in head and neck cancer patients with secondary lymphedema.

Breast cancer-related lymphedema studies. Although limited studies examined symptoms and functional difficulties related to secondary lymphedema in head and neck cancer patients, research conducted with breast cancer patients provides insight into how lymphedema can result in physical and psychological symptoms and symptom burden. In a cross-sectional, mixed-methods design that included 64 breast cancer survivors with lymphedema and 64 breast cancer survivors without lymphedema, Ridner (2005) found that breast cancer survivors with lymphedema reported a symptom cluster that included alteration in limb sensation, loss of confidence in body, decreased physical activity, fatigue, and psychological distress. In a cross-sectional descriptive study (Armer \& 
Whitman, 2002), symptoms experienced most commonly among breast cancer survivors ( $n=102)$ with lymphedema were swelling (63\%), heaviness (60\%), tenderness (45\%), and numbness (38\%). Other symptoms associated with post-breast cancer lymphedema included fatigue, pain and other sensation changes, and limitations in arm range of motion.

Furthermore, Kosir et al. (2001) stated that sensation changes (such as numbness, aching, and tingling) may be the earliest indicator of increasing interstitial pressure changes associated with lymphedema in breast cancer patients, even before observable changes or measurable volume changes. Armer et al. (2003) found that the onset of lymphedema was predicted by three symptoms: "heaviness in past year," "swelling now," and "numbness in past year." Their findings suggested that changes in sensations may be indicators of early lymphedema and need to be assessed carefully at each follow-up visit and over time. At this time, no specific tests are available to diagnose lymphedema; typically, clinicians rely on patients’ presentation and history to make a diagnosis. Lymphedema usually is not detectable clinically until the interstitial volume is about 30\% above normal (Holcomb, 2006); that is, patients with lymphedema often feel symptoms before clinical manifestations are detected. Therefore, it is important to assess patients' symptoms early.

\section{Psychological Effects}

Psychological effects refer to cognitive and emotional responses. Psychological distress is a broad term that encompasses various psychological responses, such as depression and anxiety (NCI, 2008a; Ridner, 2004; Stein, Syrjala, \& Andrykowski, 2008). Depression and anxiety are the two global indicators of emotional status often 
measured in cancer survivors (Deimling, Bowman, Sterns, Wagner, \& Kahana, 2006). Besides depression and anxiety, other psychological phenomena reported in cancer survivors include mood disturbance (NCI, 2008b), adjustment disorders (i.e., a depressed or anxious mood or a mixture of both) (Casey et al., 2006), post-traumatic stress disorder (PTSD) (Kangas, Henry, \& Bryant, 2002; Kangas, Henry, \& Bryant, 2005), and body image (Cash \& Pruzinsky, 2002; Hopwood, Fletcher, Lee, \& Ghazal, 2001; Hormes et al., 2008). The following table lists the common instruments used to assess psychological effects in cancer patients in the reviewed literature (see Table 9).

Table 9

Common Instruments Used to Measure Psychological Effects in Cancer Survivors

\begin{tabular}{ll}
\hline Psychological Effects & \multicolumn{1}{c}{ Instruments } \\
\hline Distress & Distress Thermometer, Brief Symptom Inventory \\
Anxiety & Hospital Anxiety and Depression Scale (HADS), Beck Anxiety Inventory \\
Depressive Symptoms & HADS, Center for Epidemiological Studies-Depression Scale (CES-D) \\
Mood Disturbance & Profile of Mood States (POMS), POMS-SF \\
Adjustment Disorder & Schedule Clinical Assessment in Neuropsychiatry \\
PTSD & PTSD Checklist Civilian Version, Structured Clinical Interview for DSM-IV \\
Body Image & Body Image Survey, Body Image Scale \\
\hline
\end{tabular}

Two relatively early studies reported that head and neck cancer survivors appear to be particularly vulnerable to depression or they may experience depressive symptoms (Derogatis et al., 1983; Morton, Davis, Baker, Baker, \& Stell, 1984). In addition, research has demonstrated some positive psychological impacts reported in cancer survivors, such as opportunity for personal growth and increasing social connectivity (Coreil, Wilke, \& Pintado, 2004; Kinney, Rodgers, Nash, \& Bray, 2003). 
Throughout the literature review, none of the studies report and assess psychological effects of secondary lymphedema in head and neck cancer patients. Nevertheless, head and neck lymphedema influences patients' most visible areas of their body (e.g., face and neck). Patients with head and neck lymphedema may have to wear highly visible face and neck compression garments that may cause them to avoid many social situations. Thus, the extent to which they experience body image issues needs to be examined. Moreover, the experts suggest that secondary lymphedema may affect head and neck cancer patients' psychological distress level (Murphy et al., 2007a) and they may experience a substantial degree of psychological morbidity (Dennert \& Horneber, 2007). Furthermore, the studies conducted with breast cancer patients provide information regarding psychological effects of secondary lymphedema. For instance, breast cancer patients with lymphedema experience psychological distress and loss of confidence in their body (Ridner, 2005). In addition to a negative body image (Morgan et al., 2005), they feel shock, fear, annoyance, frustration, less sexually attractive, and view lymphedema as a constant reminder of cancer (Carter, 1997). They often experience a negative emotional state (Jung \& Cho, 2006) and are more likely to develop anxiety and depression than the general population (Morgan et al., 2005).

\section{Quality of Life Effects}

Quality of life in head and neck cancer patients is a major concern throughout the treatment and survival trajectory, thus numerous studies have focused on treatmentrelated quality of life. However, recent quality of life studies suggest that the type of head and neck cancer treatment alone may not be the major contributing factor to poorer quality of life, and the symptoms and secondary complications may impact on quality of 
life (Donatelli-Lassig et al., 2008; El-Deiry, Futran, McDowell, Weymuller, \& Yueh, 2009; Langendijk et al., 2008). Throughout the literature review, only two studies, each of which having a similar small sample size, (Bruns et al., 2004; Micke et al., 2003) are available in relation to secondary lymphedema affecting head and neck cancer patients' quality of life. Bruns and colleagues (2004) explored the impact of selenium in the treatment of lymphedema of the head and neck region after radiotherapy alone or in combination with surgery. In their study, they also evaluated head and neck cancer patients' overall quality of life related to secondary lymphedema. They used a single item visual analogue scale (VAS) to assess 36 head and neck cancer patients' quality of life.

Micke et al. (2003) investigated the impact of selenium in the treatment of lymphedema after radiotherapy. In their study, they also assessed 36 head and neck cancer patients' overall quality of life related to secondary lymphedema using a VAS. They stated that the VAS is a validated tool for estimation of the patients' general health condition by the physician or the patient himself or herself. The investigators did not report detailed information about the quality of life assessment scale, such as the development process of the tool or if it was used in other studies.

In general, secondary lymphedema is viewed as a side-effect of cancer treatment. From this perspective, the instruments that assess head and neck cancer treatmentspecific quality of life might be used as the tools to evaluate secondary lymphedemarelated quality of life. Upon reviewing the literature, there are many measurement instruments available to assess treatment-specific quality of life in head and neck cancer patients. The following table lists the instruments for assessing head and neck treatmentspecific quality of life (see Table 10), including Functional Assessment of Cancer 
Therapy Scale-Head \& Neck (FACT-H\&N) (D’Antonio, Zimmerman, Cella, \& Long, 1996), the European Organization for Research and Treatment of Cancer Quality of Life Questionnaire- Head and Neck (EORTC H\&N 35) (Bjordal et al., 1999), the University of Michigan Head and Neck Quality-of-life Questionnaire (HNQOL) (Terrell et al., 1997), Head and Neck Cancer Inventory (HNCI) (Funk, Karnell, Christensen, Moran, \& Ricks, 2003), and the University of Washington Quality-of-life Instrument (UWQOL) (Hassan, \& Weymuller, 1993). Although different instruments measure quality of life from different domains, there are overlaps among them. In terms of the measurement domains and the number of items in the instruments, comparing studies in the literature revealed that FACT-H\&N and EORTC H\&N35 are more frequently used instruments in the literature to measure treatment-related quality of life in head and neck cancer patients at this time (Murphy, Ridner, Wells, \& Dietrich, 2007b; Pusic et al., 2007).

Table 10

Common Quality of Life Instruments for Head and Neck Cancer

\begin{tabular}{llll}
\hline Instruments & \multicolumn{1}{c}{ Descriptions } & \multicolumn{1}{c}{ Validity } & Reliability \\
\hline FACT-H\&N & 39-item, five major domains & Convergent validity & Cronbach’s alpha: .59-.79 \\
EORTC H\&N 35 & 35-item, seven major domains & Convergent validity & Cronbach’s alpha > .70 \\
HNQOL & 20-item, four major domains & Construct validity & Cronbach’s alpha: .79-.93 \\
HNCI & 30-item, five domains & Convergent validity & Cronbach’s alpha: .87-.94 \\
UWQOL & 12 domains & Convergent validity & Cronbach's alpha: .74-.83 \\
\hline
\end{tabular}

Overall, there are few instruments that address quality of life related to lymphedema. For example, breast cancer related lymphedema is the most commonly studied type of secondary lymphedema, but only two quality of life instruments exist. 
The Upper Limb Lymphedema-27 (ULL-27) was developed to measure breast cancer patients’ quality of life related to secondary lymphedema (Launois, Mègnigbêto, Pocquet, \& Alliot, 2002). The reliability and validity has been examined in two studies (Launois et al., 2002; Ridner, 2005). The Freiburg Life Quality Assessment Lymphedema questionnaire (FLQA-l) was a novel quality of life questionnaire developed specifically for use in lymphedema based on the previously validated FLQA vein questionnaire (Augustin, Bross, Foldi, Vanscheidt, \& Zschocke, 2005). The FLQA-l is a diseasespecific quality of life questionnaire for patients with lymphedema. The validity and reliability of the FLQA-l was examined in only one study (Augustin et al., 2005). No instruments are available in the current literature to measure secondary lymphedemarelated quality of life after head and neck cancer treatment.

Possible Risk Factors

Head and neck cancer-associated lymphedema studies. The following studies reported that possible risk factors contribute to occurrence of secondary lymphedema in head and neck area. In a cross-sectional study, Warren and Slavin (2007) reported on 11 patients with scar lymphedema from a history of trauma or prior reconstructive, excisional, or esthetic surgical procedures. The development of swelling around a scar has been attributed to lymphatic channels damaged by traumatic laceration or surgical incision, thus causing lymphatic dysfunction and trapping lymphatic fluid within a curvilinear scar. Sanguineti et al. (2007) examined the correlation between laryngeal edema and dosimetric parameters through a retrospective study design in 66 head and neck cancer patients. They found that the risk of laryngeal edema was strictly correlated with various dosimetric parameters. To minimize the risk of edema, the mean laryngeal 
radiation dose should be kept as low as possible. They stated edema of the larynx was attributed to the inflammatory process during irradiation along with disruption of lymphatic channels resulting in a common complication of head-and-neck radiotherapy.

Lymphedema results from an imbalance in capillary filtration and lymph drainage (Lymphoedema Framework, 2006), which leads to collection of fluid and protein in the extravascular and interstitial spaces of the affected head and neck region. For head and neck cancer patients with lymphedema, it seems that lymph node dissection, radiation therapy, and surgery may be the main contributing and pathological risk factors (Lymphoedema Framework, 2006). However, other possible risk factors have not been examined and reported at this time (Lymphoedema Framework, 2006). For example, factors damaging head and neck cancer patients' lymph vessel function and leading to lymphatic pathological status might include tumor characteristics, hypertension, and diabetes. Likewise, other behavioral and situational factors related to secondary lymphedema in head and neck cancer patients have not been examined, including how head and neck cancer patients' smoking and alcohol drinking behaviors might influence patients' lymph drainage functions via compromised lymph nodes and lymph vessels. For another example, head and neck cancer patients' area of residence (rural vs. urban) might influence patients' access to healthcare resources related to the lymphedema treatment and management.

Breast cancer-associated lymphedema studies. Although limited literature is available on possible risk factors related to occurrence of secondary lymphedema in head and neck cancer patients, many studies have examined the possible risk factors for 
secondary lymphedema in breast cancer patients. These risk factors may also apply to head and neck cancer patients with lymphedema, as the pathophysiology is similar.

The studies reviewed mainly focused on examining physiological and situational risk factors related to the occurrence of secondary lymphedema in breast cancer patients. The studies conducted in the United States found the following physiological factors associated with an increased risk of developing secondary lymphedema in breast cancer patients.

In a prospective study (McLaughlin et al., 2008), 936 breast cancer patients, including 600 women undergoing sentinel lymph node biopsy alone and 336 women undergoing sentinel lymph nodes biopsy and axillary lymph node dissection, were followed up five years after surgery. They found higher body mass index (BMI), and infection or injury were significant risk factors for developing lymphedema. Sentinel lymph node biopsy alone significantly lowered the patients' lymphedema odds. In another prospective study (Meeske et al., 2008), 494 breast cancer patients were followed up 50 months after diagnosis. Arm lymphedema was statistically associated with younger age at diagnosis, positive history of hypertension, obesity (or BMI $\geq 30$ ), and having surgery where 10 or more lymph nodes were excised. The risk of arm lymphedema did not differ significantly for African American and Caucasian women. The two other prospective studies (Geller, Vacek, O’Brien, \& Secker-Walker, 2003; Paskett, Naughton, McCoy, Case, \& Abbott, 2007) found receiving chemotherapy related to increasing risk of developing secondary lymphedema in breast cancer patients.

Several retrospective studies with larger sample sizes also contribute to exploration of the possible risk factors related to the occurrence of secondary 
lymphedema in breast cancer patients. A retrospective study analyzed 727 breast cancer patients and reported nodal irradiation was the only significant risk factor for arm lymphedema in patients receiving breast conservative therapy for early-stage breast cancer (Powell, Taghian, Kachnic, Coen, \& Assaad, 2003). Another retrospective study systematically examined the association of nonradiation and radiation variables with lymphedema (Hinrichs et al., 2004). They examined by the chart review method 105 patients who received postmastectomy radiation (PMRT) and found 27\% developed lymphedema after PMRT. Total dose, posterior axillary boost, and overlapping radiation fields were significantly related with lymphedema. One case-control study identified TNM stage, number of dissected nodes, number of positive nodes, tumor size, infection, allergy, diabetes mellitus, hypertension, hypothyroidism, chronic obstructive pulmonary disease, and BMI as risk factors of breast cancer-related lymphedema (Soran et al., 2006).

The studies conducted in other countries also found similar risk factors to those found in the United States. One prospective study conducted in the UK discovered hospital skin puncture, mastectomy, and $\mathrm{BMI} \geq 26$ to increase risk of developing lymphedema (Clark, Sitzia, \& Harlow, 2005). In one prospective study conducted in Australia (Hayes, Janda, Cornish, Battistutta, \& Newman, 2008), 33\% of the patients were diagnosed as having lymphedema from six to 18 months after surgery. In their study, older age, more extensive surgery or axillary node dissection, and experiencing one or more treatment-related complications or symptoms (e.g., poor range, numbness, weakness) were associated with increased odds of lymphedema. Another prospective 
study conducted in Australia found that the number of positive nodes was significant to patient-reported lymphedema (Graham, 2002).

The three prospective studies separately completed in Italy, Korea, and India also reported similar findings about the risk factors related to developing secondary lymphedema in breast cancer patients (Deo et al., 2004; Herd-Smith, Russo, Muraca, Turco, \& Cardona, 2001; Park, Lee, \& Chung, 2008). They also identified higher stage of the disease, a pathologic T2 classification, and presence of co-morbid conditions contributing to occurrence of breast cancer lymphedema. Research found that a combination of axillary dissection and axillary radiation should be avoided whenever feasible to avoid lymphedema (Deo et al., 2004).

Additionally, the studies reported some situational factors related to a risk of secondary lymphedema occurring in breast cancer patients. The situational factors include aspects of the social and physical environment that may affect the person's experience and reporting of symptoms (Lenz et al., 1997). Situational factors may include individual's vocation, lifestyle behaviors (such as diet and exercise), and area of residence. These studies found that the situational factors related to occurrence of arm lymphedema include working outside the home (Geller et al., 2003), occupation/hobby (hand use) (Soran et al., 2006), air travel, exposure to extreme temperature (cold/heat), strenuous exercise and activity (Nielsen, Gordon, \& Selby, 2008).

There is paucity of research regarding possible risk factors related to head and neck cancer-related lymphedema at this time. Based upon the similarity of pathophysiological process between breast cancer-related lymphedema and head and neck cancer-related lymphedema, researcher can examine whether the risk factors for 
development of lymphedema in breast cancer patients lead to occurrence of secondary lymphedema in head and neck cancer patients. It is significant to examine and identify whether these factors are the same risk factors for developing secondary lymphedema after head and neck cancer treatment. Once nurses and other healthcare professionals recognize and are aware of the possible risk factors, they will be able to provide head and neck cancer patients with evidence-based assessment, informed education, and, perhaps, decrease patients' symptom burden related to secondary lymphedema. Thus, it is important to research and examine the possible risk factors of secondary lymphedema in head and neck cancer patients.

\section{Advantages and Disadvantages of Methods}

Signs and Measurement

Signs are objective evidences of disease and can be seen by healthcare professionals. In the literature, head and neck cancer patients’ lymphedema signs and/or lymphedema measurement are primarily assessed by healthcare clinicians using scales and proper equipment (e.g., laryngoscope). Scales to measure external lymphedema (ACS, 2006; CTCAE v3.0, 2006) in head and neck cancer have been developed and used in clinical settings. However, due to lack of validity and reliability testing, the scales to measure external lymphedema need to be improved in future studies. Moreover, the scales used to measure internal lymphedema in head and neck cancer patients have not obtained consensus and need to be validated for their reliability and validity. That is, head and neck lymphedema measurement is still a difficult issue in clinical settings, especially for internal lymphedema. 
Currently, a laryngoscope is a common medical instrument for examining internal structures (e.g., the larynx) in head and neck cancer patients. Thus, direct visualization via endoscopy may be an option available to collect internal lymphedema data (Patterson et al. (2007). However, using only equipment (i.e., laryngoscope) does not ensure the accuracy of assessment for patients' signs of secondary lymphedema. In some circumstances, clinicians are limited by their understanding of secondary lymphedema and they do not make it common practice to examine patients' early signs of secondary lymphedema. Moreover, limited validated scales are available in clinical and research settings, which affect accurate description of patients' lymphedema. In addition, clinicians employ different scales to evaluate patients' signs related to secondary lymphedema. Thus, the measurement of signs for secondary lymphedema in head and neck cancer patients need to be improved in both research and clinical settings. Symptoms/Effects on Body Function/Quality of life

Six articles were available that investigated symptoms, effects on body function, and quality of life in head and neck cancer patients with secondary lymphedema (Bruns et al., 2004; Eisbruch et al., 2004; Machtay et al., 2004; Micke et al., 2003; Piso et al., 2001; Rudat et al., 1999). Three of them were the intervention studies exploring the treatment methods for secondary lymphedema in head and neck cancer patients. They used pretest-posttest, pre-experimental designs without control groups. The major advantages of one-group pretest-posttest designs are that they are practical and economical with small sample sizes. The rest of them were the descriptive studies using a cross-sectional design. The main advantages of cross-sectional designs are that they are 
time saving and relatively economical but not appropriate for examining causational relationship (Polit \& Beck, 2004).

In addition, the method of patients' self-reports is often used to research symptoms, effects on body function, and quality of life related to secondary lymphedema in head and neck cancer patients (Micke et al., 2003; Piso et al., 2001; Rudat et al., 1999). Traditionally, patients’ symptom data are collected by clinicians interviewing patients, eliciting, and interpreting patients’ complaints (Trotti, Colevas, Setser, \& Basch, 2007). Clinicians' individual differences may influence the accuracy of the symptom data. Thus, the subjective domain of patients' data can be associated with poor inter-rater reliability regarding grading consistency and completeness of capture (Trotti et al., 2007). For example, symptom research has documented systematic underreporting of symptoms (in number, severity, and time of onset/resolution) by clinicians compared with patients (Bruner, Carr, Curren, \& Chamberlain, 1998; Varricchio \& Sloan, 2002). A study compared the reporting of symptom severity by patients and clinicians (Basch et al., 2006). The study found that agreement was higher for symptoms that could be observed directly, such as vomiting and diarrhea, than for more subjective symptoms, such as fatigue and dyspnea. They suggested that patient reporting of symptoms could add to the current approach to symptom monitoring in cancer treatment and cancer symptom management. Compared with healthcare clinicians' interpretation, patients' self-report would be the most appropriate method to collect the severity of their symptoms (subjective experiences for diseases and treatments) (Trotti et al., 2007). As for the cost of the self-report method, it saves time and is low-cost. 
However, the self-report method requires that validated and reliable questionnaires be available to ensure accuracy and completeness of data using self-report. Although a fair amount of overlap may exist between arm lymphedema and head/neck lymphedema symptoms, the instruments used to measure arm lymphedema symptoms cannot fully describe/cover head/neck lymphedema symptoms because of the different anatomical sites, different functional impairments, and treatment methods involved. Thus, there is a need to examine symptoms and develop evidence-based symptom questionnaires for nurses and other healthcare professionals to evaluate and manage head and neck cancer-related secondary lymphedema in clinical settings. Possible Risk Factors

Two studies reviewed in the literature examined the possible risk factors related to head and neck lymphedema. One study (Sanguineti et al., 2007) used a retrospective design to collect the data related to the possible risk factors leading to occurrence of secondary lymphedema over time. The major advantage of a retrospective design is an efficient, low-cost and convenient method to find the possible risk factors. The other study used a cross-sectional design and examined the possible risk factors related to head and neck lymphedema (Warren \& Slavin, 2007). The major advantages of cross-sectional designs are that they have low cost and are practical. However, the studies reviewed mainly examined the possible risk factors from some of the physiological factors. Based on the literature on risk factors for secondary lymphedema in breast cancer patients, lymphedema symptoms are also closely related to a variety of physiological and situational factors (e.g., air travel and lifting/carrying heavy luggage) (Air Travel \& Lymphedema, 2008). Thus, examining possible multidimensional risk factors related to 
secondary lymphedema in head and neck cancer patients is needed and has the potential to optimize symptom management.

\section{Strengths and Weaknesses of Methods}

The strengths and weaknesses of the methodological approaches will be discussed based on the following components in the literature: design, sample, instruments options, and knowledge integration.

Strengths of the Methods

The strengths of the methodological approaches used to investigate the problem of interest are as follows. (1) Design: In terms of different research objectives, the studies reviewed used a variety of research designs, including one-group pretest-posttest preexperimental, longitudinal, and cross-sectional designs. The strengths of one-group preexperimental designs are that the studies used more conveniently collected data without a control group and randomization (Trochim, 2001). The strengths of longitudinal designs are appropriate to examine causation and possible risk factors of leading to a given outcome. By measuring the risk factors prior to the certain outcome, the longitudinal design makes it possible to identify the relationship between risk factors exposure and the specified result. The strengths of cross-sectional designs are that research data can be completely collected at one time thus minimizing attrition. When the research question does not involve continuity and change, a cross-sectional design is a proper method to collect data in descriptive studies (such as collecting descriptive data related to patients' symptoms, functions, and quality of life). In a cross-sectional design, there is no pretest/posttest effect and test-retest bias and subjects' burden is decreased. (2) Sample: 
Three of the studies clearly described the participant recruitment, the sampling procedure (i.e., eligibility, settings, locations, etc.), types of participants, and drop-out rates and the causes of the drop-outs (Bruns et al., 2004; Micke et al., 2003; Piso et al., 2001). (3) Instruments: In two of the studies, reliability and validity of the measurement instruments were reported in detail and each instrument measured the concept it was intended to measure (Patterson et al., 2007; Piso et al., 2002). (4) Knowledge integration: In two of the studies, the investigators reiterated the main findings and further compared them with previous research. They also offered hypotheses regarding the part of findings that were at odds with previous work. They articulated generalizibility of the study findings and described general interpretation of the results in the current evidence. The meaningful point was that some authors described clinical implications for future similar settings/participants (Micke et al., 2003; Patterson et al., 2007).

\section{Weaknesses of the Methods}

The weaknesses of the methodological approaches used to investigate the problem of interest include as follows. (1) Design: Three of the studies used a one-group pretestposttest pre-experimental design (Bruns et al., 2004; Micke et al., 2003; Piso et al., 2001). Because there is no control group, the design is at risk to most of the threats to internal validity (e.g., environmental and maturation threat). Several studies used a cross-sectional design, which is appropriate for describing symptoms, effects on body function, and quality of life but is not appropriate for exploring causation and timing (Polit \& Beck, 2004). (2) Sample: There are several concerns about the samples in some of the articles. First, the authors (Piso et al., 2001; Zimmermann et al., 2005) did not state how the sample sizes were determined and did not address statistical power analysis. They did not 
describe if the samples are homogeneous or heterogeneous. Some studies (Piso et al., 2001; Zimmermann et al., 2005) had small sample sizes (e.g., 11 and 20 subjects, respectively). The small sample sizes influence the internal and external validity of the studies. Second, the authors did not describe clearly the inclusion and exclusion criteria (Micke et al., 2003); (3) Instruments: Some of the studies did not report the reliability of instruments and how the instruments were developed (Bruns et al., 2004; Piso et al., 2001). Limited instruments are available to evaluate lymphedema-associated symptoms in head and neck cancer patients; (4) Knowledge integration: Some of the authors did not compare the research results with previous studies and did not discuss generalizability of their research findings. They did not suggest implications for future studies and did not include any limitations of their studies (Zimmermann et al., 2005).

\section{Synthesis of Knowledge}

Although early detection and multimodality treatments have decreased the mortality of cancer patients, the secondary complications from cancer and its treatment affect patients' quality of life. In approximately the past 10 years, healthcare professionals have realized the early effects and late-effects from cancer treatment and provided patients with evidence-based symptom management. However, certain head and neck cancer patients still suffer some unpleasant and distressful symptoms that are not explained and hard to control by current symptom management strategies. Secondary lymphedema is one of the refractory complications that disrupt patients' body functions and affect their quality of life. 
Although some investigators have reported and examined secondary lymphedema after head and neck cancer treatment, lack of systematic research that focuses on patients' physical and psychological symptoms, effects on body function, effects on quality of life, and possible risk factors. The data on physical symptoms and effects on body functions related to secondary lymphedema in head and neck cancer patients are obtained from studies with small sample sizes and experts' individual viewpoints. Some measurement instruments used in the literature lacked proper information about validity and reliability. There is lack of specific and unique measurement tools to assess head and neck cancer patients’ symptoms associated with secondary lymphedema. Limited studies have examined possible risk factors of leading to occurrence of head and neck lymphedema. Currently, the incidence and prevalence of secondary lymphedema in head and neck cancer patients is unpublished in the United States. Financial costs and insurance coverage for treatment of secondary lymphedema in this population are not reported. It is needed to develop treatment and management strategies of secondary lymphedema in head and neck cancer patients. Therefore, these gaps indicate more research needed in this area. The research methodological limitations in the reviewed literature also warrant systematic methodological approaches to examine lymphedema-associated symptoms, effects on body function, effects on quality of life, and possible risk factors.

Through the literature review, the following implications are proposed regarding studying secondary lymphedema related to head and neck cancer treatment.

1. There is a need to systematically research and recognize the phenomenon of secondary lymphedema (e.g., incidence, prevalence, and financial burden) in head and neck cancer populations. 
2. There is a need to conduct studies to clearly describe all types of symptoms, effects on body function, and effects on quality of life related to secondary lymphedema in the head and neck cancer population.

3. There is a need to conduct the research with appropriate sample sizes based on statistical power analysis to improve statistical and external validity of the studies.

4. There is a need to develop sensitive instruments to measure lymphedema-related symptoms in head and neck cancer patients.

5. There is a need to examine the possible risk factors to guide nurses and other healthcare professionals to identify and manage lymphedema and improve patients’ awareness of self-monitoring and self-care.

6. There is a need to explore effective treatment and management strategies of secondary lymphedema in head and neck cancer patients.

In summary, secondary lymphedema of head and neck patients is an important concept and needs to be investigated from theory, research, and evidence-based clinical intervention viewpoints.

\section{Research Hypotheses}

The research reviewed does not provide ample evidence from which to develop hypotheses. A descriptive and correlational design is indicated as a first step in developing an evidence base from which to develop hypotheses for future studies. 


\section{Key Concepts}

The key concepts related to the research study include lymphedema, symptoms, function, signs, quality of life, and risk factors. The key concepts are stated as follows. Lymphedema

Lymphedema is the general term for a set of pathologic conditions in which there is excessive, regional interstitial accumulation of protein-rich fluid. It can be either a primary or a secondary (acquired) condition (Rockson, 2001). The most common cause of secondary lymphedema in developed countries is cancer treatment (Dos et al., 2005; Lymphoedema Framework, 2006). The lymphedema related to the problem of interest includes two key points of (1) secondary lymphedema related to head and neck cancer treatment and (2) late-effect lymphedema that occurs or has not healed by three months after the end of head and neck cancer treatment (Bentzen et al., 2003; ONS Research Agenda, 2009-2013). For the purposes of this study, lymphedema refers to secondary lymphedema developing three or more months after the completion of head and neck cancer treatment.

Signs

Signs are physical manifestations of illness that are noted by a doctor, nurse, or other healthcare professional on physical exam (ACS, 2007) rather than by the patient or lay observer (Merriam-Webster’s Medical Dictionary, 2008). Signs are objective evidences of disease. The signs related to the problem of interest specify the objective manifestations of external and internal lymphedema (e.g., submental edema and laryngeal edema), which will be used to determine if a patient actually has lymphedema. 


\section{Symptom}

Symptoms are indications of disease, illness, injury, or something that is not right in the body. Symptoms are felt or noticed by a person, but may not easily be noticed by anyone else (ACS, 2007). Symptoms are a subjective experience, appraised by the patient (Liehr, 2005). Symptoms are often dichotomized as either physical symptoms or psychological symptoms (Kroenke, 2003). The symptoms related to the problem of interest may include physical symptoms (e.g., dysphagia, hoarseness, and swallowing difficulty) and psychological symptoms (e.g., distress).

\section{Function}

Function is the special, normal, or proper physiologic (or physical) activity of an organ or part (Biology-online, 2008). The functions related to the problem of interest specify the concrete physiological actions of the head and neck region, such as swallowing, hearing, and neck range of motion.

\section{Quality of Life (QOL)}

QOL is an individual's overall sense of well-being. In medical studies, QOL is a multidimensional variable and measured using various standardized questionnaires to rate such factors as pain, treatment side-effects, mood, energy level, family and social interactions, sexual function, ability to work, and ability to keep up with routine daily activities (National Anemia Action Council [NAAC], 2007). The QOL related to the problem of interest specifies the global QOL from the patients’ perspective. Symptom burden can affect a patient's perceived QOL. Risk Factors 
Risk factors are variables that may increase the chance of developing a disease or injury. Risk factors are correlational and not necessarily causal (NCI, 2008c). The possible risk factors related to the problem of interest may include physiological, psychological, and situational factors, such as tumor stage, emotional reaction to a disease, and vocation.

\section{Theoretical Framework for the Study}

Given the lack of published descriptive data about the problem of interest, lymphedema will be examined according to patients' subjective experiences (symptoms) and objective manifestations (signs). Additionally, as lymphedema also disturbs physical functions and quality of life for affected individuals, these components were also addressed. Therefore, the theoretical basis for the study should address these components. Based on the theoretical literature review, the key research variables (i.e., the symptoms, possible risk factors, and the effects of lymphedema on body functions and quality of life) related to the problem of interest best fit the three key components (i.e., the symptoms, the influencing factors, and the performances) in the Theory of Unpleasant Symptoms (Lenz et al., 1997) (see Figure 1). Thus, the Theory of Unpleasant Symptoms was chosen as the theoretical framework to direct the research study. The following operational definitions are offered to provide clarification. 


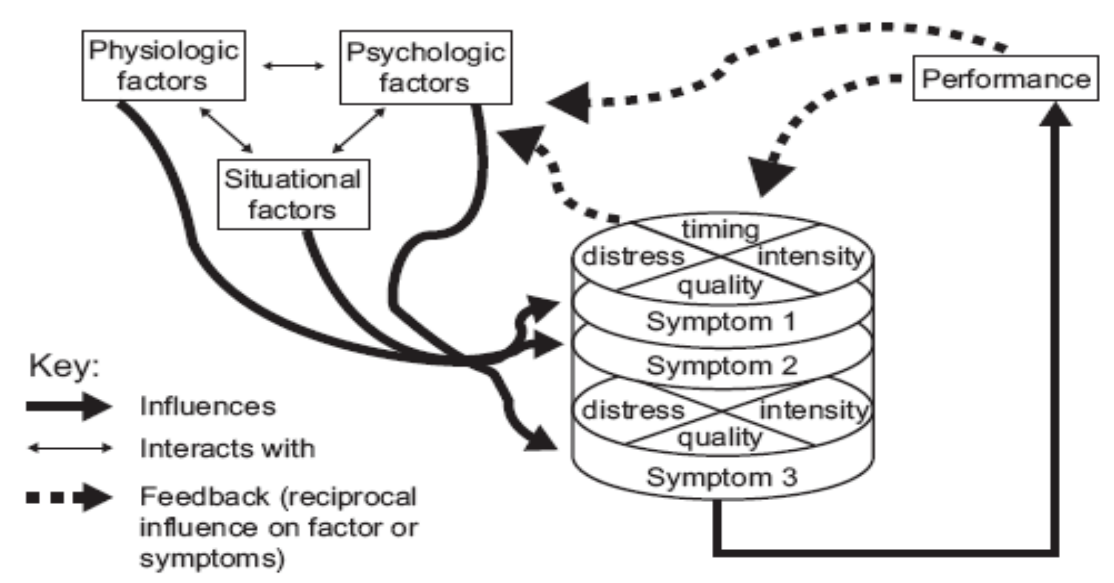

Figure 1. The Theory of Unpleasant Symptoms (Lenz et al., 1997)

\section{Symptoms}

In the study, symptoms (subjective experience) was a key variable to be assessed based on the Theory of Unpleasant Symptoms. According to the Theory of Unpleasant Symptoms, four dimensions are common across symptoms: intensity, timing, level of distress perceived, and quality. Thus, given those dimensions, symptoms related to secondary lymphedema can be assessed and described using a symptom scale, which measures intensity of the symptom, the level of distress perceived, timing, and quality. A second component related to symptoms in the Theory of Unpleasant Symptoms suggests patients seldom experience only one symptom at a time. More often, they may experience multiple symptoms or a cluster of symptoms, such as swallowing difficulties and tightness. The multiple symptoms lead to patients’ symptom burden.

2. Influencing factors (possible risk factors)

In terms of the Theory of Unpleasant Symptoms, patients’ symptoms can be driven by multidimensional influencing factors, including physiological, psychological, 
and situational factors. These three types of factors interact with one another and commonly have an impact on the symptom experience (Lenz et al., 1997). The multidimensional influencing factors in the Theory of Unpleasant Symptoms facilitate examination of possible risk factors leading to occurrence of secondary lymphedema. For example, the doses of radiation might be correlated to lymphedema development in the head and neck cancer population.

3. Performance (functional status and quality of life)

In the Theory of Unpleasant Symptoms, Lenz et al. interpreted that performance means the outcome or effect of symptom experience (Lenz et al., 1997). In the study, functional status and quality of life were examined as the effects of lymphedema. 


\section{CHAPTER III}

\section{METHODOLOGY}

The purpose of this section is to describe the methodology used in the research study of secondary lymphedema related to head and neck cancer treatment. This section will include research design and assumptions, research setting, sample and sampling plan, data collection methods, and data analysis procedures.

\section{Research Design and Assumptions}

A descriptive, correlational, cross-sectional design was used in the study. The lymphedema diagnosis and stage was established by the Staging/Grading criteria and basic diagnostic procedures (i.e., by taking the medical history, and by inspection and palpation) (Foldi et al., 2003). External lymphedema was identified using the following three scales: 1) the Stages of Lymphedema (Foldi et al., 2003), 2) Lymphedema of the Head and neck Grading Scale (CTCAE v3.0, 2006), and 3) Lymphedema of the Head and Neck Staging Criteria (ACI, 2006). Internal lymphedema was identified using Patterson’s Scale for Edema in Larynx and Pharynx (Patterson et al., 2007). The associations of the severity of lymphedema with symptoms, functional status, and quality of life in head and neck cancer patients were examined. Furthermore, possible factors contributing to the presence of secondary lymphedema in head and neck cancer patients were explored.

Three assumptions were proposed based on the comprehensive literature review and the theoretical framework of this study. 1) Patients may develop external 
lymphedema, internal lymphedema, and combined lymphedema after head and neck cancer treatment. 2) The severity of lymphedema may be associated with symptoms, functional status, and quality of life. 3) Some demographic and cancer disease and treatment factors may be related to the presence of secondary lymphedema in head and neck cancer patients.

\section{Research Setting}

The study was conducted at the Vanderbilt-Ingram Cancer Center, Tennessee, U.S.A. There are about 4,000 new cancer patients each year and more than 65,000 outpatient visits annually in the comprehensive cancer center. Study participants were identified from the cancer center.

Sample and Sampling Plan

\section{Nature and Size of Sample}

A convenience sample consisting of 103 adult head and neck cancer patients after their cancer treatment was obtained. This was a descriptive, preliminary study of lymphedema in patients who have been treated for head and neck cancer; there are no preliminary data available to guide statistical powering other than rates that have been observed in patients treated for breast cancer. This study investigated the associations between the severity of lymphedema and symptom, functional, and quality of life selfreports. Given that this was a preliminary study and many measures of associations were generated, it was important to detect the largest and most clinically relevant effects or 
associations. Therefore, it was decided that any correlations smaller than an observed beta coefficient \pm 0.30 (representing $9 \%$ shared variance) would not be considered clinically relevant at this time. Because of the large number of associations assessed in this preliminary study, it was determined also that an alpha level of .010 would be used for determining statistical significance. A sample size of 103 achieves $80 \%$ power to meet the criteria for clinical (associations of \pm 0.30 ) and statistical significance ( $p \leq$ $.010)$.

\section{Criteria for Sample Selection}

The participants recruited into the study met the following inclusion criteria: (1) 18 and over years of age; (2) $\geq 3$ months after completion of their cancer treatment; and (3) no current evidence of cancer. Individuals were excluded if they met the following the exclusion criteria: (1) actively undergoing chemotherapy or radiation therapy; (2) having metastatic cancer or any other active cancer; and (3) unable to understand the informed consent as evidenced by incorrectly describing the study when asked.

The underlying principles for the exclusion criteria are as follows. (1) Patients actively undergoing chemotherapy or radiation therapy may have cancer treatmentrelated acute edema (NCI, 2007a). The patients may experience symptom burden and functional impairments related to the acute edema. The study focuses on secondary lymphedema rather than acute edema. In order to control for the influence of acute edema, the study excluded patients actively undergoing chemotherapy or radiation therapy and recruited patients who had completed their cancer treatment greater than three months ago. (2) Patients with metastatic cancer or any other active cancer may 
experience different cancer treatment strategies, and have different physical and emotional responses from patients without metastatic cancer or any other active cancer; the responses are likely to be potential confounding variables in the research study. (3) Patients who were unable to understand the informed consent as evidenced by incorrectly describing the study when asked were excluded to avoid any confounding effects on the self-reported subjective symptoms in the research study.

\section{Participant Recruitment}

The participants were identified in the study by the PI screening the potential participants at the Vanderbilt-Ingram Cancer Center. The following specific steps were used. (1) The PI visited head and neck cancer oncologists (i.e., medical, surgical, and radiation oncologists) at the Vanderbilt-Ingram Cancer Center and told them about the purpose and procedure of the study. (2) The head and neck cancer oncologists helped tell the potential participants about the study. (3) The PI screened and recruited the persons expressing interest in the study using the screening form.

\section{Human Subjects Protection}

Prior to recruiting the participants, approval was obtained from the Vanderbilt University Institutional Review Board (IRB) and the Scientific Review Committee (SRC) at the Vanderbilt-Ingram Cancer Center. Study participation was open to all patients with head and neck cancer. No one was excluded based on gender, race, or ethnicity. The following specific steps were used to obtain the informed consent from all the participants. (1) The PI explained the study to potential participants. (2) The participants 
were provided one copy of the informed consent to read and review. (3) The PI asked the potential participants if they had any questions during and after their reading/reviewing the informed consent. (4) The PI answered all the questions the potential participants asked. (5) The potential participants agreed to be in the study and signed on the informed consent as the PI witnessed. This process took place in a private location at the cancer center to ensure confidentiality. There was no anticipated potential risk to participants for participating in the study. The study only posed some time inconvenience to the participants. Participants were free to withdraw from the study at any time, for any reason simply by telling the PI that they wished to withdraw.

Compliance with study procedures was assured by the PI and the PI's advisor, Dr. Sheila Ridner, through regular meetings. Participants’ data were randomly examined during this regular meeting. The PI reported any issues related to the study procedures to her advisor, e.g., participants' recruitment, data collection, and data entry. All files were saved in both hard copies and one password protected safe electronic database. All hard copies were placed in a locked file cabinet. All data were coded and filed without any name or other identifiable information. Dr. Ridner, Dr. Mary Dietrich (a member of the dissertation committee who served as the statistical consultant), and the PI had access to the electronic database. Only Dr. Ridner and the PI had access to the hard copy file cabinet. All the hard copy research data were stored at the Vanderbilt University School of Nursing. The PI's advisor and the PI stored the electronic database in passwordprotected electronic files. 


\section{Data Collection Methods}

\section{Procedures}

The PI contacted the head and neck cancer oncologists by using a script (see Appendix A) and told them about the study. Then the PI contacted and screened the possible participants who expressed interest in the study by using the patient's contact script (Appendix B) and the screening form (Appendix C). Once an exclusion criterion was met, no other information was gathered. If they were eligible, the participants were provided an informed consent form. After informed consent was obtained, the PI evaluated the participants' external lymphedema, neck range of motion, mouth range of motion, and hearing, and collected their demographic and lymphedema treatment information. Participants’ cancer disease and treatment information were gathered from their medical records via chart review by the PI. The skilled head and neck surgical oncologists (i.e., ENTs) and radiation oncologists evaluated internal lymphedema of the participants based on Patterson's Scale for Edema in Larynx and Pharynx. The participants completed the self-report instruments designed and/or chosen for the study. All data collected from participants were locked in a safe place.

\section{Instruments}

The instruments used in the study are listed below in terms of the following domains: (1) sample characteristics; (2) prevalence of lymphedema [Aim 1]; (3) symptoms, functional status, and quality of life [Aim 2]; and (4) possible risk factors [Aim 3]. The instruments in each domain are described based on their content and 
previous use in the literature, and information about reliability and validity.

\section{Sample Characteristics}

Demographic and Background Information Form (Appendix D). The

demographic and health behavior characteristics form included questions about age, gender, race, education, marital status, employment status, area of residence, presence of any co-morbid conditions, medical history, alcohol use, smoking assumption, dietary habits, etc. The information was obtained through interviewing the participants.

\section{Head and Neck Cancer Disease \& Treatment Information Form (Appendix E).}

The head and neck disease and treatment information form included questions about date of diagnosis of head and neck cancer, location, stage of tumor TNM (T: the extent of the tumor; N: the extent of spread to the lymph nodes; and M: the presence of metastasis), type and dates of treatment, and complications. The information was collected by the PI via medical records and chart review.

\section{Aim 1: Prevalence of Lymphedema}

External lymphedema. Four staging/grading scales (see below) were used to assess external lymphedema after head and neck cancer treatment in the study.

Stages of Lymphedema (abbreviation: Foldi's LE scale). The Stages of Lymphedema scale was developed by Foldi and his colleagues and was introduced in their Textbook of Lymphology (2003). Although the authors did not state the reliability and validity of their scale, they developed the Stages of Lymphedema based on their experience treating over 100,000 patients with lymphedema, thus content validity can be assumed. There are three major components in the Foldi et al. scale, i.e., pathology, signs and symptoms, and diagnosis. Therefore, the scale illustrates the entire picture of 
secondary lymphedema.

Lymphedema of the Head and Neck Grading Scale (abbreviation: NCI LE scale).

The National Cancer Institute developed the Lymphedema of the Head and Neck Grading Scale (CTCAE v3.0, 2006). The five grades provide a basic method of evaluating external lymphedema after treatment of the head and neck cancer. The content validity of the scale was supported by the expert panel during development of the CTCAE v3.0. The reliability of the scale has not been reported.

Lymphedema-related Fibrosis Scale (abbreviation: NCI Fibrosis scale). The National Cancer Institute developed the Lymphedema-related Fibrosis Scale (CTCAE v3.0, 2006). The three grades provide a fundamental method of evaluating lymphedemarelated skin fibrosis after cancer treatment. The content validity of the scale was supported by the expert panel during development of the CTCAE v3.0. The reliability of the scale has not been reported.

Lymphedema of the Head and Neck Staging Criteria (abbreviation: ACS LE scale). Based on the Lymphedema of the Head and Neck Grading Scale of the National Cancer Institute, the American Cancer Society provides the staging criteria for grading head and neck lymphedema from normal to severe (ACS, 2006; Cheville et al., 2003). The four stages are described to assess external lymphedema of the head and neck. The content validity of the criteria was supported by the expert panel during development of the staging criteria. The reliability of the scale has not been published.

Internal Lymphedema. One scale (see below) was used in this research study to assess internal lymphedema after head and neck cancer treatment.

Patterson's Scale for Edema in Larynx and Pharynx (abbreviation: Patterson 
scale) (Appendix F). Patterson's Scale was used to assess internal lymphedema in the larynx and pharynx (Patterson et al., 2007). The scale has good intra-rater reliability (weighted kappa, 0.84) and moderate inter-rater reliability (weighted kappa, 0.54) (Patterson et al., 2007). Based on the experts' suggestions, the rating scale was developed with good content validity. Following Patterson et al. (2007), direct visualization via endoscopy was used to collect internal lymphedema data. Head and neck surgical or radiation oncologists used the scale to collect internal lymphedema data by routinely performing the procedure of endoscopy.

In summary, the severity of lymphedema in this study as an independent variable was classified into three sub-variables, i.e., severity of external lymphedema, severity of internal lymphedema, and severity of combined lymphedema. The severity of combined lymphedema was evaluated using two different methods. Method one included NCI LE scale (for external swelling), NCI Fibrosis scale (for external fibrosis), and Patterson's scale (for internal lymphedema). Method two included Foldi's LE scale (swelling and fibrosis) and Patterson's Scale (for internal lymphedema).

Lymphedema Disease \& Treatment Information Form (Appendix G). This form included date of diagnosis of lymphedema, location of lymphedema, treatment history and current treatment of lymphedema. The information was collected through interviewing participants and was double-checked with the participants' medical records. Aim 2: Symptoms, Functional Status, and Quality of Life Symptoms

Vanderbilt Head and Neck Symptom Survey (VHNSS) (Appendix H). The VHNSS was developed to assess physical symptom burden related to head and neck 
cancer and its treatment. The 27 items are rated by respondents on a 0 to 10 numeric rating scale according to the intensity of symptoms from none to a lot. Higher scores reflect greater symptom intensity. The VHNSS was tested in over 300 patients with head and neck cancer and can be completed by patients in less than five minutes. Previous research (Murphy et al., 2004) has reported good internal consistency for the total VHNSS scale (alpha=.94) and the 12 item VHNSS swallow subscale (alpha=.91). The convergent validity of the VHNSS was supported by the correlation between the VHNSS total score and the EORTC HN-35 subscales and the PSS-HN swallow subscale (Murphy et al., 2004). Construct validity of the VHNSS swallow subscale was supported by correlation with an objective measure of swallowing function (Murphy et al., 2010).

Two instruments (see below) were used to assess psychological symptoms after head and neck cancer treatment in the research study.

Hospital Anxiety and Depression Scale (HADS) (Appendix I). The HADS was developed by Zigmond and Snaith (1983) to provide an efficient assessment tool to measure symptoms of anxiety and depression among the non-psychiatric hospitalized population. The HADS is a self-report questionnaire and only takes two to five minutes to complete (Snaith, 2003). The HADS contains 14 items that generate separate scores for depressive (7 items) and anxious (7 items) symptoms. Items are rated on a 4-point scale; to score the HADS, the 7 items on each subscale (anxiety and depression) are summed separately. Scores on each of the subscales can range from 0 to 21 . Good internal consistency has been reported in the literature (alpha for HADS-anxiety from .68 to .93 and for HADS-depression from .67 to .90) (Bjelland, Dahl, Haug, \& Neckelmann, 2002). Construct validity has been supported through correlation between the HAD 
subscales and psychiatric diagnostic interview (Razavi et al., 1992; Zigmond \& Snaith, 1983) and factor analysis (Moorey et al., 1991). Factor analyses demonstrated that the HADS is a two-factor instrument with the independent subscales for anxiety (HADS-A) and depression (HADS-D). Correlation coefficient (Pearson's) between the HADS scale's anxiety and depression sub-scales is reported to be 0.49 - 0.63 (Savard, Laberge, Gauthier, Ivers, \& Bergeron, 1998).

Body Image Scale (BIS) (Appendix J). The BIS was developed by Hopwood and colleagues to examine oncology patients' self-assessment of body image related to cancer and cancer treatment (Cash \& Pruzinsky, 2002). The 10 items are rated by respondents from 0 (not at all) to 3 (very much). The overall summary score for each respondent ranges from 0 to 30, and higher scores represent increasing symptoms/distress of body image. The scale was tested in a heterogeneous sample of 276 cancer patients and 682 patients with breast cancer. The scale has demonstrated high reliability in previous research (alpha= .93) and good discriminant validity (Hopwood et al., 2001).

\section{Functional Status}

Hearing. Two tests (i.e., the whispered voice test and the tuning fork test) were used to assess hearing impairment after head and neck cancer treatment in the study.

Whispered Voice Test (Appendix K). Hearing was evaluated using the whispered voice test (Pirozzo, Papinczak, \& Glasziou, 2003). The whispered voice test is a simple and accurate test for detecting hearing impairment. The literature reported that the whispered voice test has a sensitivity of 87\%-96\% and a specificity of 70\%-90\% (Pirozzo et al., 2003). It is one test recommended by the United Kingdom and Australia as the national health guidelines to screen for hearing impairment in the elderly population. The 
test was conducted by the PI using a standard procedure.

Tuning Fork Test. The tuning fork test (Fix, 2002) was used to distinguish between conduction hearing impairment and nerve hearing impairment. The Weber test and Rinne test was performed by the PI using a standard procedure. The test results were analyzed based on the following rationale (see Table 11).

Table 11

Tuning Fork Test Results (Fix, 2002)

\begin{tabular}{lll}
\hline Otologic Finding & Weber Test & \multicolumn{1}{c}{ Rinne Test } \\
\hline Conduction deafness (left ear) & Lateralizes to left ear & BC>AC on left AC>BC on right \\
Conduction deafness (right ear) & Lateralizes to right ear & BC $>$ AC on right AC>BC on left \\
Nerve deafness (left ear) & Lateralizes to right ear & AC>BC, both ears \\
Nerve deafness (right ear) & Lateralizes to left ear & AC>BC, both ears \\
Normal ears & No lateralization & AC $>$ BC, both ears \\
\hline
\end{tabular}

Conduction deafness=middle ear deafness (e.g., otosclerosis, otitis media); nerve deafness=sensorineural deafness (e.g., presbycusis); $\mathrm{AC}=$ air conduction; $\mathrm{BC}=$ bone conduction.

Trismus Grading Criteria (Appendix L). Trismus was evaluated using the three fingers test and graded using the CTCAE v3.0 trismus subscales (CTCAE v3.0, 2006). The three grades provide a basic method of evaluating trismus of the head and neck cancer patients in the study. The content validity of the Trismus Grading Criteria was supported by the expert panel during development of the CTCAE v3.0. Trismus was measured by the PI.

\section{Cervical Range of Motion (CROM) Device (Appendix M). The CROM device} was used to measure whether an individual has a reduced CROM. This instrument has been used to examine neck range of motion the literature. The normal CROM are as follows: forward flexion 0-45 degrees, extension 0-45 degrees, left lateral flexion 0-45 
degrees, right lateral flexion 0-45 degrees, left lateral rotation 0-80 degrees, and right lateral rotation 0-80 degrees (De Koning, van den Heuvel, Staal, Smits-Engelsman, \& Herdriks, 2008). In addition, presence or absence of elicited pain, tenderness, postural abnormalities and fixed deformity (ankylosis) of cervical spine musculature were documented (De Koning et al., 2008). The CROM measurement was performed by the PI using a standard procedure.

Quality of Life

Two instruments (see below) were used to assess quality of life after head and neck cancer treatment in the study.

Functional Assessment Cancer Therapy-Head \& Neck (FACT-H\&N) (Appendix N). The FACT-H\&N was used to measure quality of life in head and neck cancer patients related to cancer treatment. The 39-item FACT-H\&N measures concerns associated with head and neck cancer and was tested in 151 head and neck cancer patients being treated at two facilities in Chicago (List et al., 1996). Consistent with the FACT-G, a 5-point response format is used for concerns experienced during the past 7 days. There are 5 subscales on the FACT-H\&N, including physical well-being (7 items), social/family well-being (7 items), emotional well-being (6 items), functional well-being (7 items), and head and neck cancer subscale (12 items). Scores on each of the subscales can range from 0 to 28 for the physical well-being, 0 to 28 for the social/family well-being, 0 to 24 for the emotional well-being, 0 to 28 for the functional well-being, and 0 to 48 for head and neck cancer subscale. After reverse scoring the negative items in the scale, higher scores on the subscales indicate better quality of life. In past studies, the internal consistency of the subscales have been shown to be adequate (alpha $=.59$-.79) (List et al., 1996). The 
FACT-H\&N has been used in head and neck cancer trials, and has demonstrated sensitivity to change in disease status (Murphy et al., 2007b).

Quality of Life Scale (Linear Analog Self Assessment, LASA) (Appendix O). The 5-item linear analog scale assessment of quality of life was published by Locke et al. in 2007. The literature supported that the LASA is a psychometrically validated brief measure of quality of life. In previous reports, the scale has showed good reliability (alpha $=.83-.88$ ) and good concurrent/construct validity (Locke et al., 2007). Despite its brevity, it provides an overall estimate and covers four major subcomponents of quality of life (i.e., physical, emotional, spiritual, and intellectual). Therefore, the LASA gives a global, comprehensive view of a patient's quality of life.

\section{Aim 3: Possible Risk Factors}

The possible risk factors contributing to the presence of lymphedema in head and neck cancer patients were examined based on data from two forms, Demographic and Background Information Form and Head and Neck Cancer Disease \& Treatment Information Form, which were described above in the sample characteristics section (see page 68).

The following list summarizes the coding of key factors for purposes of the analyses conducted in this study.

(1) Location of head and neck cancer was recoded into paranasal sinuses, oral cavity, nasopharynx/oropharynx, hypopharynx, larynx, and other. The 'other category' included participants with salivary gland tumors and others.

(2) Histological type of tumor was coded as squamous cell carcinoma (SCC) and non-SCC. The later included acinic cell carcinoma, clear cell mucoepidermoid, 
embryonal rhabdomyosarcoma, hemangiopericytoma, and small cell carcinoma.

(3) Dosage of radiation therapy was coded as low dose $(\leq 6000 \mathrm{cGy})$ and high dose (> 6000 cGy).

(4) Type of chemotherapy was collapsed into taxol/carboplatin group and nontaxol/carboplatin group.

(5) Total treatment received for head and neck cancer was coded as one modality of cancer treatment (i.e., surgery only or radiation only), two modalities of cancer treatment (i.e., surgery with radiation, or concurrent chemotherapy and radiotherapy), three modalities of cancer treatment (i.e., surgery and concurrent chemotherapy and radiotherapy; chemo-induction and concurrent chemotherapy and radiotherapy), and four modalities of cancer treatment (i.e., surgery, chemo-induction, and concurrent chemotherapy and radiotherapy).

\section{Summary}

The following table (see Table 12) lists the data resources and data collection methods used in the study.

\section{Table 12}

Data Resources and Data Collection Methods

\begin{tabular}{|c|c|c|c|}
\hline $\begin{array}{c}\text { Domains/ } \\
\text { Concepts } \\
\text { Measured }\end{array}$ & $\begin{array}{c}\text { Measurement } \\
\text { Variables }\end{array}$ & $\begin{array}{c}\text { Measurement } \\
\text { Instruments }\end{array}$ & $\begin{array}{c}\text { Data Collection } \\
\text { Methods }\end{array}$ \\
\hline \multirow{2}{*}{$\begin{array}{c}\text { Sample } \\
\text { Characteristics }\end{array}$} & $\begin{array}{c}\text { Demographic data } \\
\text { health behavior data }\end{array}$ & $\begin{array}{c}\text { Demographic and Background } \\
\text { Information Form }\end{array}$ & The PI Interview \\
\cline { 2 - 3 } & $\begin{array}{c}\text { Head and neck cancer } \\
\text { disease and treatment } \\
\text { data }\end{array}$ & $\begin{array}{c}\text { Head and Neck Cancer Disease \& } \\
\text { Treatment Information Form }\end{array}$ & $\begin{array}{c}\text { The PI Chart } \\
\text { Review }\end{array}$ \\
\cline { 2 - 3 } $\begin{array}{c}\text { Aim 1: } \\
\text { Prevalence of } \\
\text { Lymphedema }\end{array}$ & External lymphedema & NCI LE scale & \multirow{2}{*}{$\begin{array}{c}\text { The PI Interview/ } \\
\text { Examination }\end{array}$} \\
\cline { 3 - 3 }
\end{tabular}




\begin{tabular}{|c|c|c|c|}
\hline & & ACS LE scale & \\
\hline & Internal lymphedema & Patterson's scale & MDs/the PI \\
\hline \multirow{3}{*}{ Aim 2: Symptoms } & Physical symptoms & VHNSS & \multirow{3}{*}{$\begin{array}{l}\text { Participant Self- } \\
\text { report }\end{array}$} \\
\hline & \multirow{2}{*}{$\begin{array}{l}\text { Psychological } \\
\text { symptoms }\end{array}$} & HADS & \\
\hline & & BIS & \\
\hline \multirow{5}{*}{$\begin{array}{l}\text { Aim 2: Functional } \\
\text { Status }\end{array}$} & \multirow{2}{*}{ Hearing } & Whispered Voice Test & \multirow{5}{*}{ The PI Examination } \\
\hline & & Tuning Fork Test & \\
\hline & \multirow{2}{*}{ Mouth range of motion } & Three Fingers Test & \\
\hline & & Trismus Grading Criteria & \\
\hline & Neck range of motion & Cervical Range of Motion & \\
\hline \multirow{2}{*}{$\begin{array}{c}\text { Aim 2: Quality of } \\
\text { Life }\end{array}$} & \multirow{2}{*}{ Quality of life } & FACT-H\&N & \multirow{2}{*}{$\begin{array}{l}\text { Participant Self- } \\
\text { report }\end{array}$} \\
\hline & & LASA & \\
\hline \multirow{2}{*}{$\begin{array}{l}\text { Aim 3: Possible } \\
\text { Risk Factors }\end{array}$} & Demographic data & $\begin{array}{l}\text { Demographic and Background } \\
\text { Information Form }\end{array}$ & The PI Interview \\
\hline & Cancer treatment data & $\begin{array}{l}\text { Head and Neck Cancer Disease \& } \\
\text { Treatment Information Form }\end{array}$ & $\begin{array}{l}\text { The PI Chart } \\
\text { Review }\end{array}$ \\
\hline
\end{tabular}

\section{Credibility, Rigor, and Validity}

The study ensured rigor through the following aspects.

\section{Internal validity}

The study used a cross-sectional design and limited its explanation about causal relationships between research variables due to lack of a time dimension. However, the cross-sectional design was a most appropriate and ideal design based on the current state of science of the phenomenon of interest. Throughout the literature review, limited literature is available related to secondary lymphedema in head and neck cancer patients and thus it is critical to conduct descriptive studies delineating this understudied phenomenon. Thus, this dissertation focused on describing the prevalence of secondary lymphedema, its associations with symptomatology, functional status, quality of life, and the possible risk factors. 


\section{External validity}

Due to a cross-sectional design, the study had a particularly low missing data and most instances of missing data were random. Moreover, no participants were excluded based on gender, race, or ethnicity. The study sample characteristics were similar to most of literature reports. The study result can be generalized to adult head and neck cancer populations after their cancer treatment $\geq 3$ months. Thus, the study had a good external validity.

Reliability

The study used the validated instruments to collect patients’ self-reported data. These instruments had been tested with good reliability and validity parameters. This study used Cronbach's alpha coefficients to assess internal consistency of the instruments and the alpha values for each instrument were similar to literature reports. This further demonstrated that there was good internal consistency of all the instruments. Moreover, the physical examinations across the study were accurate and consistent. The PI was a licensed-nurse and trained by a physical therapist regarding how to measure CROM before all data collection activity. The two skilled oncologists who conducted endoscopic examinations were trained on use of the Patterson's scale by the PI. All the physical measurements were performed using the standard procedures. Thus, the study had a good reliability and ensured the quality of data in this study.

\section{Objectivity}

The study not only collected subjective (self-reported) data but also objective data (physical examination), which engendered confidence in the truth of the data. The univariate and multivariate statistical methodologies were employed to clearly analyze 
and demonstrate the study findings. As a preliminary study to describe an understudied phenomenon, the study focused on detecting rather large effects or associations and used a minimal significant level $(\mathrm{p} \leq .010)$ to interpret the study findings. This method of interpreting the findings minimized the type I and type II errors.

\section{Data Analysis}

Data were double entered by the PI into the statistical software package SPSS version 17.0. After data entry, data validation and data cleaning procedure were used to check for outliers and internal data consistency (Polit \& Beck, 2004). The PI examined the distribution and patterning of missing data. Because it was a cross-sectional study, most instances of missing data were random, particularly some item responses within the self-report measures. Missing responses to items within measures were handled according to the protocols specified by the authors of those measures.

Descriptive statistics were used to describe the sample and to summarize the distributions of the study variables, including demographic information, head and neck cancer disease/treatment information, lymphedema disease/treatment information, as well the measures of symptom, functional status, and quality of life. Categorical and ordinal data (e.g., gender) were summarized using frequency distributions. Ordinal data summaries also included median and $25^{\text {th }}-75^{\text {th }}$ inter-quartile ranges. Continuous data values were evaluated visually with histograms and measures of skewness for determining the appropriate descriptive statistics. If normality could be assumed, the distributions were described using means and standard deviations; if not, the distributions were described using median and $25^{\text {th }}-75^{\text {th }}$ inter-quartile ranges, minimum, and 
maximum values.

Severity of lymphedema was assessed on an ordinal scale, and self-reports of symptom/function were, as expected, highly skewed; therefore data were transformed to ranks prior to inclusion in correlation and regression analyses. Data were analyzed based on each specific aim in the study.

Aim1: To examine the prevalence of external lymphedema, internal lymphedema and combined lymphedema in head and neck cancer patients.

Statistical Analysis Methods: Frequency distributions were used to describe the prevalence of lymphedema in this study.

Aim 2: To examine the associations between severity of lymphedema in head and neck cancer patients and (a) the symptom scores; (b) functional status scores; and (c) QOL scores.

(2a) Analyze the associations between severity of lymphedema and symptoms in head and neck cancer patients.

Statistical Analysis Methods: Measures used to assess symptoms in this study included the Vanderbilt Head and Neck Symptom Survey (VHNSS), the Hospital Anxiety and Depression Scale (HADS) and the Body Image Scale (BIS). Simple linear regression of transformed data was used to examine the association between each measure of lymphedema severity and symptoms scores. Multiple linear regression of transformed data was used to assess the association of both internal and external lymphedema severity with symptom self-reports. Given that this was an exploratory study and given that a large number of statistical tests were conducted, to control for Type I error, an association of at least 0.30 (indicating $9 \%$ shared variability) was used 
for making interpretations.

(2b) Analyze the associations between severity of lymphedema and functional status in head and neck cancer patients.

Statistical Analysis Methods: Functional status was assessed using Cervical Range of Motion (CROM), Whispered Voice Test, Tuning Fork Test, and Trismus Grading Criteria. Simple linear regression of the transformed data was used to examine the association between severity of lymphedema and the continuous functional status scores (CROM and Trismus). Logistic regression analyses were used to examine the associations of lymphedema severity with the dichotomous functional status values (Whispered Voice Test and Tuning Fork Test). Respective multiple linear and logistic regressions were used to assess the associations of both internal and external lymphoma severity with functional status values. As with the previous analyses, an association of at least 0.30 (indicating $9 \%$ shared variability) was used for making interpretations of the associations with the continuous variables. A critical alpha of at least .010 $(p \leq .010)$ was used for making interpretations of the associations with the dichotomous variables.

(2c) Analyze the associations between severity of lymphedema and quality of life in head and neck cancer patients.

Statistical Analysis Methods: Quality of life was assessed using Functional Assessment Cancer Therapy-Head \& Neck (FACT-H\&N) and QOL Scale (Linear Analog Self Assessment, LASA). As with the previously described analyses, simple linear regression of transformed data was used to examine the association of each measure of severity of lymphedema with quality of life scores. Multiple linear regressions of transformed data were used to assess the associations of both internal and 
external lymphoma severity with the quality of life values. Again, an association of at least 0.30 (indicating 9\% shared variability) was used for making interpretations of the associations.

Aim 3: To examine the possible risk factors contributing to the presence of secondary lymphedema in head and neck cancer patients.

Statistical Analysis Methods: Information about possible factors contributing to the development of lymphedema was collected via the use of two instruments (the Demographic and Background Information Form, and the Head and Neck Cancer Disease \& Treatment Information Form. Univariate (unadjusted) logistic regressions were used to examine the association of each possible factor with the occurrence of secondary lymphedema. As with the previous research question, due to the large number of tests conducted, a critical alpha of at least .010 $(p \leq .010)$ was used for making interpretations of the associations. 


\section{CHAPTER IV}

\section{FINDINGS}

This chapter presents the study findings based on statistical analyses. Two primary sections are given. Section one focuses on a description of the study participants. Section two presents the results from the study aims.

\section{Sample Characteristics}

Four aspects of the study sample: (1) demographic characteristics, (2) health behavior characteristics, (3) head and neck cancer disease and treatment characteristics, and (4) internal consistency and sample scores on the instruments will be summarized in this section.

A convenience sample of 103 adult head and neck cancer patients were recruited by the PI at the Vanderbilt-Ingram Cancer Center. Data were collected from December 2009, through May 2010. All the participants were three months or more post-treatment. Eighty-one participants (78.6\%) also underwent endoscopy examination by their surgical oncologists or radiation oncologists during enrollment in the study. Internal lymphedema data were collected using the Patterson's scale on each of those eighty-one participants, while the remaining twenty-two participants (21.4\%) did not have an endoscopic exam. Of those twenty-two participants, half of them $(n=11)$ had no surgical oncologists' or radiation oncologists' appointments scheduled, while the other half $(n=11)$ had an endoscopy exam scheduled beyond the study data collection period. 


\section{Demographic Characteristics}

Demographic characteristics are summarized in Table 13. The sample was $68.9 \%$ male and ranged in age from 33 to 86 years. Most participants were White (89.3\%) and at least high school graduates (89.3\%). The majority of the participants (64.1\%) were married or living with partner. More than half of the participants were receiving government insurance aid (57.3\%) and lived in a Metropolitan area (63.1\%). Thirty-five percent of the participants lived in households with more than $\$ 50,000$ annual income.

\section{Health Behavior Characteristics}

Few of the participants (12.6\%) reported special dietary habits, including eating sweet, spicy, and sour food. Sixty-six percent reported a smoking history and 37.9\% reported drinking alcohol. Summaries of the health behavior characteristics of the study sample are presented in Table 14.

\section{Head and Neck Cancer Disease and Treatment Characteristics}

Disease and treatment characteristics of the sample are summarized in Table 15. The oropharynx was the most common primary tumor location (43.7\%). Advanced stage disease (III/IV) was present in $80.6 \%$ of all participants. The histological type of most participants’ tumors was squamous cell carcinoma (93.2\%). Sixteen participants (15.5\%) with oropharyngeal carcinoma had HPV testing with $50 \%$ of them testing positive. One out of three participants with nasopharyngeal carcinoma (2.9\%) was identified as having Epstein Barr Virus infection. Eleven participants (10.7\%) had tracheostomy tube due to a total laryngectomy. 


\section{Table 13}

\section{Demographic Characteristics}

\begin{tabular}{|c|c|}
\hline Characteristic & Frequency $(\%)(\mathrm{N}=103)$ \\
\hline \multicolumn{2}{|l|}{ Gender } \\
\hline Male & $71(68.9)$ \\
\hline Female & $32(31.1)$ \\
\hline \multicolumn{2}{|l|}{ Race } \\
\hline White & 92 (89.3) \\
\hline Black & $11(10.7)$ \\
\hline \multicolumn{2}{|l|}{ Education Level } \\
\hline$<12$ th grade & $11(10.7)$ \\
\hline 12th grade & 38 (36.9) \\
\hline College & $44(42.7)$ \\
\hline Graduate & $10(9.7)$ \\
\hline \multicolumn{2}{|l|}{ Marital Status } \\
\hline Single & $23(22.3)$ \\
\hline Married/Living with partner & $66(64.1)$ \\
\hline Widowed & $11(10.7)$ \\
\hline Other & $3(2.9)$ \\
\hline \multicolumn{2}{|l|}{ Employment Status } \\
\hline Employed & $52(50.5)$ \\
\hline Retired & $33(32.0)$ \\
\hline Disabled & $10(9.7)$ \\
\hline Unemployed & $8(7.8)$ \\
\hline \multicolumn{2}{|l|}{ Residence Area } \\
\hline Metropolitan & $65(63.1)$ \\
\hline Rural & 38 (36.9) \\
\hline \multicolumn{2}{|l|}{ Insurance Coverage } \\
\hline Medicare/ Medicaid/TennCare/TriCare & $59(57.3)$ \\
\hline Private Insurance /HMO & $37(35.9)$ \\
\hline None/other & $7(6.8)$ \\
\hline \multicolumn{2}{|l|}{ Yearly Household Income } \\
\hline$<=20,000$ & $19(18.4)$ \\
\hline$\$ 20,001$ to $\$ 50,000$ & $15(14.6)$ \\
\hline Over $\$ 50,000$ & $36(35.0)$ \\
\hline Do not care to respond & $33(32.0)$ \\
\hline Age (Mean, Median, IQR25-75, Min, Max) & $59.80,60.22,51.91 / 66.59,33.08,86.65$ \\
\hline
\end{tabular}


Table 14

Health Behavior Characteristics

\begin{tabular}{|c|c|c|c|c|}
\hline Characteristics & \multicolumn{4}{|c|}{ Frequency $(\%)(\mathrm{N}=103)$} \\
\hline \multicolumn{5}{|l|}{ Special Dietary Habit } \\
\hline Yes & \multicolumn{4}{|c|}{$13(12.6)$} \\
\hline None & \multicolumn{4}{|c|}{$90(87.4)$} \\
\hline \multicolumn{5}{|l|}{ Smoking } \\
\hline Current & \multicolumn{4}{|c|}{$13(12.6)$} \\
\hline Past & \multicolumn{4}{|c|}{$55(53.4)$} \\
\hline None & \multicolumn{4}{|c|}{$35(34.0)$} \\
\hline \multicolumn{5}{|l|}{ Drinking Alcohol } \\
\hline Current & \multicolumn{4}{|c|}{$13(12.6)$} \\
\hline Past & \multicolumn{4}{|c|}{$26(25.3)$} \\
\hline None & \multicolumn{4}{|c|}{$64(62.1)$} \\
\hline Characteristic & Mean & Median & Min & Max \\
\hline Smoking (years) & 27.96 & 30.00 & 5 & 50 \\
\hline Numbers of Cigarettes (per day) & 29.63 & 20.00 & 10 & 70 \\
\hline Drinking Alcohol (years) & 23.49 & 20.00 & 2 & 55 \\
\hline Times of Drinking Alcohol (per week) & 5.44 & 4.00 & 2 & 20 \\
\hline
\end{tabular}


Table 15

Head and Neck Cancer Disease and Treatment Characteristics

\begin{tabular}{|c|c|c|c|c|c|c|}
\hline \multirow{2}{*}{$\begin{array}{ll} & \text { Characteristic } \\
\text { Location }\end{array}$} & \multicolumn{6}{|c|}{ Frequency (\%) (N=103) } \\
\hline & & & & & & \\
\hline Paranasal sinuses & \multicolumn{6}{|c|}{$5(4.9)$} \\
\hline Oral cavity & \multicolumn{6}{|c|}{$14(13.6)$} \\
\hline Nasopharynx & \multicolumn{6}{|c|}{$3(2.9)$} \\
\hline Oropharynx & \multicolumn{6}{|c|}{45 (43.7) } \\
\hline Hypopharynx & \multicolumn{6}{|c|}{$4(3.9)$} \\
\hline Larynx & \multicolumn{6}{|c|}{$16(15.5)$} \\
\hline Salivary gland & \multicolumn{6}{|c|}{$2(1.9)$} \\
\hline Other & \multicolumn{6}{|c|}{$14(13.6)$} \\
\hline \multicolumn{7}{|l|}{ Tumor Staging at Diagnosis } \\
\hline Stage I & \multicolumn{6}{|c|}{$6(5.8)$} \\
\hline Stage II & \multicolumn{6}{|c|}{$9(8.7)$} \\
\hline Stage III & \multicolumn{6}{|c|}{$16(15.5)$} \\
\hline Stage IVa & \multicolumn{6}{|c|}{$59(57.3)$} \\
\hline Stage IVb & \multicolumn{6}{|c|}{$8(7.8)$} \\
\hline Could not be staged & \multicolumn{6}{|c|}{$5(4.9)$} \\
\hline \multicolumn{7}{|l|}{ Type of Tumor } \\
\hline Squamous cell carcinoma (SCC) & \multicolumn{6}{|c|}{$96(93.2)$} \\
\hline Non-SCC & \multicolumn{6}{|c|}{$7(6.8)$} \\
\hline \multicolumn{7}{|l|}{ Surgery Type } \\
\hline Radical neck dissection & \multicolumn{6}{|c|}{$1(1.7)$} \\
\hline Modified neck dissection & \multicolumn{6}{|c|}{33 (56.9) } \\
\hline Selective neck dissection & \multicolumn{6}{|c|}{$16(27.6)$} \\
\hline Other & & & $8(1$ & & & \\
\hline Chemotherapy Type & & & & & & \\
\hline Taxol+Carboplatin & & & $51(7$ & .8) & & \\
\hline Cisplatin/ Taxotere/ Erbitux & & & $10(1$ & 4.1) & & \\
\hline Other & & & $10(1$ & 4.1) & & \\
\hline Complete Treatment Received & & & & & & \\
\hline Surgery alone & & & $8(7$ & & & \\
\hline Radiation alone & & & $2(1$ & & & \\
\hline Concurrent Chemo-radiation (CCR) & & & $13(1$ & $2.6)$ & & \\
\hline Surgery and radiation & & & 10( & & & \\
\hline Surgery and CCR & & & $30(2$ & 9.1) & & \\
\hline Chemo-induction and CCR & & & $30(2$ & $9.1)$ & & \\
\hline Surgery, chemo-induction, and CCR & & & 10( & & & \\
\hline Characteristic & Mean & Median & IQR ( & $5,75)$ & Min & Max \\
\hline Total Dosage of Radiation (cGy) & 6576.68 & 6930.00 & 6300.00 & 6930.00 & 3750.00 & 7500.00 \\
\hline Prophylactic Dosage of Radiation (cGy) & 5372.36 & 5400.00 & 5040.00 & 5610.00 & 4500.00 & 7500.00 \\
\hline Number of Lymph Nodes Removed & 21.19 & 17.00 & 7.00 & 29.25 & 0.00 & 81.00 \\
\hline Number of Positive Lymph Nodes & 2.05 & 0.00 & 0.00 & 2.00 & 0.00 & 49.00 \\
\hline Head and Neck Cancer Duration (years) & 2.77 & 2.11 & 0.96 & 3.87 & 0.45 & 14.58 \\
\hline Time Since Treatment Ended (months) & 27.36 & 19.91 & 6.01 & 39.29 & 3.09 & 156.39 \\
\hline
\end{tabular}


Internal Consistency and Current Sample’s Scores on the Instruments

The internal consistency and this sample’s scores on the instruments are summarized in Table 16.

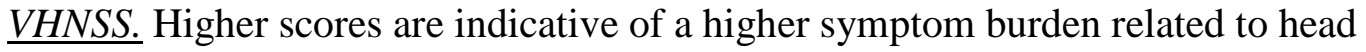
and neck cancer and its treatment. Mean scores on each VHNSS subscale can range from 0 (none) to 10 (a lot). In this study, the VHNSS subscale mean scores of participant ranged from 1.65 to 3.69 . Due to the skewed nature of these distributions, the median values are more descriptive of the typical values. As shown, most medians were in the range of 0.00 to 3.00 . These data suggest that most of the participants in this study had mild symptom burden.

$\underline{H A D S}$. In this study actual HADS scores on the two subscales ranged from 0 to 16 (mean=3.94, median=3.00) for anxiety and 0 to 14 (mean=3.31, median=2.00) for depression. The results show that most of the participants in this study had few or relatively slight anxiety and depressive symptoms.

$\underline{B I S}$. Actual BIS scores in this study ranged from 0 to 30 (mean=6.03, median=3.00). These results indicate most of the participants in this study had quite mild body image issues.

$\underline{F A C T-H \& N}$. In this study, the FACT-H\&N subscale scores of participant ranged from 2 to 28 for physical well-being subscale (mean=23.35, median=25.00), 7 to 28 for social/family well-being subscale (mean=23.18, median=24.00), 1 to 24 for emotional well-being subscale (mean=20.26, median=22.00), 0 to 28 for functional well-being subscale (mean=21.22, median=22.00), 6 to 59 for head and neck cancer subscale (mean=43.08, median=44.50). These data indicate that most of the participants had a 
moderate to high degree of quality of life.

$\underline{L A S A}$. LASA was used to evaluate participants' general and overall quality of life in the study. Scores on the each item of LASA can range from 0 to 10 . Higher scores indicate a high level of quality of life. Actual mean scores in this study ranged from 7.42 to 8.70. These results indicate most of participants in this study had a moderate to high degree of quality of life.

Table 16

Internal Consistency and Sample Scores on the Instruments

\begin{tabular}{|c|c|c|c|c|c|c|c|c|}
\hline Instrument (\# items) & $\mathrm{N}$ & Mean & Median & \multicolumn{2}{|c|}{ IQR $(25,75)$} & Min & Max & $\begin{array}{c}\text { Cronbach's } \\
\text { Alpha }\end{array}$ \\
\hline \multicolumn{8}{|l|}{ VHNSS (28) } & .94 \\
\hline Nutrition (5) & 98 & 1.65 & 1.10 & 0.00 & 2.25 & 0.00 & 10.00 & .69 \\
\hline Pain (4) & 98 & 1.77 & 0.00 & 0.00 & 3.31 & 0.00 & 8.25 & .77 \\
\hline Voice (2) & 98 & 2.42 & 1.00 & 0.00 & 4.50 & 0.00 & 10.00 & .84 \\
\hline Swallow (7) & 98 & 2.36 & 1.29 & 0.14 & 4.00 & 0.00 & 10.00 & .92 \\
\hline Mucous/Dry Mouth (6) & 98 & 3.69 & 3.00 & 1.33 & 5.71 & 0.00 & 10.00 & .87 \\
\hline Dentition (1) & 98 & 1.76 & 0.00 & 0.00 & 1.25 & 0.00 & 10.00 & -- \\
\hline Hearing (1) & 98 & 1.75 & 0.00 & 0.00 & 2.25 & 0.00 & 10.00 & -- \\
\hline \multicolumn{9}{|l|}{ HADS } \\
\hline Anxiety (7) & 98 & 3.94 & 3.00 & 0.75 & 6.25 & 0.00 & 16.00 & .88 \\
\hline Depression (7) & 98 & 3.31 & 2.00 & 1.00 & 4.25 & 0.00 & 14.00 & .83 \\
\hline BIS (10) & 97 & 6.03 & 3.00 & 0.00 & 9.50 & 0.00 & 30.00 & .92 \\
\hline \multicolumn{9}{|l|}{ FACT-H\&N (39) } \\
\hline Physical subscale (7) & 98 & 23.35 & 25.00 & 21.75 & 27.00 & 2.00 & 28.00 & .83 \\
\hline Social subscale (7) & 98 & 23.18 & 24.00 & 21.00 & 27.00 & 7.00 & 28.00 & .73 \\
\hline Emotional subscale (6) & 98 & 20.26 & 22.00 & 18.00 & 24.00 & 1.00 & 24.00 & .61 \\
\hline Functional subscale (7) & 98 & 21.22 & 22.00 & 17.00 & 26.00 & 0.00 & 28.00 & .86 \\
\hline Head/Neck Subscale (12) & 98 & 43.08 & 44.50 & 37.00 & 51.25 & 6.00 & 59.00 & .79 \\
\hline LASA (5) & & & & & & & & .85 \\
\hline Physical item (1) & 98 & 7.42 & 8.00 & 6.00 & 10.00 & 2.00 & 10.00 & -- \\
\hline Emotional item (1) & 98 & 7.99 & 9.00 & 6.00 & 10.00 & 2.00 & 10.00 & -- \\
\hline Spiritual item (1) & 98 & 8.70 & 10.00 & 8.00 & 10.00 & 0.00 & 10.00 & -- \\
\hline Intellectual item (1) & 98 & 8.36 & 9.00 & 7.00 & 10.00 & 2.00 & 10.00 & -- \\
\hline Overall item (1) & 98 & 8.46 & 9.00 & 7.00 & 10.00 & 4.00 & 10.00 & -- \\
\hline
\end{tabular}


Aim 1: To examine the prevalence of external lymphedema, internal lymphedema and combined lymphedema in head and neck cancer patients.

The prevalence of external lymphedema, internal lymphedema, and combined lymphedema are presented in Table 17. Of the participants with an endoscopy examination ( $\mathrm{n}=81,78.6 \%), 75.3 \%(n=61)$ had some form of lymphedema, i.e., internal lymphedema only, external lymphedema only, and combined lymphedema.

Table 17

Prevalence of Secondary Lymphedema

\begin{tabular}{lc}
\hline Type of Lymphedema & Frequency (\%) \\
\hline No Lymphedema & $20(24.7)$ \\
Some Form of Lymphedema & $61(75.3)$ \\
Total & $81(100.0)$ \\
\hline External Lymphedema Only & $6(9.8)$ \\
Internal Lymphedema Only & $24(39.4)$ \\
Combined Lymphedema & $31(50.8)$ \\
\hline
\end{tabular}

Note: 81 participants completed both endoscopic and skin examination.

The internal lymphedema data are listed in Table 18 and Table 19. Of those scoped participants, 67.9\% (n=55) had internal lymphedema. As shown in Table 19, in the participants with mild internal lymphedema, the most commonly involved anatomical sites included the arytenoids, base of tongue, posterior pharyngeal wall, and pharyngoepiglottic folds. In the participants with moderate lymphedema, the most commonly involved sites were the interarytenoid space, valleculae, and aryepiglottic folds. In the participants with severe lymphedema, the most commonly involved sites were the pyriform sinus and the interarytenoid space. 
Table 18

Internal Lymphedema Data

\begin{tabular}{lc}
\hline Endoscopic Examination $(\mathrm{N}=81)$ & Frequency (\%) \\
\hline No Internal Lymphedema & $26(32.1)$ \\
Mild Internal Lymphedema & $19(23.5)$ \\
Moderate Internal Lymphedema & $25(30.9)$ \\
Severe Internal Lymphedema & $11(13.6)$ \\
\hline
\end{tabular}

Table 19

Location and Extent of Internal Lymphedema

\begin{tabular}{lcccccc}
\hline & Sample & \multicolumn{5}{c}{ Frequency (\%) } \\
\cline { 3 - 7 } $\begin{array}{l}\text { Location of } \\
\text { Lymphedema }\end{array}$ & $(\mathrm{N})$ & $\begin{array}{c}\text { No } \\
\text { Lymphedema }\end{array}$ & Mild & Moderate & Severe & Total \\
\hline Base of tongue & 80 & $53(66.3)$ & $26(32.5)$ & $1(1.3)$ & $0(0.0)$ & $80(100.00)$ \\
Posterior pharyngeal & 81 & $54(66.7)$ & $26(32.1)$ & $1(1.2)$ & $0(0.0)$ & $81(100.00)$ \\
wall & 72 & $35(48.6)$ & $22(30.6)$ & $12(16.7)$ & $3(4.2)$ & $72(100.00)$ \\
Epiglottis & 73 & $36(49.3)$ & $24(32.9)$ & $10(13.7)$ & $3(4.1)$ & $73(100.00)$ \\
Pharyngoepiglottic folds & 73 & $34(46.6)$ & $20(27.4)$ & $16(21.9)$ & $3(4.1)$ & $73(100.00)$ \\
Aryepiglottic folds & 74 & $36(48.6)$ & $16(21.6)$ & $17(23.0)$ & $5(6.8)$ & $74(100.00)$ \\
Interarytenoid space & 69 & $51(73.9)$ & $17(24.6)$ & $1(1.4)$ & $0(0.0)$ & $69(100.00)$ \\
Cricopharyngeal & 74 & $32(43.2)$ & $26(35.1)$ & $14(18.9)$ & $2(2.7)$ & $74(100.00)$ \\
prominence & 74 & $38(51.4)$ & $21(28.4)$ & $13(17.6)$ & $2(2.7)$ & $74(100.00)$ \\
Arytenoids & 74 & $58(78.4)$ & $9(12.2)$ & $7(9.5)$ & $0(0.0)$ & $74(100.00)$ \\
False vocal folds & 73 & $62(84.9)$ & $10(13.7)$ & $1(1.4)$ & $0(0.0)$ & $73(100.00)$ \\
True vocal folds & 76 & $41(53.9)$ & $17(22.4)$ & $17(22.4)$ & $1(1.3)$ & $76(100.00)$ \\
Anterior commissure & 75 & $42(56.0)$ & $16(21.3)$ & $10(13.3)$ & $7(9.3)$ & $75(100.00)$ \\
Valleculae & & & & &
\end{tabular}

The external lymphedema data are listed in Table 20. In terms of Foldi’s LE scale, 48 participants were identified to have external lymphedema. In this study, the most common sites of external lymphedema were neck $(n=17,35.4 \%)$ and submental area 
( $\mathrm{n}=12,25 \%$ ). Based on the nearly identical NCI LE scale or ACS LE scale, 37

participants were identified to have external lymphedema. Due to lack of a component of fibrosis in these two scales, 11 participants with fibrosis only were not captured and graded using the NCI LE and ACS LE scales. Due to the interchangeable degrees between NCI LE scale and/or ACS LE scale, the severity of lymphedema based on ACS LE scale was removed from further analysis.

Table 20

External Lymphedema Data

\begin{tabular}{|c|c|c|c|}
\hline \multirow{2}{*}{ Lymphedema Grade } & \multicolumn{3}{|c|}{ Frequency (\%) (N=103) } \\
\hline & NCI LE scale & Foldi's LE scale & ACS LE scale \\
\hline None & $66(64.0)$ & -- & $66(64.0)$ \\
\hline Grade I/Stage O & $22(21.4)$ & $55(53.4)$ & $22(21.4)$ \\
\hline Grade II /Stage I & $12(11.7)$ & $21(20.4)$ & $12(11.7)$ \\
\hline Grade III/Stage II & $3(2.9)$ & $27(26.2)$ & $3(2.9)$ \\
\hline Grade IV/Stage III & $0(0.0)$ & $0(0.0)$ & $0(0.0)$ \\
\hline Grade V & $0(0.0)$ & -- & -- \\
\hline Total & 103(100.0) & 103(100.0) & $103(100.0)$ \\
\hline \multicolumn{4}{|l|}{ NCI Lymphedema-related Fibrosis } \\
\hline None & & $80(77.7)$ & \\
\hline Grade I & & $16(15.5)$ & \\
\hline Grade II & & $7(6.8)$ & \\
\hline Grade III & & $0(0.0)$ & \\
\hline Location of External Lymphedema & & Foldi’s LE scale & \\
\hline One site & & $33(68.8)$ & \\
\hline Two sites & & $11(22.9)$ & \\
\hline Three sites & & $4(8.3)$ & \\
\hline
\end{tabular}

Aim 2. To examine the associations between severity of lymphedema in head and neck cancer patients and (a) symptoms, (b) functional status, and (c) quality of life. (2a) Analyze the associations between severity of lymphedema and symptoms.

VHNSS. The associations of the severity of lymphedema and symptom scores on 
the VHNSS are summarized in Table 21. Statistically significant multivariate and univariate associations of the severity of fibrosis with reports of nutrition problems were found in this study (see Table 21). The multivariate association of the combined Foldi (combines fibrosis with external lymphedema) and Patterson indices with nutrition was statistically significant $(R=0.35, p=.008)$ with most of that association explained by the Foldi index ( beta $=0.32, p=.007)$. The univariate associations demonstrated a similar pattern. Associations of nutrition problems with severity of internal lymphedema were not statistically significant.

As shown, regardless of which set of measures was used, the combined associations of the severity of combined lymphedema were found to be statistically significant with swallowing difficulties (NCI scales and Patterson: $R=0.40, p=.011$; Foldi and Patterson: $R=0.40, p=.001$ ), and with mucous/dry mouth symptoms (NCI scales and Patterson: $R=0.40, p=.001$; Foldi and Patterson: $R=0.45, p<.001$ ). These findings were consistent with the patterns of univariate associations of each of the measures with the different clusters of symptom scores. As severity increased on each of the individual measures of internal/external lymphedema and fibrosis, there were statistically significant associations with increasing mucous/dry mouth symptoms (correlations ranging from 0.32 to $0.35, p<.004$ ). The univariate associations increasing severity with increasing reports of swallowing problems were not as consistent as those with mucous/dry mouth symptoms. The strongest associations were seen with a measure that combines external and fibrotic severity (Foldi: beta $=0.31, p=.002$ ) and with severity of internal lymphedema (Patterson: beta $=0.31, p=.006)$. Nevertheless, while not meeting the adjusted alpha level used in this study (i.e., $p \leq .010$ ), the other measures 
of lymphedema severity showed similar patterns of associations with swallowing burden.

No statistically significant univariate or multivariate associations of severity of lymphedema were seen with the clusterings of pain, voice, dentition, and hearing symptom burden reports. The strongest associations not reaching the minimal level used in this study were those of the severity of internal lymphedema with reports of painrelated symptom scores $($ beta $=0.24, p=.034)$ and with voice problems (beta $=0.29, p=$ $.012)$.

Table 21

Associations between Severity of Lymphedema (LE) and VHNSS Scores

\begin{tabular}{|c|c|c|c|c|c|c|c|c|}
\hline \multirow[b]{2}{*}{ Severity of LE } & \multicolumn{8}{|c|}{ Beta ( $P$-value) } \\
\hline & $\begin{array}{l}\text { Sample } \\
\text { size (n) }\end{array}$ & $\begin{array}{l}\text { Nutri- } \\
\text { tion }\end{array}$ & Pain & Voice & Swallow & $\begin{array}{c}\text { Mucous } \\
\text { /Dry } \\
\text { mouth }\end{array}$ & $\begin{array}{l}\text { Denti- } \\
\text { tion }\end{array}$ & $\begin{array}{l}\text { Hear- } \\
\text { ing }\end{array}$ \\
\hline \multicolumn{9}{|l|}{$\begin{array}{l}\text { Severity of } \\
\text { External LE }\end{array}$} \\
\hline NCI LE Scale & 87 & $\begin{array}{c}0.23 \\
(.036)\end{array}$ & $\begin{array}{c}0.11 \\
(.328)\end{array}$ & $\begin{array}{c}0.06 \\
(.601)\end{array}$ & $\begin{array}{c}0.29 \\
(.006)\end{array}$ & $\begin{array}{c}0.32 \\
(.002)\end{array}$ & $\begin{array}{c}0.05 \\
(.642)\end{array}$ & $\begin{array}{c}0.00 \\
(.989)\end{array}$ \\
\hline $\begin{array}{l}\text { Foldi's LE } \\
\text { Scale }\end{array}$ & 98 & $\begin{array}{c}0.26 \\
(.011)\end{array}$ & $\begin{array}{c}0.05 \\
(.596)\end{array}$ & $\begin{array}{c}0.10 \\
(.342)\end{array}$ & $\begin{array}{c}0.31 \\
(.002)\end{array}$ & $\begin{array}{c}0.35 \\
(.000)\end{array}$ & $\begin{array}{c}0.13 \\
(.198)\end{array}$ & $\begin{array}{l}-0.05 \\
(.632)\end{array}$ \\
\hline $\begin{array}{l}\text { NCI Fibrosis } \\
\text { Scale }\end{array}$ & 98 & $\begin{array}{c}0.34 \\
(.001) \\
\end{array}$ & $\begin{array}{c}0.08 \\
(.425) \\
\end{array}$ & $\begin{array}{c}0.20 \\
(.044) \\
\end{array}$ & $\begin{array}{c}0.28 \\
(.005)\end{array}$ & $\begin{array}{c}0.33 \\
(.001)\end{array}$ & $\begin{array}{c}0.20 \\
(.044)\end{array}$ & $\begin{array}{l}-0.08 \\
(.460)\end{array}$ \\
\hline \multicolumn{9}{|l|}{$\begin{array}{l}\text { Severity of } \\
\text { Internal LE }\end{array}$} \\
\hline $\begin{array}{l}\text { Patterson's } \\
\text { Scale }\end{array}$ & 77 & $\begin{array}{c}0.18 \\
(.126) \\
\end{array}$ & $\begin{array}{c}0.24 \\
(.034)\end{array}$ & $\begin{array}{c}0.29 \\
(.012) \\
\end{array}$ & $\begin{array}{c}0.31 \\
(.006)\end{array}$ & $\begin{array}{c}0.34 \\
(.003) \\
\end{array}$ & $\begin{array}{c}0.10 \\
(.410) \\
\end{array}$ & $\begin{array}{c}0.04 \\
(.748) \\
\end{array}$ \\
\hline \multicolumn{9}{|l|}{$\begin{array}{l}\text { Severity of } \\
\text { Combined LE }\end{array}$} \\
\hline Multiple R & & $\begin{array}{c}0.29 \\
(.120)\end{array}$ & $\begin{array}{c}0.24 \\
(.291)\end{array}$ & $\begin{array}{c}0.24 \\
(.291)\end{array}$ & $\begin{array}{c}0.40 \\
(.011)\end{array}$ & $\begin{array}{c}0.40 \\
(.001)\end{array}$ & $\begin{array}{c}0.18 \\
(.538)\end{array}$ & $\begin{array}{c}0.11 \\
(.858)\end{array}$ \\
\hline NCI LE Scale & & $\begin{array}{c}0.24 \\
(.086)\end{array}$ & $\begin{array}{c}0.11 \\
(.435)\end{array}$ & $\begin{array}{c}0.01 \\
(.962)\end{array}$ & $\begin{array}{c}0.27 \\
(.046)\end{array}$ & $\begin{array}{c}0.29 \\
(.026)\end{array}$ & $\begin{array}{l}-0.09 \\
(.543)\end{array}$ & $\begin{array}{l}-0.01 \\
(.974)\end{array}$ \\
\hline $\begin{array}{l}\text { NCI Fibrosis } \\
\text { Scale }\end{array}$ & 70 & $\begin{array}{l}0.05 \\
(.705)\end{array}$ & $\begin{array}{l}-0.09 \\
(.509)\end{array}$ & $\begin{array}{l}-0.15 \\
(.263)\end{array}$ & $\begin{array}{c}0.04 \\
(.785)\end{array}$ & $\begin{array}{c}0.02 \\
(.849)\end{array}$ & $\begin{array}{c}0.19 \\
(.184)\end{array}$ & $\begin{array}{l}-0.10 \\
(.457)\end{array}$ \\
\hline Patterson's & & 0.07 & 0.20 & 0.26 & 0.21 & 0.18 & 0.06 & 0.06 \\
\hline Scale & & $(.582)$ & $(.123)$ & $(.047)$ & $(.093)$ & $(.150)$ & $(.637)$ & $(.663)$ \\
\hline \multicolumn{9}{|l|}{$\begin{array}{l}\text { Severity of } \\
\text { Combined LE }\end{array}$} \\
\hline Multiple R & & $\begin{array}{c}0.35 \\
(.008)\end{array}$ & $\begin{array}{c}0.24 \\
(.107)\end{array}$ & $\begin{array}{c}0.24 \\
(.107)\end{array}$ & $\begin{array}{c}0.40 \\
(.001)\end{array}$ & $\begin{array}{c}0.45 \\
(.000)\end{array}$ & $\begin{array}{c}0.10 \\
(.397)\end{array}$ & $\begin{array}{c}0.10 \\
(.682)\end{array}$ \\
\hline Foldi's LE & & 0.32 & -0.01 & -0.00 & 0.28 & 0.31 & 0.04 & -0.10 \\
\hline Scale & 78 & $(.007)$ & (.959) & $(.971)$ & $(.017)$ & $(.005)$ & $(.734)$ & $(.417)$ \\
\hline Patterson's & 18 & 0.07 & 0.24 & 0.29 & 0.22 & 0.24 & 0.08 & 0.07 \\
\hline Scale & & $(.521)$ & $(.044)$ & $(.017)$ & $(.054)$ & $(.034)$ & $(.505)$ & $(.573)$ \\
\hline
\end{tabular}

Beta is highlighted if it is $\geq 0.30$. 
A secondary analysis of the patterns in the VHNSS symptom scores revealed two distinct clusters of patients. One group ( $\mathrm{n}=62,62 \%)$ had very low levels of any type of symptom scores (Low Symptom) while the other group ( $\mathrm{n}=38,38 \%)$ demonstrated relatively high levels of nutrition, pain, voice, swallowing and mucous/dry mouth symptom scores (High Symptom). Subsequently, a crosstabulation analysis of these two groups of patients with the measures of lymphedema and fibrosis revealed that the most severe levels of internal/external lymphedema, as well as of fibrosis, were disproportionately represented in the cluster (group) of participants with increased burden in the multiple symptom areas. Of the participants with at least some external lymphedema, 52.1\% ( $\mathrm{n}=25$ of 48) were in the High Symptom group compared to only $25.0 \%$ ( $n=13$ of 52) of the patients without external lymphedema $\left(\chi^{2}=7.77, p=.005\right)$. Within the Low Symptom group of patients, only 8.5\% (5 of 59) had either a Grade 2 or 3 level of external lymphedema using the NCI LE criteria while within the high symptom cluster 33.3\% (10 of 30) of the patients were graded at those levels $\left(\chi^{2}=9.09, p=.028\right)$. There were greater differences between the clusters of patients for the distributions of the levels of severity using the Foldi criteria (Low Symptom: 11 of 62, 17.7\% Stage II; High Symptom: 16 of $38,42.1 \%$ Stage II, $\left.\chi^{2}=9.12, p=.010\right)$. Approximately $36.8 \%$ (14 of 38) of the patients in the High Symptom cluster group had Grade 1 or 2 fibrosis, while none had Grade 2 and only $14.5 \%(n=9)$ had Grade 1 in the Low Symptom group $\left(\chi^{2}=\right.$ $13.17, p=.001)$. Finally, $45.3 \%$ of the patients with some level of internal lymphedema $(n=24$ of 53) were clustered in the High Symptom group compared to only $12.0 \%$ ( $n=3$ of 25 ) of the patients without internal lymphedema $\left(\chi^{2}=8.31, p=.004\right)$. Approximately $55.6 \%$ (15 of 27) of the patients in the High Symptom cluster group had moderate to 
severe levels of internal lymphedema, while only $37.3 \%$ ( $n=19$ of 51) had those levels of internal LE severity in the Low Symptom group $\left(\chi^{2}=9.95, p=.019\right)$.

BIS \& HADS. The associations of the severity of lymphedema and symptom scores on the BIS/HADS are summarized in Table 22. As shown, the multivariate association of the severity of combined lymphedema with body image-related symptoms was statistically significant (NCI scales and Patterson: $R=0.37, p=.024$ ) with most of that association explained by the NCI Fibrosis index (beta $=0.30, p=.026)$. No statistically significant univariate associations of severity of lymphedema were seen with body image-related symptom reports. The strongest associations not reaching the minimal level of significance used in this study were those of the severity of external lymphedema with body image-related symptoms (NCI LE scale: beta $=0.22, p=.041$;

Foldi's scale: beta $=0.21, p=.043$; NCI Fibrosis scale: beta $=0.23, p=.021$ ). Associations of body-image problems with severity of internal lymphedema were not statistically significant.

No statistically significant univariate or multivariate associations of severity of lymphedema were seen with the HADS anxiety or depressive symptom reports. The strongest associations not reaching the minimal level used in this study was the severity of external lymphedema with anxiety subscale scores (NCI LE scale, beta $=0.26, p=$ $.013)$. 
Table 22

Associations between Severity of Lymphedema (LE) and BIS/HADS Scores

\begin{tabular}{|c|c|c|c|c|c|}
\hline \multirow[b]{2}{*}{ Severity of LE } & \multicolumn{2}{|c|}{$\begin{array}{l}\text { HADS- } \\
\text { Anxiety }\end{array}$} & \multirow{2}{*}{$\begin{array}{c}\begin{array}{c}\text { HADS- } \\
\text { Depression }\end{array} \\
\text { Beta ( } P \text {-value) }\end{array}$} & \multicolumn{2}{|c|}{ BIS } \\
\hline & $\begin{array}{l}\text { Sample } \\
\text { size (n) }\end{array}$ & Beta ( $P$-value) & & $\begin{array}{l}\text { Sample } \\
\text { size (n) }\end{array}$ & Beta ( $P$-value) \\
\hline \multicolumn{6}{|l|}{$\begin{array}{l}\text { Severity of External } \\
\text { LE }\end{array}$} \\
\hline NCI LE Scale & 87 & $0.26(.013)$ & $0.18(.102)$ & 86 & $0.22(.041)$ \\
\hline Foldi’s LE Scale & 98 & $0.18(.083)$ & $0.16(.112)$ & 97 & $0.21(.043)$ \\
\hline NCI Fibrosis Scale & 98 & $0.17(.091)$ & $0.16(.124)$ & 97 & $0.23(.021)$ \\
\hline \multicolumn{6}{|l|}{ Severity of Internal LE } \\
\hline Patterson's Scale & 77 & $0.09(.435)$ & $0.17(.143)$ & 76 & $0.20(.091)$ \\
\hline \multicolumn{6}{|l|}{ Severity of Both } \\
\hline Multiple R & & $0.25(.241)$ & $0.25(.238)$ & & $0.37(.024)$ \\
\hline NCI LE Scale & & $0.22(.126)$ & $0.14(.316)$ & & $0.11(.416)$ \\
\hline NCI Fibrosis Scale & 70 & $0.05(.708)$ & $0.12(.400)$ & 69 & $0.30(.026)$ \\
\hline Patterson's Scale & & $0.03(.833)$ & $0.08(.538)$ & & $0.03(.802)$ \\
\hline \multicolumn{6}{|l|}{ Severity of Both } \\
\hline Multiple R & & $0.20(.225)$ & $0.24(.113)$ & & $0.29(.039)$ \\
\hline Foldi’s LE Scale & 7 & $0.19(.124)$ & $0.18(.137)$ & & $0.23(.056)$ \\
\hline Patterson's Scale & 10 & $0.03(.801)$ & $0.11(.354)$ & $7 /$ & $0.12(.297)$ \\
\hline
\end{tabular}

Beta is highlighted if it is $\geq 0.30$.

(2b) Analyze the associations between severity of lymphedema and functional status.

In this study, functional status was evaluated through hearing tests (tuning fork test and whispered voice test), trismus, and cervical range of motion. Functional status of the sample is summarized in Table 23. 
Table 23

\section{Functional Status Data}

\begin{tabular}{|c|c|c|c|}
\hline Characteristic & \multicolumn{3}{|c|}{ Frequency (\%) } \\
\hline \multicolumn{4}{|l|}{ Whispered Voice Test (WVT) } \\
\hline Pass & \multicolumn{3}{|c|}{$89(86.4)$} \\
\hline Fail & \multicolumn{3}{|c|}{$13(12.6)$} \\
\hline Not applicable & \multicolumn{3}{|c|}{$1(1.0)$} \\
\hline \multicolumn{4}{|l|}{ Tuning Fork Test (TFT) } \\
\hline Normal & \multicolumn{3}{|c|}{73 (70.9) } \\
\hline Conduction deafness (left ear) & \multicolumn{3}{|c|}{$3(2.9)$} \\
\hline Conduction deafness (right ear) & \multicolumn{3}{|c|}{$2(1.9)$} \\
\hline Nerve deafness (left ear) & \multicolumn{3}{|c|}{$13(12.6)$} \\
\hline Nerve deafness (right ear) & \multicolumn{3}{|c|}{$11(10.7)$} \\
\hline \multicolumn{4}{|l|}{ Trismus } \\
\hline None & \multicolumn{3}{|c|}{$70(68.0)$} \\
\hline Grade 1 & \multicolumn{3}{|c|}{$16(15.5)$} \\
\hline Grade 2 & \multicolumn{3}{|c|}{$14(13.6)$} \\
\hline Grade 3 & \multicolumn{3}{|c|}{$3(2.9)$} \\
\hline \multicolumn{4}{|l|}{ Signs in Neck/Shoulder Area } \\
\hline Elicited Pain & \multicolumn{3}{|c|}{$25(24.3)$} \\
\hline Tenderness & \multicolumn{3}{|c|}{$32(31.1)$} \\
\hline Postural abnormalities & \multicolumn{3}{|c|}{$13(12.6)$} \\
\hline Fixed deformity & \multicolumn{3}{|c|}{$4(3.9)$} \\
\hline Cervical Range of Motion & Mean Median & IQR $(25,75)$ & Min Max (Degree) \\
\hline Forward flexion & $43.53 \quad 42.67$ & 33.3350 .33 & 19.3370 .00 \\
\hline Extension & $49.17 \quad 48.00$ & 38.3360 .83 & 15.3388 .67 \\
\hline Left lateral flexion & $32.78 \quad 32.00$ & 23.3341 .00 & $13.33 \quad 58.67$ \\
\hline Right lateral flexion & $31.28 \quad 31.33$ & 22.5039 .33 & $11.00 \quad 58.00$ \\
\hline Left lateral rotation & $54.64 \quad 53.33$ & 45.0062 .67 & 29.3380 .67 \\
\hline Right lateral rotation & 53.8252 .00 & 44.6764 .00 & $26.00 \quad 80.00$ \\
\hline
\end{tabular}

Hearing. The associations of the severity of lymphedema with hearing test status are summarized in Table 24. As shown, no statistically significant univariate or multivariate associations of severity of lymphedema were seen with the ratings on the hearing tests. The strongest associations not reaching the minimal level used in this study were those of the severity of combined lymphedema with tuning fork test status (Foldi and Patterson scales: $\chi^{2}=6.25, p=.044$ ), and with whispered voice test status (NCI 
scales and Patterson scales: $\chi^{2}=8.45, p=.038$; Foldi and Patterson scales: $\chi^{2}=7.29, p=$ .026). No statistically significant univariate associations of severity of internal lymphedema were seen with the ratings on the hearing test.

Table 24

Associations of Severity of Lymphedema (LE) with Hearing Test

\begin{tabular}{|c|c|c|c|c|c|c|c|c|c|}
\hline \multirow{3}{*}{ Type of LE } & \multirow{3}{*}{$\begin{array}{l}\text { Sample } \\
\text { size (n) }\end{array}$} & \multicolumn{4}{|c|}{ Tuning Fork (Yes/No) } & \multicolumn{4}{|c|}{ Whispered Voice Test (Yes/No) } \\
\hline & & \multirow{2}{*}{ O.R. } & \multirow{2}{*}{$\begin{array}{c}P- \\
\text { value }\end{array}$} & \multicolumn{2}{|c|}{$\begin{array}{l}\text { 95\% C.I. for } \\
\text { O.R. }\end{array}$} & \multirow{2}{*}{ O.R. } & \multirow{2}{*}{$\begin{array}{c}P \text { - } \\
\text { value }\end{array}$} & \multicolumn{2}{|c|}{ 95\% C.I. for O.R. } \\
\hline & & & & Lower & Upper & & & Lower & Upper \\
\hline \multicolumn{10}{|l|}{$\begin{array}{l}\text { Severity of } \\
\text { External LE }\end{array}$} \\
\hline NCI LE Scale & 91 & 1.02 & .057 & 1.00 & 1.04 & 0.97 & .120 & 0.94 & 1.01 \\
\hline $\begin{array}{l}\text { Foldi's LE } \\
\text { Scale }\end{array}$ & 102 & 1.01 & .139 & 1.00 & 1.03 & 0.98 & .105 & 0.95 & 1.00 \\
\hline $\begin{array}{l}\text { NCI Fibrosis } \\
\text { Scale }\end{array}$ & 102 & 1.01 & .347 & 0.99 & 1.03 & 0.99 & .663 & 0.97 & 1.02 \\
\hline \multicolumn{10}{|l|}{$\begin{array}{l}\text { Severity of } \\
\text { Internal LE }\end{array}$} \\
\hline $\begin{array}{l}\text { Patterson's } \\
\text { Scale }\end{array}$ & 80 & 1.02 & .078 & 1.00 & 1.05 & 1.02 & .167 & 0.99 & 1.05 \\
\hline \multicolumn{10}{|l|}{$\begin{array}{l}\text { Severity of } \\
\text { Combined LE }\end{array}$} \\
\hline Chi-square & & 6.07 & .108 & & & 8.45 & .038 & & \\
\hline NCI LE Scale & & 1.02 & .106 & 1.00 & 1.05 & 0.96 & .108 & 0.91 & 1.01 \\
\hline $\begin{array}{l}\text { NCI Fibrosis } \\
\text { Scale }\end{array}$ & 71 & 1.01 & .755 & 0.97 & 1.04 & 0.69 & .999 & -- & -- \\
\hline $\begin{array}{l}\text { Patterson's } \\
\text { Scale }\end{array}$ & & 1.01 & .362 & 0.99 & 1.04 & 1.03 & .072 & 1.00 & 1.07 \\
\hline \multicolumn{10}{|l|}{$\begin{array}{l}\text { Severity of } \\
\text { Combined LE }\end{array}$} \\
\hline Chi-square & & 6.25 & .044 & & & 7.29 & .026 & & \\
\hline $\begin{array}{l}\text { Foldi's LE } \\
\text { Scale }\end{array}$ & 80 & 1.02 & .089 & 1.00 & 1.04 & 0.97 & .044 & 0.94 & 1.00 \\
\hline $\begin{array}{l}\text { Patterson's } \\
\text { Scale }\end{array}$ & 80 & 1.02 & .219 & 0.99 & 1.04 & 1.03 & .060 & 1.00 & 1.06 \\
\hline
\end{tabular}

Trismus. The associations of the severity of lymphedema and trismus are summarized in Table 25. As shown, no statistically significant univariate or multivariate associations of severity of lymphedema were seen with the trismus degrees. 
Table 25

Associations of Severity of Lymphedema (LE) with Trismus

\begin{tabular}{lcc}
\hline Severity of LE & Sample size & Grade of Trismus \\
\cline { 2 - 3 } & $(\mathrm{n})$ & Beta $(P$-value $)$ \\
\hline Severity of External LE & & \\
$\quad$ NCI LE Scale & 92 & $-0.07(.509)$ \\
$\quad$ Foldi's LE Scale & 103 & $0.04(.729)$ \\
$\quad$ NCI Fibrosis Scale & 103 & $0.15(.130)$ \\
\hline Severity of Internal LE & & \\
$\quad$ Patterson's Scale & 81 & $0.18(.116)$ \\
\hline Severity of Both & & $0.24(.272)$ \\
Multiple R & & $-0.04(.795)$ \\
$\quad$ NCI LE Scale & 72 & $-0.11(.414)$ \\
$\quad$ NCI Fibrosis Scale & & $0.23(.064)$ \\
$\quad$ Patterson's Scale & & \\
\hline Severity of Both & & $0.18(.291)$ \\
Multiple R & & $0.02(.898)$ \\
Foldi's LE Scale & & $0.17(.147)$ \\
$\quad$ Patterson's Scale & &
\end{tabular}

$\underline{C R O M}$. The associations of the severity of lymphedema and neck range of motion degrees on the CROM are summarized in Table 26. As shown, no statistically significant univariate or multivariate associations of severity of lymphedema were seen with the CROM scores. The strongest associations not reaching the minimal level used in this study were those of the severity of external lymphedema with forward flexion degrees (NCI LE scale: beta $=-0.22, p=.041$ ), and with left rotation degrees (NCI Fibrosis scale: beta $=-0.20, p=.044)$. 
Table 26

Associations of Severity of Lymphedema (LE) with CROM

\begin{tabular}{|c|c|c|c|c|c|c|c|}
\hline \multirow[b]{2}{*}{ Severity of LE } & \multicolumn{7}{|c|}{ Beta ( $P$-value) } \\
\hline & $\begin{array}{l}\text { Sample } \\
\text { size (n) }\end{array}$ & Forward & Extension & $\begin{array}{c}\text { Left } \\
\text { Lateral }\end{array}$ & $\begin{array}{c}\text { Right } \\
\text { Lateral }\end{array}$ & $\begin{array}{c}\text { Left } \\
\text { Rotation }\end{array}$ & $\begin{array}{c}\text { Right } \\
\text { Rotation }\end{array}$ \\
\hline \multicolumn{8}{|l|}{$\begin{array}{l}\text { Severity of External } \\
\text { LE }\end{array}$} \\
\hline NCI LE Scale & 90 & $\begin{array}{l}-0.22 \\
(.041)\end{array}$ & $\begin{array}{l}-0.11 \\
(.307)\end{array}$ & $\begin{array}{l}-0.11 \\
(.306)\end{array}$ & $\begin{array}{l}-0.13 \\
(.215)\end{array}$ & $\begin{array}{l}-0.17 \\
(.121)\end{array}$ & $\begin{array}{l}-0.13 \\
(.207)\end{array}$ \\
\hline Foldi’s LE Scale & 101 & $\begin{array}{l}-0.18 \\
(.065)\end{array}$ & $\begin{array}{l}-0.10 \\
(.305)\end{array}$ & $\begin{array}{l}-0.08 \\
(.453)\end{array}$ & $\begin{array}{l}-0.12 \\
(.219)\end{array}$ & $\begin{array}{l}-0.15 \\
(.123)\end{array}$ & $\begin{array}{l}-0.15 \\
(.142)\end{array}$ \\
\hline NCI fibrosis Scale & 101 & $\begin{array}{l}-0.19 \\
(.058)\end{array}$ & $\begin{array}{l}-0.15 \\
(.126)\end{array}$ & $\begin{array}{l}-0.10 \\
(.318)\end{array}$ & $\begin{array}{l}-0.14 \\
(.172)\end{array}$ & $\begin{array}{l}-0.20 \\
(.044)\end{array}$ & $\begin{array}{l}-0.15 \\
(.135)\end{array}$ \\
\hline \multicolumn{8}{|l|}{ Severity of Internal LE } \\
\hline Patterson’s Scale & 79 & $\begin{array}{l}-0.18 \\
(.108)\end{array}$ & $\begin{array}{l}0.01 \\
(.950)\end{array}$ & $\begin{array}{l}-0.07 \\
(.549)\end{array}$ & $\begin{array}{c}0.00 \\
(.997)\end{array}$ & $\begin{array}{l}-0.02 \\
(.886) \\
\end{array}$ & $\begin{array}{l}-0.20 \\
(.084)\end{array}$ \\
\hline \multicolumn{8}{|l|}{$\begin{array}{l}\text { Severity of Combined } \\
\text { LE }\end{array}$} \\
\hline Multiple R & & $\begin{array}{c}0.19 \\
(.509)\end{array}$ & $\begin{array}{l}0.13 \\
(.764)\end{array}$ & $\begin{array}{c}0.13 \\
(.790)\end{array}$ & $\begin{array}{c}0.18 \\
(.552)\end{array}$ & $\begin{array}{l}0.20 \\
(.462)\end{array}$ & $\begin{array}{c}0.24 \\
(.271)\end{array}$ \\
\hline NCI LE Scale & & $\begin{array}{l}-0.07 \\
(.606)\end{array}$ & $\begin{array}{l}-0.13 \\
(.367)\end{array}$ & $\begin{array}{l}-0.12 \\
(.408)\end{array}$ & $\begin{array}{l}-0.20 \\
(.155)\end{array}$ & $\begin{array}{l}-0.15 \\
(.282)\end{array}$ & $\begin{array}{l}-0.20 \\
(.144)\end{array}$ \\
\hline NCI fibrosis Scale & 72 & $\begin{array}{l}-0.07 \\
(.601)\end{array}$ & $\begin{array}{l}0.04 \\
(.788)\end{array}$ & $\begin{array}{c}0.08 \\
(.562)\end{array}$ & $\begin{array}{c}0.06 \\
(.675)\end{array}$ & $\begin{array}{l}-0.08 \\
(.556)\end{array}$ & $\begin{array}{l}0.02 \\
(.905)\end{array}$ \\
\hline Patterson’s Scale & & $\begin{array}{l}-0.11 \\
(.391)\end{array}$ & $\begin{array}{l}0.10 \\
(.455)\end{array}$ & $\begin{array}{l}-0.05 \\
(.702)\end{array}$ & $\begin{array}{l}0.06 \\
(.662)\end{array}$ & $\begin{array}{l}0.09 \\
(.456)\end{array}$ & $\begin{array}{l}-0.10 \\
(.451)\end{array}$ \\
\hline \multicolumn{8}{|l|}{$\begin{array}{l}\text { Severity of Combined } \\
\text { LE }\end{array}$} \\
\hline Multiple R & & $\begin{array}{c}0.20 \\
(.223)\end{array}$ & $\begin{array}{l}0.12 \\
(.574)\end{array}$ & $\begin{array}{c}0.10 \\
(.708)\end{array}$ & $\begin{array}{l}0.18 \\
(.274)\end{array}$ & $\begin{array}{l}0.16 \\
(.378)\end{array}$ & $\begin{array}{l}0.24 \\
(.097)\end{array}$ \\
\hline Foldi’s LE Scale & & $\begin{array}{c}-0.08 \\
(.514)\end{array}$ & $\begin{array}{l}-0.13 \\
(.295)\end{array}$ & $\begin{array}{l}-0.07 \\
(.565)\end{array}$ & $\begin{array}{c}-0.19 \\
(.109)\end{array}$ & $\begin{array}{l}-0.17 \\
(.166)\end{array}$ & $\begin{array}{l}-0.15 \\
(.196)\end{array}$ \\
\hline Patterson’s Scale & 80 & $\begin{array}{l}-0.16 \\
(.182)\end{array}$ & $\begin{array}{c}0.05 \\
(.706)\end{array}$ & $\begin{array}{l}-0.05 \\
(.693)\end{array}$ & $\begin{array}{c}0.06 \\
(.627)\end{array}$ & $\begin{array}{c}0.03 \\
(.777)\end{array}$ & $\begin{array}{l}-0.15 \\
(.203)\end{array}$ \\
\hline
\end{tabular}

Signs (Physical Examination). In this study, signs in the neck and shoulder area including elicited pain, tenderness, postural abnormalities, and fixed deformity were evaluated. The associations of the severity of lymphedema and signs are summarized in Table 27. Statistically significant univariate associations of the severity of external lymphedema with elicited pain status were found in this study (NCI LE scale: O.R. = 1.04, $p=.001$; Foldi LE scale: $O . R .=1.03, p=.002$ ). The multivariate association of the 
severity of combined lymphedema with elicited pain status was statistically significant (Foldi and Patterson scales: $\chi^{2}=9.36, p=.009$ ) with most of that association explained by the Foldi index $(O . R .=1.03, p=.006)$.

No statistically significant univariate or multivariate associations of severity of lymphedema were seen with tenderness, postural abnormalities, and fixed deformity. The strongest associations not reaching the minimal level of significance used in this study were those of the severity of external lymphedema with tenderness (NCI LE scale: O.R. $=$ 1.02, $p=.017$ ), with postural abnormalities (NCI LE scale: $O . R .=1.04, p=.015$; Foldi's LE scale: $O . R .=1.03, p=.015$ ), and fixed deformity (NCI Fibrosis scale: $O . R .=1.06, p$ $=.022$ ); and those of the severity of combined lymphedema with combined lymphedema with postural abnormalities (Foldi and Patterson scales: $\chi^{2}=6.47, p=.039$ ), and with fixed deformity (Foldi and Patterson scales: $\chi^{2}=8.28, p=.016$ ). 
Table 27

Associations between Severity of Lymphedema (LE) and Signs in Neck and Shoulder

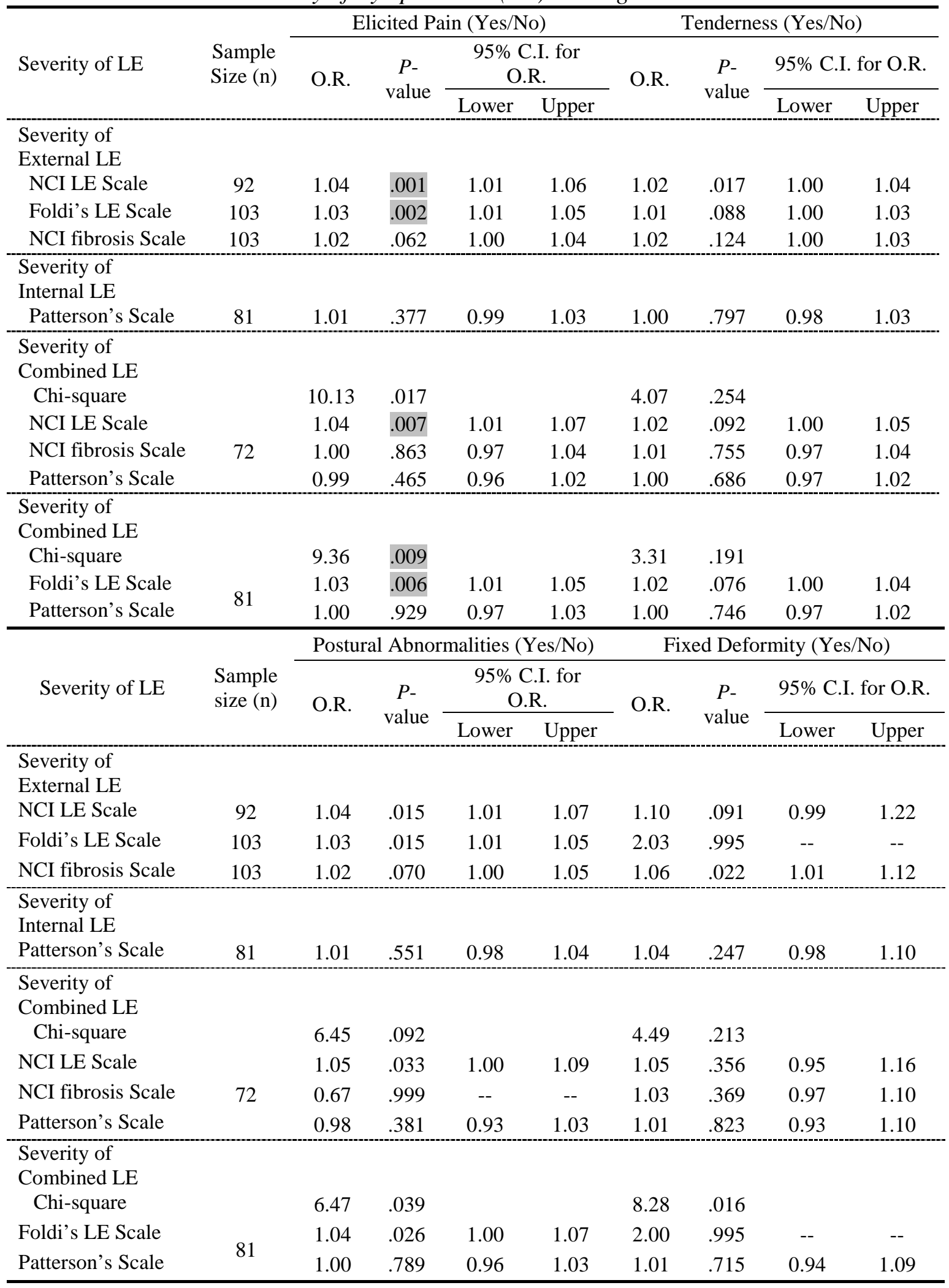


(2b) Analyze the associations between severity of lymphedema and quality of life.

FACT-H\&N. The associations of the severity of lymphedema and quality of life scores on the FACT-H\&N are summarized in Table 28. Statistically significant multivariate associations of the severity of combined lymphedema with functional subscale scores (NCI scales and Patterson: $R=0.35, p=.036$; Foldi and Patterson scales: $R=0.36, p=.006$ ), with head and neck cancer subscale scores (NCI scales and Patterson scale: $R=0.41, p=.008$; Foldi and Patterson scales: $R=0.41, p=.001$ ), with FACT-G subscale scores (NCI scales and Patterson scale: $R=0.35, p=.037$; Foldi and Patterson scales: $R=0.30, p=.028$ ), and with FACT-H\&N total scores (NCI scales and Patterson scale: $R=0.42, p=.006$; Foldi and Patterson scales: $R=0.39, p=.002$ ). These findings were consistent with the patterns of univariate associations of the severity of external lymphedema with head and neck cancer subscale scores (NCI LE scale: beta $=-0.33, p=$ .002; Foldi's LE scale: beta $=-0.30, p=.003$ ) and with FACT-H\&N total scores (NCI LE scale: beta $=-0.32, p=.002$ ). Moreover, the severity of internal lymphedema was statistically significantly associated with head and neck cancer subscale scores (beta $=$ $-0.33, p=.004)$.

No statistically significant univariate or multivariate associations of severity of lymphedema were seen with the physical, social/family, and emotional subscale scores. The strongest associations not reaching the minimal level used in this study were those of the severity of external lymphedema with the physical subscale scores (NCI Fibrosis scale: beta $=-0.24, p=.020$ ) and with emotional subscale scores (NCI LE scale: beta $=$ $-0.23, p=.036)$.

Moreover, no statistically significant univariate associations of severity of 
external lymphedema were seen with the functional and FACT-G subscale scores. The strongest associations not reaching the minimal level used in this study were those of the severity of external lymphedema with functional subscale scores (NCI LE scale: beta = $-0.28, p=.009$; Foldi's LE scale: beta $=-0.28, p=.005$; NCI Fibrosis scale: beta $=$ - 0.23, $p=.025$ ) and with FACT-G subscale scores (NCI LE scale: beta $=-0.25, p=$ .018; Foldi’s LE scale: beta $=-0.20, p=.050$; NCI Fibrosis scale: beta $=-0.21, p=$ .035).

In addition, no statistically significant univariate associations of severity of internal lymphedema were seen with the physical, social/family, emotional, functional, FACT-G, and FACT-H\&N total scores. The strongest association not reaching the minimal level used in this study was the severity of internal lymphedema with the FACT$\mathrm{H} \& \mathrm{~N}$ total scores $($ beta $=-0.27, p=.017)$. 
Table 28

Associations of Severity of Lymphedema (LE) and FACT-H\&N

\begin{tabular}{|c|c|c|c|c|c|c|c|c|}
\hline \multirow[b]{2}{*}{ Severity of LE } & \multicolumn{8}{|c|}{ Beta ( $P$-value $)$} \\
\hline & $\begin{array}{l}\text { Sample } \\
\text { size (n) }\end{array}$ & $\begin{array}{l}\text { Physical } \\
\text { subscale }\end{array}$ & $\begin{array}{c}\text { Social } \\
\text { subscale }\end{array}$ & $\begin{array}{l}\text { Emotional } \\
\text { subscale }\end{array}$ & $\begin{array}{c}\text { Function } \\
\text { al } \\
\text { subscale }\end{array}$ & $\begin{array}{c}\text { Head } \\
\text { /Neck } \\
\text { Cancer } \\
\text { subscale }\end{array}$ & $\begin{array}{l}\text { FACT- } \\
\text { G }\end{array}$ & $\begin{array}{l}\text { FACT- } \\
\text { HN }\end{array}$ \\
\hline \multicolumn{9}{|l|}{$\begin{array}{l}\text { Severity of } \\
\text { External LE }\end{array}$} \\
\hline NCI LE Scale & 87 & $\begin{array}{l}-0.16 \\
(.151)\end{array}$ & $\begin{array}{c}0.04 \\
(.734)\end{array}$ & $\begin{array}{l}-0.23 \\
(.036)\end{array}$ & $\begin{array}{l}-0.28 \\
(.009)\end{array}$ & $\begin{array}{l}-0.33 \\
(.002)\end{array}$ & $\begin{array}{l}-0.25 \\
(.018)\end{array}$ & $\begin{array}{l}-0.32 \\
(.002)\end{array}$ \\
\hline $\begin{array}{l}\text { Foldi's LE } \\
\text { Scale }\end{array}$ & 98 & $\begin{array}{l}-0.15 \\
(.129)\end{array}$ & $\begin{array}{c}0.03 \\
(.782)\end{array}$ & $\begin{array}{l}-0.12 \\
(.239)\end{array}$ & $\begin{array}{l}-0.28 \\
(.005)\end{array}$ & $\begin{array}{l}-0.30 \\
(.003)\end{array}$ & $\begin{array}{l}-0.20 \\
(.050)\end{array}$ & $\begin{array}{l}-0.28 \\
(.006)\end{array}$ \\
\hline $\begin{array}{l}\text { NCI fibrosis } \\
\text { Scale }\end{array}$ & 98 & $\begin{array}{l}-0.24 \\
(.020)\end{array}$ & $\begin{array}{l}-0.06 \\
(.584)\end{array}$ & $\begin{array}{l}-0.09 \\
(.355)\end{array}$ & $\begin{array}{l}-0.23 \\
(.025)\end{array}$ & $\begin{array}{l}-0.29 \\
(.003)\end{array}$ & $\begin{array}{l}-0.21 \\
(.035)\end{array}$ & $\begin{array}{l}-0.28 \\
(.005)\end{array}$ \\
\hline \multicolumn{9}{|l|}{$\begin{array}{l}\text { Severity of } \\
\text { Internal LE }\end{array}$} \\
\hline $\begin{array}{l}\text { Patterson's } \\
\text { Scale } \\
\end{array}$ & 77 & $\begin{array}{l}-0.10 \\
(.376) \\
\end{array}$ & $\begin{array}{l}-0.18 \\
(.118) \\
\end{array}$ & $\begin{array}{l}-0.08 \\
(.493) \\
\end{array}$ & $\begin{array}{r}-0.21 \\
(.071) \\
\end{array}$ & $\begin{array}{l}-0.33 \\
(.004) \\
\end{array}$ & $\begin{array}{c}-0.22 \\
(.054) \\
\end{array}$ & $\begin{array}{r}-0.27 \\
(.017) \\
\end{array}$ \\
\hline \multicolumn{9}{|l|}{$\begin{array}{l}\text { Severity of } \\
\text { Combined LE }\end{array}$} \\
\hline Multiple R & & $\begin{array}{c}0.23 \\
(.340)\end{array}$ & $\begin{array}{c}0.29 \\
(.126)\end{array}$ & $\begin{array}{c}0.21 \\
(.398)\end{array}$ & $\begin{array}{l}0.35 \\
(.036)\end{array}$ & $\begin{array}{c}0.41 \\
(.008)\end{array}$ & $\begin{array}{c}0.35 \\
(.037)\end{array}$ & $\begin{array}{c}0.42 \\
(.006)\end{array}$ \\
\hline NCI LE Scale & & $\begin{array}{l}-0.14 \\
(.313)\end{array}$ & $\begin{array}{c}0.16 \\
(.245)\end{array}$ & $\begin{array}{l}-0.16 \\
(.268)\end{array}$ & $\begin{array}{l}-0.23 \\
(0.93)\end{array}$ & $\begin{array}{l}-0.25 \\
(.062)\end{array}$ & $\begin{array}{l}-0.15 \\
(.257)\end{array}$ & $\begin{array}{l}-0.24 \\
(.070)\end{array}$ \\
\hline $\begin{array}{l}\text { NCI fibrosis } \\
\text { Scale }\end{array}$ & 70 & $\begin{array}{l}-0.13 \\
(.339)\end{array}$ & $\begin{array}{l}-0.25 \\
(.069)\end{array}$ & $\begin{array}{l}-0.10 \\
(.471)\end{array}$ & $\begin{array}{l}-0.17 \\
(.190)\end{array}$ & $\begin{array}{l}-0.07 \\
(.602)\end{array}$ & $\begin{array}{l}-0.23 \\
(.088)\end{array}$ & $\begin{array}{l}-0.20 \\
(.127)\end{array}$ \\
\hline $\begin{array}{l}\text { Patterson’s } \\
\text { Scale }\end{array}$ & & $\begin{array}{c}0.03 \\
(.845)\end{array}$ & $\begin{array}{l}-0.18 \\
(.168)\end{array}$ & $\begin{array}{l}0.03 \\
(.832)\end{array}$ & $\begin{array}{l}-0.03 \\
(.807)\end{array}$ & $\begin{array}{l}-0.22 \\
(.073)\end{array}$ & $\begin{array}{l}-0.07 \\
(.580)\end{array}$ & $\begin{array}{l}-0.11 \\
(.358)\end{array}$ \\
\hline \multicolumn{9}{|l|}{$\begin{array}{l}\text { Severity of } \\
\text { Combined LE }\end{array}$} \\
\hline Multiple R & & $\begin{array}{c}0.21 \\
(.176)\end{array}$ & $\begin{array}{c}0.19 \\
(.260)\end{array}$ & $\begin{array}{l}0.15 \\
(.427)\end{array}$ & $\begin{array}{c}0.36 \\
(.006)\end{array}$ & $\begin{array}{c}0.41 \\
(.001)\end{array}$ & $\begin{array}{c}0.30 \\
(.028)\end{array}$ & $\begin{array}{c}0.39 \\
(.002)\end{array}$ \\
\hline $\begin{array}{l}\text { Foldi's LE } \\
\text { Scale } \\
\text { Patterson's } \\
\text { Scale }\end{array}$ & 78 & $\begin{array}{l}-0.20 \\
(.101) \\
-0.04 \\
(.748)\end{array}$ & $\begin{array}{c}0.06 \\
(.611) \\
-0.20 \\
(.102)\end{array}$ & $\begin{array}{l}-0.14 \\
(.268) \\
-0.04 \\
(.768)\end{array}$ & $\begin{array}{l}-0.31 \\
(.008) \\
-0.11 \\
(.352)\end{array}$ & $\begin{array}{l}-0.26 \\
(.021) \\
-0.24 \\
(.033)\end{array}$ & $\begin{array}{l}-0.22 \\
(.065) \\
-0.15 \\
(.201)\end{array}$ & $\begin{array}{l}-0.29 \\
(.010) \\
-0.18 \\
(.120)\end{array}$ \\
\hline
\end{tabular}

Beta is highlighted if it is $\geq 0.30$.

$\underline{L A S A}$. The associations of the severity of lymphedema and quality of life scores on the LASA are summarized in Table 29. Statistically significant multivariate associations of the severity of combined lymphedema with the overall well-being scores were found in this study (NCI scales and Patterson scale: $R=0.40, p=.010$; Foldi and Patterson scales: $R=0.31, p=.027)$. The univariate association demonstrated that the 
severity of external fibrosis was statistically significantly associated with the physical well-being scores (NCI fibrosis scale: beta $=-0.31, p=.002$ ).

No statistically significant univariate or multivariate associations of severity of lymphedema were seen with the emotional well-being, spiritual well-being, and intellectual well-being scores. The associations of each domain score of LASA with severity of internal lymphedema were not statistically significant.

Table 29

Associations between Severity of Lymphedema (LE) and LASA

\begin{tabular}{|c|c|c|c|c|c|c|}
\hline \multirow{2}{*}{$\begin{array}{c}\text { Severity of } \\
\text { LE }\end{array}$} & \multicolumn{6}{|c|}{ Beta ( $P$-value $)$} \\
\hline & $\begin{array}{l}\text { Sample } \\
\text { size (n) }\end{array}$ & $\begin{array}{c}\text { Physical } \\
\text { well-being }\end{array}$ & $\begin{array}{l}\text { Emotional } \\
\text { well-being }\end{array}$ & $\begin{array}{c}\text { Spiritual } \\
\text { well-being }\end{array}$ & $\begin{array}{l}\text { Intellectual } \\
\text { well-being }\end{array}$ & $\begin{array}{c}\text { Overall } \\
\text { well-being }\end{array}$ \\
\hline \multirow{2}{*}{\multicolumn{7}{|c|}{$\begin{array}{l}\text { Severity of } \\
\text { External LE }\end{array}$}} \\
\hline & & \\
\hline $\begin{array}{l}\text { NCI LE } \\
\text { Scale }\end{array}$ & 87 & $-0.16(.148)$ & $-0.14(.200)$ & $-0.17(.114)$ & $-0.12(.279)$ & $-0.25(.021)$ \\
\hline $\begin{array}{l}\text { Foldi's LE } \\
\text { Scale }\end{array}$ & 98 & $-0.18(.071)$ & $-0.08(.430)$ & $-0.17(.091)$ & $-0.08(.435)$ & $-0.19(.056)$ \\
\hline $\begin{array}{l}\text { NCI fibrosis } \\
\text { Scale }\end{array}$ & 98 & $-0.31(.002)$ & $-0.13(.198)$ & $-0.18(.084)$ & $-0.07(.525)$ & $-0.21(.042)$ \\
\hline \multicolumn{7}{|l|}{ Severity of } \\
\hline \multicolumn{7}{|l|}{ Internal LE } \\
\hline $\begin{array}{l}\text { Patterson's } \\
\text { Scale }\end{array}$ & 77 & $-0.12(.294)$ & $-0.08(.508)$ & $-0.08(.458)$ & $-0.04(.760)$ & $-0.18(.116)$ \\
\hline \multicolumn{7}{|l|}{ Severity of } \\
\hline \multicolumn{7}{|l|}{ Combined LE } \\
\hline Multiple R & & $0.33(.055)$ & $0.18(.561)$ & 0.12 (.818) & $0.17(.602)$ & $0.40(.010)$ \\
\hline $\begin{array}{l}\text { NCI LE } \\
\text { Scale }\end{array}$ & & $-0.06(.652)$ & -0.07 (.633) & $-0.04(.761)$ & $-0.16(.250)$ & $-0.21(.114)$ \\
\hline $\begin{array}{l}\text { NCI fibrosis } \\
\text { Scale }\end{array}$ & 70 & $-0.28(.038)$ & $-0.13(.355)$ & $-0.07(.632)$ & $0.15(.275)$ & $-0.20(.125)$ \\
\hline $\begin{array}{l}\text { Patterson's } \\
\text { Scale }\end{array}$ & & $-0.07(.602)$ & $-0.02(.860)$ & $-0.05(.697)$ & $-0.01(.936)$ & $-0.12(.315)$ \\
\hline \multicolumn{6}{|l|}{ Severity of } & Combined LE \\
\hline Multiple R & & $0.27(.064)$ & $0.13(.510)$ & $0.16(.368)$ & $0.10(.710)$ & $0.31(.027)$ \\
\hline $\begin{array}{l}\text { Foldi’s LE } \\
\text { Scale }\end{array}$ & & $-0.25(.036)$ & $-0.12(.341)$ & $-0.15(.220)$ & $-0.09(.443)$ & $-0.26(.029)$ \\
\hline $\begin{array}{l}\text { Patterson's } \\
\text { Scale }\end{array}$ & 78 & $-0.04(.734)$ & $-0.04(.747)$ & $-0.03(.787)$ & $-0.01(.966)$ & $-0.10(.408)$ \\
\hline
\end{tabular}

Beta is highlighted if it is $\geq 0.30$. 
Aim 3. To examine the possible factors contributing to the development of secondary lymphedema in head and neck cancer patients.

In this study, the type of lymphedema included any lymphedema (yes/no) and combined lymphedema (yes/no). Thus, factors were examined to identify whether or not they were associated with presence of any lymphedema or combined lymphedema.

(a) Factors Associated with Any Lymphedema

Associations of possible risk factors included in this study with the occurrence of lymphedema are summarized in Table 30. Factors with statistically significant associations with whether or not individuals had any lymphedema included whether or not the patient had radiotherapy $(O . R .=38.23, p=.001)$, had CCR therapy $(O . R .=5.07$, $p=.004)$, and the total amount of head and neck cancer treatment received $(O . R .=1.03$, $p=.006)$.

No other factors included in this study were identified to be statistically significantly associated with the occurrence of any lymphedema. The strongest associations not reaching the minimal level used in this study were gender $(O . R .=2.86, p$ $=.048)$, area of residence $(O . R .=3.20, p=.026)$, location of tumor $(O . R .=1.03, p=$ $.013)$, surgery therapy $(O . R .=0.30, p=.045)$, and chemo-induction therapy $(O . R=4.29$, $p=.030)$. 
Table 30

Logistic Regression of Possible Factors on Any Lymphedema

\begin{tabular}{|c|c|c|c|c|c|}
\hline \multirow{2}{*}{ Factors } & \multirow{2}{*}{$\begin{array}{l}\text { Sample } \\
\text { size } \\
(\mathrm{N})\end{array}$} & \multirow{2}{*}{ O.R. } & \multirow{2}{*}{$P$-value } & \multicolumn{2}{|c|}{ 95\% C.I. for O.R. } \\
\hline & & & & Lower & Upper \\
\hline Age & 92 & 0.99 & .260 & 0.97 & 1.01 \\
\hline Gender & 92 & 2.86 & .048 & 1.01 & 8.11 \\
\hline Race & 92 & -- & .999 & -- & -- \\
\hline Education & 92 & 1.00 & .805 & 0.99 & 1.02 \\
\hline Marital status & 89 & 0.75 & .627 & 0.24 & 2.36 \\
\hline Employment Status & 92 & 0.63 & .370 & 0.23 & 1.73 \\
\hline Residence Area & 92 & 3.20 & .026 & 1.15 & 8.89 \\
\hline Smoking (Yes/No) & 92 & 1.42 & .501 & 0.51 & 3.95 \\
\hline Drinking Alcohol (Yes/No) & 92 & 1.49 & .451 & 0.53 & 4.16 \\
\hline Dietary Habit & 92 & 0.57 & .399 & 0.16 & 2.10 \\
\hline Inflammatory Disease & 92 & 0.53 & .483 & 0.09 & 3.12 \\
\hline Hypertension & 92 & 0.60 & .316 & 0.22 & 1.63 \\
\hline Diabetes Mellitus & 92 & 2.38 & .428 & 0.28 & 20.21 \\
\hline BMI & 82 & 1.02 & .126 & 1.00 & 1.04 \\
\hline Stages of Tumor & 88 & 1.02 & .074 & 1.00 & 1.04 \\
\hline Locations of Tumor & 92 & 1.03 & .013 & 1.01 & 1.05 \\
\hline $\begin{array}{l}\text { Squamous Cell Carcinoma } \\
\text { (Yes/No) }\end{array}$ & 92 & 2.56 & .324 & 0.40 & 16.46 \\
\hline Radiation (Yes/No) & 92 & 38.23 & .001 & 4.33 & 337.23 \\
\hline Surgery (Yes/No) & 92 & 0.30 & .045 & 0.09 & 0.97 \\
\hline CCR (Yes/No) & 92 & 5.07 & .004 & 1.68 & 15.32 \\
\hline Chemo-Induction (Yes/No) & 92 & 4.29 & .030 & 1.15 & 15.93 \\
\hline Total Treatment Received & 92 & 1.03 & .006 & 1.01 & 1.05 \\
\hline $\begin{array}{l}\text { Total Dosage of Radiation } \\
\text { (Low/High) }\end{array}$ & 66 & 3.35 & .107 & 0.77 & 14.55 \\
\hline Days of Radiation & 76 & 1.01 & .309 & 0.99 & 1.04 \\
\hline $\begin{array}{l}\text { Neck Dissection } \\
\text { (Unilateral/Bilateral) }\end{array}$ & 55 & 1.48 & .405 & 0.59 & 3.74 \\
\hline Number of Lymph Nodes Removed & 55 & 1.00 & .907 & 0.97 & 1.04 \\
\hline Number of Positive Lymph Nodes & 55 & 1.02 & .340 & 0.98 & 1.07 \\
\hline Number of Cycles (CCR ) & 60 & 0.98 & .349 & 0.95 & 1.02 \\
\hline $\begin{array}{l}\text { Number of Cycles (Chemo- } \\
\text { Induction) }\end{array}$ & 33 & 0.97 & .616 & 0.87 & 1.09 \\
\hline
\end{tabular}




\section{(b)Factors Associated with Combined Lymphedema}

Associations of possible risk factors included in this study with the occurrence of combined internal and external lymphedema are summarized in Table 31. Factors found to be significantly associated with whether or not individuals had combined lymphedema included dosage of radiotherapy $(O . R .=16.25, p=.010)$, chemo-induction therapy (O.R. $=3.78, p=.007)$, and total head and neck cancer treatment received $(O . R .=1.04, p=$ .010). No other factors included in this study were found to be statistically significantly associated with the occurrence of both internal and external lymphedema. The strongest associations not reaching the minimal level used in this study were days of radiotherapy $(O . R .=1.03, p=.017)$ and whether or not the patient received CCR therapy $(O . R .=6.82$, $p=.015)$. 
Table 31

Logistic Regression of Possible Factors on Combined Lymphedema

\begin{tabular}{|c|c|c|c|c|c|}
\hline \multirow[b]{2}{*}{ Factors } & \multirow{2}{*}{$\begin{array}{c}\text { Sample } \\
\text { size } \\
(\mathrm{N})\end{array}$} & \multirow[b]{2}{*}{ O.R. } & \multirow[b]{2}{*}{$P$-value } & \multicolumn{2}{|c|}{ 95\% C.I. for O.R. } \\
\hline & & & & Lower & Upper \\
\hline Age & 81 & 0.99 & .185 & 0.98 & 1.01 \\
\hline Gender & 81 & 1.23 & .684 & 0.45 & 3.37 \\
\hline Race & 81 & 1.22 & .679 & 0.48 & 3.09 \\
\hline Education & 81 & 1.00 & .711 & 0.99 & 1.02 \\
\hline Marital status & 78 & 1.03 & .951 & 0.40 & 2.65 \\
\hline Employment Status & 81 & 1.12 & .804 & 0.46 & 2.75 \\
\hline Residence Area & 81 & 1.32 & .560 & 0.52 & 3.32 \\
\hline Smoking (Yes/No) & 81 & 1.26 & .642 & 0.48 & 3.33 \\
\hline Drinking Alcohol (Yes/No) & 81 & 0.87 & .770 & 0.35 & 2.18 \\
\hline Dietary Habit & 81 & 1.01 & .988 & 0.30 & 3.42 \\
\hline Inflammatory Disease & 81 & 1.08 & .935 & 0.17 & 6.86 \\
\hline Hypertension & 81 & 0.65 & .353 & 0.26 & 1.62 \\
\hline Diabetes Mellitus & 81 & 1.70 & .476 & 0.39 & 7.37 \\
\hline BMI & 71 & 1.01 & .428 & 0.99 & 1.03 \\
\hline Stages of Tumor & 77 & 1.02 & .123 & 1.00 & 1.04 \\
\hline Locations of Tumor & 81 & 1.01 & .112 & 1.00 & 1.03 \\
\hline Squamous Cell Carcinoma (Yes/No) & 81 & -- & .999 & -- & -- \\
\hline Radiation (Yes/No) & 81 & -- & .999 & -- & -- \\
\hline Surgery (Yes/No) & 81 & 0.68 & .413 & .27 & 1.70 \\
\hline CCR (Yes/No) & 81 & 6.82 & .015 & 1.45 & 32.19 \\
\hline Chemo-Induction (Yes/No) & 81 & 3.78 & .007 & 1.43 & 9.99 \\
\hline Total Treatment Received & 81 & 1.04 & .010 & 1.01 & 1.07 \\
\hline Total Dosage of Radiation (Low/High) & 59 & 16.25 & .010 & 1.96 & 135.01 \\
\hline Days of Radiation & 67 & 1.03 & .017 & 1.01 & 1.05 \\
\hline Neck Dissection (Unilateral/Bilateral) & 49 & 1.07 & .940 & 0.18 & 6.54 \\
\hline Number of Lymph Nodes Removed & 43 & 0.98 & .284 & 0.94 & 1.02 \\
\hline Number of Positive Lymph Nodes & 49 & 0.99 & .640 & 0.95 & 1.03 \\
\hline Number of Cycles (CCR ) & 51 & 1.00 & .928 & 0.97 & 1.03 \\
\hline Number of Cycles (Chemo-Induction) & 26 & 1.00 & .939 & 0.92 & 1.08 \\
\hline
\end{tabular}




\section{CHAPTER V}

\section{DISCUSSION}

This chapter presents a summary and discussion of the study findings in the following five sections: (a) sample characteristics, (b) aims, (c) study strengths and limitations, (d) implications, and (e) recommendations for future research.

\section{Sample Characteristics}

The study recruited the head and neck cancer patients who had completed their cancer treatment $\geq 3$ months prior to study entry. The characteristics of the sample in this study were similar to those of previous studies reported in the literature. The mean age of 59.8 years in this study was very close to the 60.0 years mean age in Graeff et al.’s (2000) study, and similar to the 59.0 years mean age in Terrell et al.'s (2004) study and the 58.8 years mean age in Murphy et al.’s (2009) study. Of the 103 participants, 68.9\% were male and $31.1 \%$ were female, which was similar to two recent studies (El-Deiry, Futran, McDowell, Weymuller, \& Yueh, 2009; Gourin, Boyce, Vaught, Burkhead, \& Podolsky, 2009). More males than females are diagnosed with head and neck cancer (Itano \& Taoka, 2005; NCI, 2010), as reflected in this study. The majority of the study participants (64.1\%) were married or living with partners, which was correspondingly the case in Terrell et al.'s (2004) study. The employment distribution in this study showed that 50.5\% were employed and $49.5 \%$ described themselves as currently not employed (including retired, disabled, and unemployed), which was similar to Taylor et al.'s (2004) 
study. Regarding area of residence, $63.1 \%(\mathrm{n}=65)$ of the participants lived in Metropolitan areas, while the remaining lived in rural areas $36.9 \%(n=38)$, which almost mirrored the data of geographical statistics (U.S. Census Bureau, 2000) that $63.6 \%$ of the population in Tennessee live in Metropolitan areas. More than half of all participants had insurance through government program (including Medicare, Medicaid, TennCare, and TriCare), which closely matched Gourin \& Podolsky's (2006) study. The $35.0 \%$ of the sample with more than $\$ 50,000$ income annually was lower than geographical statistics (U. S. Census Bureau, 2006-2008) that show 43.9\% of the population in Tennessee with an annual income of over $\$ 50,000$. Nevertheless, $32 \%$ of the sample did not care to respond their annual income, which may influence the actual income distributions in the study sample.

Race distribution showed that $89.3 \%$ were White and only $10.7 \%$ Black, which was similar to several reports (Taylor et al., 2004; Terrell et al., 2004). However, this race ratio of minority to non-minority participants was higher than Gourin et al.’s (2009) study (White 73\% and Black 27\%), and geographical statistics (U.S. Census Bureau, 20062008) (White 79.3\% and Black 16.5\% in Tennessee). This indicates that Black and other minority (e.g., Asians) patients were underrepresented in the current sample. This is of concern as, although Whites currently have the highest incidence rates of head and neck cancer, mortality is still highest in Black patients (NCI, 2010). Moreover, Black patients are reported to have a higher incidence of advanced head and neck cancer (Gourin \& Podolsky, 2006). Therefore, efforts to improve Black and other minority population involvement in future studies are critical as improved representation will assist in developing a greater understanding of the impact of lymphedema on the Black and other 
minority population after head and neck cancer treatment. In this study, 89.3\% of participants were high school graduates or higher. This education level is higher than geographical statistics (U.S. Census Bureau, 2006-2008) that reveal 81.8\% of the population in Tennessee has an equivalent education level.

Health behaviors regarding cigarette smoking and alcohol consumption rates were similar to Hapner \& Wise’s (2010) study. However, the cigarette smoking rate (current) in this study was lower than Shuman et al.’s (2010) study, but the alcohol consumption rate (current) was close to Shuman et al.’s (2010) study. The rates of alcohol consumption (current and past) were lower than the data from the Center for Disease Control and Prevention for the general population (CDC, 2009) raising concerns about the accuracy of self-report alcohol assumptions in the study sample.

The primary characteristics for head and neck cancer disease and treatment were similar to those reported in the head and neck cancer treatment-related literature (Murphy et al., 2009; Shuman et al., 2010; Weber, Dommerich, Pau, \& Kramp, 2010). That is, the most common primary tumor sites of the participants were oropharynx and larynx; the majority of the participants had advanced stage of tumors at the time of diagnosis of head and neck cancer; the histological type of most participants’ tumors was squamous cell carcinoma; and the majority of the participants received at least two modalities of cancer treatment.

\begin{abstract}
Aims
Aim 1. To examine the prevalence of external lymphedema, internal lymphedema and combined lymphedema in head and neck cancer patients.
\end{abstract}


This is the first reported study to examine the prevalence of secondary lymphedema in head and neck cancer patients in the United States. The study identified that $75.3 \%$ of the participants had some form of lymphedema, including $9.8 \%$ with external lymphedema only, 39.4\% with internal lymphedema only, and 50.8\% with combined lymphedema. This rate is substantially higher than rates reported in other studies done in other parts of the world. Four European studies reported the prevalence of secondary lymphedema after head and neck cancer treatment (Buntzel et al., 2007; Dietz et al., 1998; Schiefke et al., 2009; Wolff et al., 2009). The first study (Dietz et al., 1998) reported 54\% of the participants developed laryngeal lymphedema after CCR treatment but did not mention external lymphedema. The second study (Buntzel et al., 2007) reported $48.4 \%$ of participants developed submental or supraglottal lymphedema after head and neck cancer treatment. However, the study did not report the detailed occurrence rates, i.e., external lymphedema only, internal lymphedema only, and combined lymphedema. The third study (Schiefke et al., 2009) found that $17 \%-36 \%$ of the participants had external lymphedema after surgery treatment but they did not examine whether or not they developed internal lymphedema simultaneously. The last study (Wolff et al., 2009) reported that $12 \%$ of the patients developed subcutaneous lymphedema and fibrosis after head and neck cancer as identified through magnifying laryngoscopy examination. Use of different instruments may have contributed to the different findings. However, none of these studies clearly reported findings of internal and external lymphedema at the same time. This dissertation study is the largest study to date to conduct detailed assessments of both internal and external lymphedema in head and neck cancer patients $\geq 3$ months post-treatment and to report external, internal, and 
combined lymphedema occurrence rates in this population.

It is important to note that the variation in prevalence of secondary lymphedema in head and neck cancer patients in the literature may also reflect differences in the choice of grading criteria, variations in the structures assessed for manifestations of lymphedema (e.g., internal vs. external), differences in the duration of follow-up (Bruns, Micke, \& Bremer, 2003), and different cancer treatment regimens among the studies. Therefore, more studies, especially longitudinal studies using standardized grading criteria, are necessary to identify the prevalence and clinical characteristics of secondary lymphedema in head and neck cancer patients.

This study found that $13.6 \%$ ( $\mathrm{n}=11$ of 81 )of the participants had severe internal lymphedema and the most commonly involved sites were the pyriform sinus and interarytenoid space. Both are important anatomical sites in the pharynx and larynx, respectively. Unfortunately, no literature addressing lymphedema in these anatomical sites is available for review. This finding suggests that more studies are needed to examine the sites of internal lymphedema and the potential impact on symptoms and function. Additionally, clinicians need to examine these sites when they conduct endoscopy examinations. Findings that the most commonly involved anatomical sites for external lymphedema were the submental and neck areas were consistent with literature reports (Buntzel et al., 2007; Hammond, 2007; Zimmermann et al., 2005). In addition, the participants with fibrosis only ( $\mathrm{n}=11$ ) were not identified by using the NCI LE and ACS LE scales. This indicates that developing a standardized measurement tool for external lymphedema is important to future research.

Aim 2. To examine the associations between severity of lymphedema in head and neck 
cancer patients and (a) symptoms (physical and psychological), (b) functional status, and (c) quality of life.

Associations between Severity of Lymphedema and Symptoms

Nutrition-related symptoms. Nutrition status is particularly important for head and neck cancer patients (Oates et al., 2008). Literature supports that malnutrition increases head and neck cancer patients’ risk of morbidity (van Bokhorst-de van der Schueren et al., 1997) and mortality (Jager-Wittenaar et al., 2007). However, nutrition-related symptoms are not well addressed in head and neck cancer patients (Eisele, Koch, Tarazi, \& Jones, 1991; Jager-Wittenaar et al., 2007; Oates et al., 2008). This indicates that other unknown factors may influence patients’ nutrition status. This study found that severity of external lymphedema (fibrosis) and combined lymphedema was statistically significantly associated with nutrition-related symptoms. This is the first study to report that individuals with more severe external lymphedema (fibrosis) or more severe combined lymphedema were more likely to have nutrition-related symptoms.

In order to understand this association, it is critical to understand how lymphedema may be related to both losing weight and appetite, which were two major components of nutrition-related symptoms in this study. Lymphedema may contribute to nutrition-related symptoms through two possible mechanisms. One may be related to architectural factors. Lymphedema-related swelling or fibrosis may compromise key anatomical sites, such as external structures (e.g., facial or neck muscles) and/or internal structures (e.g., oral cavity or pharynx). These key anatomical sites are involved in the critical swallowing process (Eisele, et al., 1991; Murphy \& Gilbert, 2009). Studies conducted in breast cancer patients with secondary lymphedema found that lymphedema 
does cause limb skin architectural changes (Lymphoedema Framework, 2006; Rockson, 2009). Thus, it is possible that head and neck cancer patients may have architectural changes in the critical anatomical sites that affect swallowing. Well designed, longitudinal, swallowing and symptom studies are needed to explore the possible relationship between lymphedema and nutrition symptoms and to examine whether head and neck cancer patients with lymphedema have architectural changes in these key anatomical sites.

Many studies have found that lymphedema is a chronic inflammatory process which produces inflammatory mediators in the interstitial space such as cytokines and chemokines (Nakamura, Radhakrishnan, Wong, \& Rockson, 2009; Tabibiazar et al., 2006). It is possible that these inflammatory mediators may enter the bloodstream through the lymphatic system and be taken to the whole body through the circulation system. These inflammatory mediators may trigger systemic inflammatory responses and symptoms (e.g., decreased appetite) as well as cause digestive system dysfunction (e.g., influencing the process of absorption). Mechanisms regarding the possible relationships among lymphedema, inflammation, and nutrition status warrant future study. However, pending such studies, healthcare professionals still may wish to examine whether or not head and neck cancer patients develop lymphedema, determine its severity, and evaluate if patients with lymphedema have nutrition problems after their head and neck cancer treatment. If problems are found, referral of such patients to lymphedema therapy could be beneficial.

Swallowing-related symptoms. This study found the severity of lymphedema (external only or combined lymphedema) was statistically significantly correlated with 
self-reported swallowing symptoms. This finding is consistent with the reports from three previous studies with small sample sizes ( $N=11-26)$ (Eisbruch et al., 2004; Machtay et al., 2004; Piso et al., 2001). Eisbruch et al. (2004) reported laryngeal lymphedema and fibrosis, as a side effect of radiotherapy and chemotherapy, impaired swallowing function based on a direct endoscopy examination. The two other studies reported that head and neck cancer patients with external lymphedema had subjective swallowing difficulty. None of them have examined whether or not patients developed combined lymphedema and its association with swallowing-related symptoms. This dissertation study examined external, as well as internal, lymphedema, and found that combined lymphedema was related to swallowing problems, although the exact mechanisms require investigation.

In order to interpret the associations between severity of lymphedema and swallowing issues, it is important to understand the normal swallowing mechanism. The process of swallowing is a complex and precise coordination that involves muscles and structures in the oral cavity, pharynx, larynx, and esophagus (Manikantan et al., 2009; Murphy \& Gilbert, 2009). Any compromise of these muscles and structures could cause swallowing dysfunction. From this standpoint, it seems logical and explicable that lymphedema (external and/or internal) may impede the swallowing process.

In patients with external lymphedema, swelling or fibrosis of the soft tissues in the neck area may interrupt the precise coordination of the muscles and nerves that are involved in the swallowing process. Lymphedema-related swelling or fibrosis of soft tissues in the neck area may increase pressure on the pharynx and larynx anatomical structures that may interfere with and restrict the swallowing process. Neck soft tissue fibrosis may also impair laryngeal elevation and lead to poor pharyngeal clearance 
(Eisele et al., 1991) which affects the swallowing reflex. In patients with internal lymphedema, swelling or fibrosis of anatomical structures in the base of tongue, pharynx, and larynx may affect swallowing process and swallowing reflex through the following several aspects: (1) the swelling or fibrosis may make it difficult for food to pass through these critical sites from the oral cavity to the esophagus; and (2) the swelling or fibrosis may interrupt the precise coordination of the swallowing reflex, such as inadequate closure of the larynx, limited contraction of the pharyngeal constrictors, limited laryngeal elevation, and delayed relaxation of the cricopharyngeus that affect passing of the food bolus into the esophagus. Late-effect lymphedema may also damage neural structures that regulate the swallowing process (Murphy \& Gilbert, 2009). Although these potential explanations regarding the relationship of lymphedema with swallowing were extrapolated from swallowing mechanisms, they need to be confirmed in future studies. Nevertheless, this finding indicates that it is critical for healthcare professionals to examine whether patients have lymphedema externally and internally, especially those with swallowing problems.

Mucous/Dry mouth (xerostomia)-related symptoms. One of the notable findings in this study is that severity of the lymphedema (external only, internal only, or combined lymphedema) was statistically significantly associated with mucous and/or dry mouthrelated symptoms. In other words, head and neck cancer patients with more severe lymphedema had more mucous and/or dry mouth-related symptoms. This finding is unexpected and no literature is available for interpreting this association.

Studies have reported that inflammation causes secretions of copious mucous during cancer treatment (Mallick \& Waldron, 2009). However, the issue of copious 
mucous months after head and neck cancer treatment is not fully understood (Murphy et al., 2009). Mucous can accumulate in the airways, which causes patients' discomfort and a sensation of airway obstruction. The copious mucous causes patients' choking, gagging, and sometimes influences sleeping. Some patients have to deal with self-management of copious secretions in their daily lives after their head and neck cancer treatment. Thus, addressing copious mucous is an important issue for head and neck cancer patients. This is the first study to report the association between severity of lymphedema and mucousrelated symptoms. Although this finding is unexpected, it may provide an insight to a better understanding of the mucous issue in the head and neck cancer population. Two theoretical explanations are proposed. One is that lymphedema (swelling or fibrosis) could build up pressure on patients’ paranasal sinuses, which may obstruct the nasal passage, interrupt nasal discharge, lead to mucous accumulated in sinuses and later result in copious mucous symptoms. Second, some patients with severe internal lymphedema may have mucous accumulated in their oral cavity or throat due to severe swallowing dysfunction. In addition, lymphedema is a chronic inflammatory process and it may produce rich inflammatory mediators that trigger an ongoing secretion of mucous. However, all these possible explanations are only speculative and need to be examined in future longitudinal studies.

Studies have found that cancer treatment (especially radiotherapy) affects the salivary gland function, causing dry mouth symptoms (xerostomia) (Dirix, Nuyts, Vander Poorten, Delaere, \& Van den Bogaert, 2008; Itano \& Taoka, 2005; NCI, 2010). In recent years, intensity-modulated radiotherapy (IMRT) has rapidly been used in the management of head and neck cancer, which decreases dry mouth incidence (Eisbruch, 
2007) through sparing the parotid salivary glands. However, a certain number of head and neck cancer patients still develop dry mouth symptoms after their cancer treatment. This study found that patients with more severe lymphedema have more severe dry mouth-related symptoms. Lymphedema, as a chronic inflammatory process, may impact salivary production through inflammatory mediators or facial lymphedema (swelling or fibrosis) may cause salivary ductal obstruction. Nonetheless, these explanations need to be explored in future research.

Other symptoms. This study did not find significant associations between severity of lymphedema with self-reported pain or with voice-related symptoms. These findings are somewhat inconsistent with the current literature. Regarding self-reported pain, one study found that head and neck cancer patients with external lymphedema had selfreported pain in the submandibular region, but the study only recruited 11 participants within 30 days after surgery (Piso et al., 2001). Furthermore, multiple studies conducted in breast cancer patients with secondary lymphedema have demonstrated that lymphedema patients may have altered sensation-related symptoms, such as tightness, tingling, and numbness in the affected skin area (Ridner, 2005). Additionally, in the PI’s previous observation study (data unpublished) similar altered sensation-related symptoms in head and neck cancer patients with secondary lymphedema were noted. However, these symptoms were not captured in this study by the instruments used. This indicates that development of a lymphedema specific symptom instrument is needed.

Voice-related symptoms were reported in one study of 16 head and neck cancer patients with internal pharyngeal edema who had voice dysfunction (Machtay et al., 2004). Assessment of the impact of lymphedema on voice in future studies is needed 
given these mixed findings.

The secondary analysis of the patterns in the VHNSS symptom scores revealed two distinct clusters of the study sample, i.e., one group with low symptom scores and a second group with high symptom scores. The high symptom group was likely to have more severe lymphedema. This finding further supported that the severity of lymphedema was significantly associated with symptomatology in head and neck cancer patients. This indicates that clinicians need to examine lymphedema and its severity in head and neck cancer patients to determine symptom burden.

Body image-related symptoms. This is the first published study to examine the association between severity of lymphedema and body image-related symptoms in head and neck cancer patients. The finding of a significant relationship with primary contributing factor being fibrosis was not surprising as body image issues have been frequently reported in breast cancer patients with secondary lymphedema (Jager et al., 2006; Morgan et al., 2005; Ridner, 2005; Speck et al., 2010). This study found that head and neck cancer patients developed external lymphedema in their face, neck, submental area, and around the eyes. All these anatomical sites are highly visible and directly contribute to one's self image. It is possible that lymphedema may result in a major alteration in body image because of highly visible skin color and/or texture changes (swelling or fibrosis) in the head and neck area. External lymphedema may cause facial disfiguration and distress in head and neck cancer patients (Murphy et al., 2007a; Ridner, 2008; Smith \& Lewin, 2010). Body image issues related to external lymphedema are highly important in head and neck cancer patients, as such concerns may contribute to self consciousness and increase the risk of social isolation. As a result, it is essential for 
healthcare professionals to detect external lymphedema early and refer patients to appropriate lymphedema management in an attempt to reduce the degree of visible swelling/fibrosis.

The lack of a statistically significant correlation between severity of lymphedema and anxiety was unexpected. Although no studies are available for comparison regarding these relationships in head and neck cancer patients, studies conducted in breast cancer patients found that patients with more severe lymphedema had more anxiety (Heppner et al., 2009; Meeske et al., 2009). Another interesting finding in this study is that patients with more severe lymphedema did not report more depressive symptoms. This finding was consistent with at least one study conducted in breast cancer patients with secondary lymphedema (Ridner, 2009). Small sample size may have contributed to this negative finding.

Associations between Severity of Lymphedema and Functional Status

Hearing. In head and neck cancer patients, hearing impairment includes conductive and sensorineural hearing loss due to cancer treatment (Hitchcock, Tward, Szabo, Bentz, \& Shrieve, 2009; Person, Meyer, Adams, \& Ondrey, 2006). This is the first published study to evaluate the relationship between severity of lymphedema and hearing impairment in head and neck cancer patients with lymphedema. We assessed hearing in this study based on the theoretical assumptions that (1) lymphedema (swelling) in pharynx and larynx may lead to pressure changes in the inner ear or impact on opening of the Eustachian tube (Jereczek-Fossa, Zarowski, Milani, \& Orecchia, 2003) or (2) fibrosis occurring at the pharyngeal orifice of the Eustachian tube and atrophy of its mucosal lining could lead to hyperpatency of the tube. Weak associations were found between 
severity of lymphedema (internal or combined lymphedema) and hearing loss based on the whispered voice test and the tuning fork test. However, given the limited sample size and grossness of the hearing assessment, it may be simply that the relationship between lymphedema and hearing impairment needs to be examined in future studies using more sensitive hearing measures such as a formal audiological testing. In addition, a larger sample is needed to clarify the association between severity of lymphedema and hearing impairment.

Trismus. Trismus is a common complication of head and neck cancer treatment. Studies have found that cancer treatment results in damage and fibrosis of the muscles of mastication (i.e., the temporomandibular joints, the pterygoid muscles, or the masseter muscle) which is a major cause of trismus (Bensadoun et al., 2010; Dijkstra, Kalk, Roodenbrug, 2004; Hsiung, Huang, Ting, \& Huang, 2008). An abnormal proliferation of fibroblasts from radiation or surgery is an important initial factor for trismus. No studies have examined the relationship of lymphedema with trismus. Based on a theoretical hypothesis, lymphedema may contribute to trismus in head and neck cancer patients if lymphatic fibrosis affects the muscles of mastication. However, the study finding did not support this hypothesis. One possible explanation for this finding is that only eight participants with facial lymphedema (swelling or fibrosis) were identified in this study. Thus, the relationship between lymphedema and trismus could not truly be assessed with this study. There is a need to recruit more participants with facial lymphedema and further examine whether or not facial lymphedema (fibrosis) is related to trismus in future research. 
CROM. Decreased neck range of motion is a common complication after head and neck cancer treatment (Teymoortash, Hoch, Eivazi, \& Werner, 2010; van Wilgen, Dijkstra, van der Laan, Plukker, Roodenburg, 2004). From a theoretical hypothesis, individuals with more severe lymphedema (swelling or fibrosis) may be likely to decrease their neck range of motion. Weak associations were found between severity of external lymphedema with forward flexion degrees and with left rotation degrees. The possible associations between severity of lymphedema and CROM degrees needs to be examined in future studies.

Signs (Physical Examination). The study evaluated the signs in neck and shoulder area by direct physical examination of participants. Only elicited pain in the neck and shoulder area was statistically significantly associated with severity of external lymphedema or combined lymphedema. This finding was consistent with one study's report (Piso et al., 2001). No statistically significant associations were identified between severity of external lymphedema and tenderness, postural abnormalities, and fixed deformity. These finding were unexpected. Whether these findings represent a sampling bias or an actual relationship is unknown and will need to be examined in future research. Associations between Severity of Lymphedema and Quality of Life

One of the most important findings in this study was that severity of lymphedema (external, internal, and combined) was statistically significantly associated with head and neck cancer-treatment related quality of life. This is the first published study to examine this relationship. Although no other studies on head and neck cancer patients are available for review, this finding was expected and similar to the outcomes from the studies conducted in the breast cancer population (Morgan et al., 2005). This dissertation 
study identified that head and neck cancer patients with more severe lymphedema tended to experience poorer physical well-being, functional well-being, treatment-related wellbeing, and overall quality of life than patients with less or no lymphedema. This indicates that management of lymphedema in head and neck cancer patients may be critical to improving patients' quality of life. Intervention studies are desired to identify appropriate strategies to manage lymphedema and improve quality of life in head and neck cancer patients.

Aim 3. To examine the possible risk factors contributing to the presence of secondary lymphedema in head and neck cancer patients.

This is the first published study to examine the relationships between demographic, health behavior, cancer disease, and treatment-related factors with the presence of lymphedema after head and neck cancer treatment.

\section{Factors Associated with Any Type of Lymphedema}

The study found that the type of treatment, including radiotherapy, CCR, and multi-modality head and neck cancer treatment, was statistically significantly related to the presence of lymphedema.

Radiotherapy. In this study, whether or not patients received radiotherapy was statistically significantly associated with the presence of lymphedema. This finding was expected and logical, as one study reported that laryngeal lymphedema was significantly related to radiotherapy (Sanguineti et al., 2007). This finding was also similar to the studies of breast cancer patients with lymphedema (Hayes, Janda, Cornish, Battistutta, \& Newman, 2008; Hinrichs et al., 2004; Powell et al., 2003). Several studies have found that radiation damages lymph nodes’ structure and lymph vessels, leads to abnormal 
lymphatic flow as well as stimulates inflammatory response. Inflammation may be a key factor related to the development of lymphedema. For example, studies found that the chronic inflammatory response with tissue hypoxia results in fibroblast proliferation and eventual scarring and fibrosis (Avraham et al., 2009; Chopra \& Bogart, 2010; Rockson, 2009). Studies also reported that anti-inflammatory pharmacotherapy reduced experimental lymphedema in a murine model (Nakamura et al., 2009), which further demonstrated that lymphedema may be caused by a chronic inflammatory response. One recent study examined the possible mechanisms of radiation therapy leading to the development of lymphedema in mouse (Avraham et al., 2010). They found that radiation caused tissue edema that resolved in 12-24 weeks. After edema was resolved in the mice tail, irradiated tissue displayed continuing lymphatic dysfunction. That is, radiotherapy depletes lymphatic vessels and lymphatic endothelial cells (LECs), and promotes irradiated soft tissue fibrosis. This experimental phenomenon mirrors a clinical manifestation; radiation not only induces acute edema but also leads to chronic lymphedema.

CCR. Concurrent chemoradiation is frequently used in patients with locally advanced head and neck cancer. Due to patients receiving radiotherapy and chemotherapy simultaneously, CCR results in numerous treatment-related toxicities (such as severe mucositis) (Machtay et al., 2008). However, no studies are available for examining the relationship between CCR and lymphedema in head and neck cancer patients. This is the first study to report that CCR was statistically significantly associated with the presence of lymphedema. This finding was expected and logical. A plausible explanation is that CCR may lead to severe cutaneous toxicity (Pryor et al., 2009), such 
as severe skin and mucosal reactions and lymphatic damage, and later chronic inflammation damages skin and interstitial tissues. This mechanism is still unknown at this time. However, this finding suggests that clinicians need to evaluate whether or not head and neck cancer patients have lymphedema after their CCR treatment.

Number of treatment modalities received. The number of head and neck cancer treatment modalities received was statistically significantly associated with the presence of lymphedema. This finding was expected and logical as a larger treatment dose (more treatments) may lead to more severe damage than single modality cancer treatment. This finding indicates that healthcare professionals need to provide the minimal amount of treatment need to promote a cure in order to reduce the negative impact on patients.

\section{Factors Associated with Combined Lymphedema}

This is the first published study to report that three factors (dosage of radiotherapy, chemo-induction therapy (yes/no), and number of head and neck cancer treatment modalities received) were statistically significantly associated with whether or not individuals had combined internal and external lymphedema. Studies have demonstrated that radiation toxicity is closely related to radiation dosage (Hinrichs et al., 2004). Individuals treated by CCR with chemo-induction reported more severe toxicity than individuals treated by CCR without chemo-induction (Geller et al., 2003; Paskett et al., 2007). Multi-modality cancer treatment increased treatment-related toxicity more than single modality treatment. This finding indicates that clinicians need to routinely examine patients for the development of combined lymphedema if they receive high dosage radiotherapy, or chemo-induction therapy, or multi-modality cancer treatment.

Many studies found that age (Hayes et al., 2008; Meeske et al., 2008), BMI (Clark 
et al., 2005; Mclaughlin et al., 2008; Meeske et al., 2005; Ridner, 2005; Soran et al., 2006), hypertension (Meeske et al., 2005; Soran et al., 2006), diabetes mellitus (Soran et al., 2006), stage of tumor (Deo et al., 2004; Herd-Smith et al., 2001; Park et al., 2008; Soran et al., 2006), number of lymph nodes excised, and the number of positive lymph nodes excised (Hayes et al., 2008; Meeske et al., 2008; Soran et al., 2006) were significantly related to increasing risk of developing lymphedema in breast cancer patients. This study did not find that these factors were associated with the presence of lymphedema in this sample of head and neck cancer patients. In addition, race, inflammatory disease (yes/no), cigarette smoking (yes/no) and drinking alcohol (yes/no) were also not statistically significantly associated with the presence of lymphedema in this study. Given the size and cross-sectional nature of this study, large longitudinal studies of these factors would be required to ascertain risk factors for developing lymphedema in head and neck cancer patients.

\section{Study Strengths and Limitations}

This dissertation research study is unique in that it is the first study to systematically examine secondary lymphedema in head and neck cancer patients. It is also unique in that it was done by a nurse researcher. The major strengths are discussed in terms of methodology and research content.

\section{Strengths}

Strengths in Methodology. The study captured the basic characteristics of lymphedema in head and neck cancer patients. Moreover, it was the first study to objectively evaluate external lymphedema in head and neck cancer patients through 
physical examination. The study graded external lymphedema by using four national and international lymphedema scales and identified the similarities and differences among these scales. These comparisons among measures provide an empirical basis for future studies regarding developing lymphedema measurement tools in head and neck cancer patients. Furthermore, it was the first study to grade internal laryngopharyngeal lymphedema in head and neck cancer patients by using Patterson's scale.

Strengths in Research Content. This study identified that head and neck cancer patients not only developed external lymphedema, but also internal lymphedema and combined lymphedema. The findings of $75 \%$ lymphedema prevalence in the study sample reveal that it is likely that lymphedema is a common late-effect in head and neck cancer patients. There are multiple clinical manifestations (swelling and/or fibrosis) and multiple sites involved in lymphedema (external and/or internal lymphedema). Moreover, this is the first study to examine the associations between severity of lymphedema and symptoms, functional status, and quality of life in head and neck cancer populations. Some important findings were identified, such as severity of lymphedema was significantly associated with swallowing and mucous/dry mouth-related symptoms and overall quality of life in head and neck cancer patients. These findings indicate that secondary lymphedema is an important clinical phenomenon and needs to be managed in clinical settings. Nurses can play a key role in identification of external lymphedema and in assessment of patient symptoms. Furthermore, the study explored the possible risk factors associated with the presence of lymphedema in head and neck cancer populations. The types and dosages of head and neck cancer treatment may be related to the presence of secondary lymphedema in head and neck cancer patients. 


\section{Limitations}

There are some limitations in this study. (1) External validity (generalizability). The study used a convenience sampling method rather than random selection of participants. Study participants were recruited from a single comprehensive cancer center. Thus, the findings from this study may be generalized only to head and neck cancer populations coming to the type of clinic sampled in this study, that is, there were primary white and black population with little other minority representatives. (2) Internal validity. The main threat to the internal validity of a cross-sectional design stems from problems in establishing cause without a time dimension. The study investigated only possible risk factors associated with the presence of secondary lymphedema. Statements about relationships with the development or causes cannot be made. For example, the study could not explain the transition between swelling and fibrosis. In other words, the study could not explicate whether or not head and neck cancer patients had swelling first and later developed fibrosis or patients developed fibrosis only without a swelling process. In addition, the sample was too small for multivariate assessments. Given the complexity of disease processes, it is highly unlikely that simply univariate associations will be informative. Larger, longitudinal studies are needed to evaluate possible underlying multivariate, causative factors leading to the development of lymphedema. (3) Potential reliability issue. The Patterson's Scale is the only valid instrument published in the current literature to evaluate anatomical sites of internal lymphedema. Although it has strong intra-rater reliability and moderate inter-rater reliability, it had previously been tested in only a small ( $n=25)$ study (Patterson et al., 2007). In this study, two trained oncologists collected the internal lymphedema data along with the PI. However, an inter- 
rater reliability issue may exist as, due to physician scheduling difficulties, the PI was unable to directly examine inter-rater reliability. This suggests that taking pictures during scoping and comparing findings across physicians conducting the procedures is important to enable us to test inter-rater reliability in future research. Additionally, in studies when more than one rater use external lymphedema scales, the inter-rater reliability needs to be carefully monitored. (4) The use of existing valid and reliable instruments that were not lymphedema specific to evaluate symptoms may have limited ability to assess certain potential lymphedema driven symptoms such as altered sensation in swollen areas. (5) Other possible confounding factors. The study recruited the participants three months or more post-treatment. The results showed the time from completion of cancer treatment ranged from 3.09 months to159 months in this study. Thus, unknown confounding factors may impact the study findings.

\section{Implications}

Lymphedema in head and neck cancer patients is an under-recognized and understudied clinical phenomenon. Throughout the current literature inconsistent measurement/staging/grading methods are noted and limited research data are available regarding prevalence, symptoms, functional status, quality of life and possible risk factors of secondary lymphedema in head and neck cancer patients. Poor understanding of this phenomenon has critically compromised healthcare professionals’ ability to assess, diagnose, and manage secondary lymphedema in head and neck cancer patients. Successfully guided by the Theory of Unpleasant Symptoms, this dissertation study focused on examining the prevalence of secondary lymphedema, the associations 
between severity of lymphedema and symptoms, functional status, quality of life, and lymphedema risk factors in an effort to fill some of the many gaps related to this phenomenon of interest.

Several critical findings were generated from this study. First, the study findings suggest that lymphedema in head and neck cancer patients may be a very common lateeffect. The study identified that head and neck cancer patients may not only develop internal lymphedema (such as pharynx and larynx), but also have external lymphedema (such as facial and neck area) after their cancer treatment. The findings from this study demonstrated that the severity of lymphedema was significantly associated with swallowing difficulty, mucous/dry mouth-related symptoms, and impaired body image. Furthermore, the study found that the severity of combined lymphedema was significantly associated with head and neck cancer patients' quality of life status. Finally, the study found that types and dosages of cancer treatment were significantly associated with the presence of lymphedema in this sample of head and neck cancer patients. Thus, the findings from this dissertation study have shed light on the clinical importance of secondary lymphedema in head and neck cancer patients. This study also provides an insight regarding the importance of addressing lymphedema in head and neck cancer patients.

There are several implications from the study findings. Healthcare professionals need to be equipped with the knowledge related to risk factors for head and neck lymphedema, its clinical manifestations, its impact, and appropriate management strategies. Health care professionals need to be aware of lymphedema as a common lateeffect in head and neck cancer patients and inform patients about their risk. They need to 
regularly examine head and neck cancer patients, many of whom are at risk of lymphedema, but they should be exceptionally vigilant in on-going monitoring of patients that may be of higher risk than others, e.g., those receiving multi-modality cancer treatment and high dosage of radiotherapy.

Healthcare professionals, especially nurses, need to evaluate patients’ lymphedema-related symptomatology and conduct physical examinations to detect early lymphedema, such as skin examination of the face and neck to identify any swelling and/or fibrosis. Specifically, in patients with nutrition, swallowing, and mucous/dry mouth-related symptoms, healthcare professionals need to conduct internal examination (e.g., endoscopy) for oral cavity, pharynx, and larynx fluid as this could be a contributing factor to their problems. Healthcare professionals need to document lymphedema-related symptoms (such as swallowing-related symptoms) and evaluate their effects on quality of life. Given positive findings related to swallowing, nutrition, and quality of life, a multidisciplinary approach to lymphedema management is indicated.

Although more research is needed, given the high prevalence of lymphedema found in this study, several clinical implications are noteworthy and could be implemented immediately in patient care environments. First, as previously noted, head and neck cancer patients should be told of their risks for developing lymphedema and patient education about how to identify developing lymphedema should be provided. Physicians, when discussing treatment options, can inform patients of the risk. Nurses can serve as key team players in discussing symptoms of developing lymphedema such as swelling in the submental or facial areas several months after treatment. Second, when conducting endoscopic examinations of head and neck cancer patients, routine 
observation for lymphedema and any lymphedema covering vital structures should be documented. Third, anytime internal or external lymphedema is noted, patients should be referred for lymphedema treatment by certified lymphedema therapists or knowledgeable physical therapists. Fourth, patients with lymphedema may need to be assessed for swallowing problems. Fifth, patients with known lymphedema should be queried by nurses or physicians at every clinic/office visit regarding any potential problems/symptoms they may have related to the swelling.

\section{Recommendations for Future Research}

The study findings can be used to guide future research through the following aspects.

In this study the majority of the study participants were White and the study data were collected from one comprehensive cancer center. This indicates that future studies should attempt to obtain a more racially diverse sample and more research sites should be involved in the studies. In future studies, it is a need to control for the time since end of head and neck cancer treatment. Studies are needed to examine the study findings trending toward significance (e.g., the association between severity of lymphedema and hearing).

The study found that the manifestations of lymphedema varied in head and neck cancer patients. For example, some patients had swelling only, some had fibrosis only, and some had both lymphedema and fibrosis. This finding suggests that it is essential to conduct longitudinal studies to identify causal mechanisms for lymphedema (i.e., inflammation), the relationships among lymphedema manifestations, including the 
transition between swelling and fibrosis, and the differences between lymphedemarelated fibrosis and non lymphedema-related fibrosis. Longitudinal studies are also needed to tease out whether or not head and neck cancer patients developed internal lymphedema and external lymphedema at the same time or if one leads to the other. Moreover, studies are needed to determine whether or not internal edema is a transitional or a chronic clinical phenomenon in this population.

In addition, the study findings demonstrated that the four external lymphedema scales resulted in the different occurrence rates of lymphedema. None of them clearly captured all the characteristics of external lymphedema. The NCI lymphedema scale and the ACS lymphedema scale lack a fibrosis component, while the NCI fibrosis scale is short of a swelling component. Although Foldi's lymphedema scale captured both swelling and fibrosis in this study, its pathological component is not well-defined and not easily understood, which may cause inconsistency in grading the severity of external lymphedema (an inter-rater reliability issue). These findings indicate that there is a need to develop a validated scale of external lymphedema to be consistently used among researchers and clinicians. Such a scale could have significant clinical utility as it could be easily used by nurses during each office/clinic visit to evaluate external lymphedema during the routine collection of vital signs and weight. Also, it is important to develop an instrument to evaluate lymphedema specific symptoms and a tool to examine economic impact of secondary lymphedema in head and neck cancer populations. Further, the Patterson's scale was the only one used to evaluate internal lymphedema, and its validity and reliability needs further testing.

The study found that severity of lymphedema was statistically significantly 
associated with swallowing, mucous/dry mouth, and nutrition status, as well as quality of life. Studies exploring the temporal presentations of lymphedema and symptoms are needed to clearly elucidate the relationship between lymphedema, symptomatology, and quality of life. Interventional studies are needed to explore strategies regarding treatment of lymphedema, symptomatology, and improving quality of life in head and neck cancer patients with lymphedema.

If armed with information from these proposed studies, knowledgeable healthcare professionals, such as nurses, could make significant contributions to improve head and neck cancer patients' lymphedema related symptomatology and quality of life. 


\section{APPENDIX A}

\section{MDS CONTACT SCRIPT}

Hello. My name is Jie Deng. I am a PhD (c) at Vanderbilt University School of Nursing. I am conducting my dissertation study and focusing on secondary lymphedema related to head and neck cancer treatment. I would like to tell you about my study if you have a few minutes.

The study is being done to help us better understand lymphedema that happens after head and neck cancer treatment. This study would require participants to perform the following tasks only one time: (1) filling out some forms that ask them about their symptoms, ability to carry out daily activities, and quality of life; (2) answering questions about their demographic information (e.g., education, insurance) and any treatment they have had for lymphedema; and (3) their head and neck cancer disease \& treatment information (e.g., date and type of surgery) will be collected from their medical records. In addition, I will evaluate them to see if they have swelling/tightness in their head and neck region, neck range of movement, mouth range of motion, and hearing. The time involved in this study is estimated to be 75-85 minutes.

Would you mind telling the potential participants about my study information? Or, would you prefer I go talk to them?

If yes (they want to talk to patients), I give them the inclusion and exclusion criteria about the participant recruitment in the proposed dissertation study. And then tell them my contact information (including phone number and email address) and thank them for their assistance.

If not, thank them for their time. 


\section{APPENDIX B}

\section{PATIENTS CONTACT SCRIPT}

Hello. My name is Jie Deng. I am a PhD (c) at Vanderbilt University School of Nursing. I am conducting my dissertation study and focusing on swelling/tightness related to head and neck cancer treatment. I would like to tell you about my study if you have a few minutes.

The study is being done to help us better understand swelling/tightness that happens after head and neck cancer treatment. This study would require you to perform the following tasks only one time: (1) filling out some forms that ask you about your symptoms, ability to carry out daily activities, and quality of life; (2) answering questions about your demographic information (e.g., education, insurance) and any treatment you have had for swellings; and (3) your head and neck cancer disease \& treatment information (e.g., date and type of surgery) will be collected from your medical records. In addition, I will evaluate you to see if you have swelling/tightness in your head and neck region, neck range of movement, mouth range of motion, and hearing. The time involved in this study is estimated to be 75-85 minutes.

Do you think you might be interested? (If yes, then screen them using the screening form) Thank you so much. 


\section{APPENDIX C}

\section{SCREENING FORM}

\begin{tabular}{|l|l|l|}
\hline $\begin{array}{l}\text { 1. How old are you? } \\
\text { (Required: To be } 18 \text { and over years of age) }\end{array}$ & Yes-Continue & No-Ineligible \\
\hline 2. Have you had head and neck cancer? & Yes-Continue & No-Ineligible \\
\hline $\begin{array}{l}\text { 3. Have you completed your cancer treatment for more } \\
\text { than } 3 \text { months? } \\
\text { (Last Treatment Date_ }\end{array}$ & Yes-Continue & No-Ineligible \\
\hline $\begin{array}{l}\text { 4. Do you currently have cancer? } \\
\text { 5. Do you currently have any problems understanding } \\
\text { what is taking place around you? }\end{array}$ & No-Continue & Yes-Ineligible \\
\hline $\begin{array}{l}\text { 6. Thank you for answering those questions. It seems } \\
\text { that you are eligible for this research study. Do you have } \\
\text { any questions for me? } \\
\text { (After answering any questions and thanks participants } \\
\text { again for their time). }\end{array}$ & Yes-Ineligible \\
\hline
\end{tabular}

Note: (1) Stop asking questions when the first exclusion criterion is met.

(2) If ineligible, please tell the participants about the following content: "I am sorry that you would not be eligible for this study. Thank you so much for your time”. 


\section{APPENDIX D}

\section{DEMOGRAPHIC AND BACKGROUND INFORMATION FORM}

\section{What is your birthdate?}

_ _ _ _ (month/day/year)

2. Gender:
(1) Female
(2) Male
(3) Other
(4) Do not care to respond

\section{What is your race?}

(1) American Indian/Alaskan Native

(2) Asian

(3) Native Hawaiian or Other Pacific Islander

(4) Black or African American

(5) White

Nation of Origin:

4. What is the highest grade of education you completed? (Please circle)

$\begin{array}{lllllllllll}1 & 2 & 3 & 4 & 5 & 6 & 7 & 8 & 9 & 10 & 11\end{array}$

12 (high school) $13 \quad 14 \quad 15 \quad 16$ (college)

1718 (master) 1920 (doctorate)

\section{What is your marital status?}

(1) Single

(2) Single, living with partner

(3) Married

(4) Widowed

(5) Other

\section{What is your current employment} status?

(1) Employed full time

(2) Employed part time

(3) Homemaker

(4) Retired

(5) Unemployed

(6) Other

Vocation

7. What best describes your area of residence?
(1) City
(2) Country
(3) Other

8. Do you have any special dietary habits?

(1) No

(2) Yes__ (Spicy, Sweet, Sour, etc.)

(Please describe)

\section{Health Maintenance}

9.1 Smoking

(1) No

(2) Yes___ (Tobacco_or Marijuana_or

years cigarettes per day

(3) Quit

(4) Not Quit cigarettes per day (Current)

\subsection{Drinking Alcohol}

(1) No

(2) Yes years times per week

(3) Quit

(4) Not Quit times per week (Current)

10. What is your insurance coverage?
(1) Medicare
(2) Medicaid
(3) TennCare
(4) Private Insurance
(5) $\mathrm{HMO}$
(6) None
(7) Other

11. Do you have any medical problems?

(1) No

(2) Yes (e.g., HBP, DM, Obesity, Injury History)

12. What is your yearly household income?
(1) $\$ 10,000$ or less
(2) $\$ 10,001$ to $\$ 20,000$
(3) $\$ 20,001$ to $\$ 30,000$
(4) $\$ 30,001$ to $\$ 40,000$
(5) $\$ 40,001$ to $\$ 50,000$
(6) $\$ 50,001$ to $\$ 60,000$
(7) Over $\$ 60,000$
(8) Do not care to respond 


\section{APPENDIX E}

HEAD AND NECK CANCER DISEASE \& TREATMENT INFORMATION FORM

\section{Diagnosis}

Date I____ ( $1 \mathrm{~mm} / \mathrm{dd} /$ year $)$

\section{Type}

(Location/Originating cancerous lesions)
(1) Nasal cavity
(2) Paranasal sinuses
(3) Oral cavity
(4) Nasopharynx
(5) Oropharynx
(6) Hypopharynx
(7) Larynx
(8) Salivary gland
(9) Other

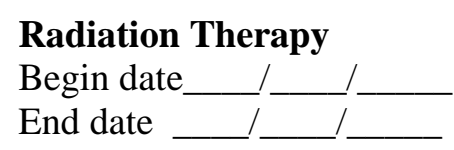

\section{Chemotherapy}

Induction __ None (0) __ some (1)

Number of cycles

End date

Type:

5-FU (1)

Erbitux (Cetuximab) (2)

Cisplation (Platinol) (3)

Docetaxel (Taxotere) (4)

Taxol+Carboplatin (5)

Other (6):

\section{ChemoXRT}

None (0)

Some (1)

Number of cycles

Begin date

End date

Type:

5-FU (1)

Erbitux (Cetuximab) (2)

Cisplation (Platinol) (3)

Docetaxel (Taxotere) (4)

Taxol+Carboplatin (5)

Other (6):

\section{Total treatment received}

(1) Surgery only

(2) Radiotherapy only

(3) Surgery+Radiotherapy

(4) Surgery+ChemoXRT

(5) Chemo-Induction+ChemoXRT

(6) Surgery+Chemo-induction

$$
+ \text { ChemoXRT }
$$

(7) other

Treatment-related complications 


\section{APPENDIX F}

\section{PATTERSON'S SCALE FOR EDEMA IN LARYNX AND PHARYNX}

Based upon your examination of the participant, please use the following scale to grade lymphedema/edema in the laryngopharyngeal structures.

\begin{tabular}{|c|c|c|c|c|}
\hline & \multicolumn{4}{|c|}{ Rating of Edema } \\
\hline & Normal & Mild & Moderate & Severe \\
\hline Structures & & & & \\
\hline 1) Base of tongue & 1) & . & - & - \\
\hline 2) Posterior pharyngeal wall & 2) & {[} & $\overline{-}$ & - \\
\hline 3) Epiglottis & 3) & 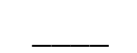 & - & - \\
\hline 4) Pharyngoepiglottic folds & 4) & $\longrightarrow$ & & \\
\hline 5) Aryepiglottic folds & 5) & - & $\square$ & - \\
\hline 6) Interarytenoid space & - & & 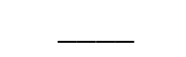 & - \\
\hline 7) Cricopharyngeal prominence & 7) & 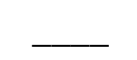 & & \\
\hline 8) Arytenoids & 8) & 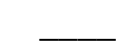 & 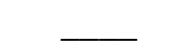 & - \\
\hline 9) False vocal folds & 9) & 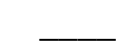 & 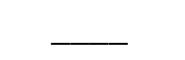 & \\
\hline 10) True vocal folds & 10) & & 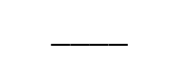 & \\
\hline 11) Anterior commissure & 11) & 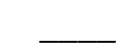 & - & 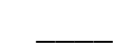 \\
\hline Spaces & Normal & $\begin{array}{r}\text { Mildly } \\
\text { Reduced }\end{array}$ & $\begin{array}{l}\text { Moderately } \\
\text { Reduced }\end{array}$ & $\begin{array}{l}\text { Severely } \\
\text { Reduced }\end{array}$ \\
\hline 12) Valleculae & $12)_{-}$ & 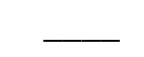 & 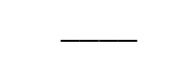 & 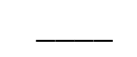 \\
\hline 13) Pyriform sinus & $13)$ & $\underline{-}$ & 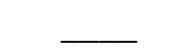 & 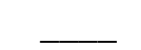 \\
\hline
\end{tabular}




\section{APPENDIX G}

\section{LYMPHEDEMA DISEASE \& TREATMENT INFORMATION FORM}

\section{Do you have swelling/fibrosis?}

No (If met, stop collecting other data)

Yes (If met, continue collecting the following data)

\section{Diagnosis}

Date:______ ( $\quad$ _

Location:

Treatment history

Initial treatment:

No
Yes

Location

Method

Effect

\section{Current treatment:}

No

Yes

Location

Method

Effect

Other information (e.g., self-care, other care providers): 


\section{APPENDIX H}

THE VANDERBILT HEAD AND NECK CANCER SYMPTOM SURVEY (VHNSS)

Directions: Please read all questions and circle the number that best describes your symptoms over the past week. In general, a "0" indicates the least amount of problems with a particular symptom and " 10 " indicates the most problems.

1. I have been losing weight

$\begin{array}{lllllllllllll}\text { None } & 0 & 1 & 2 & 3 & 4 & 5 & 6 & 7 & 8 & 9 & 10 & \text { A lot }\end{array}$

2. I have lost my appetite

$\begin{array}{lllllllllllll}\text { “Normal” } & 0 & 1 & 2 & 3 & 4 & 5 & 6 & 7 & 8 & 9 & 10 & \text { No appetite }\end{array}$ appetite

3. My taste is altered

$\begin{array}{lllllllllllll}\text { None } & 0 & 1 & 2 & 3 & 4 & 5 & 6 & 7 & 8 & 9 & 10 & \text { A lot }\end{array}$

4. I worry about having to get a $\square$ N/A-I already have a PEG tube feeding tube

None $\quad \begin{array}{llllllllllll}0 & 1 & 2 & 3 & 4 & 5 & 6 & 7 & 8 & 9 & 10 & \text { A lot }\end{array}$

5. I have to use liquid supplements (like Ensure ${ }^{\circledR}$ or Boost ${ }^{\circledR}$ ) to maintain my weight

$\begin{array}{lllllllllllll}\text { None } & 0 & 1 & 2 & 3 & 4 & 5 & 6 & 7 & 8 & 9 & 10 & \text { All liquid }\end{array}$ supplements

6. I have trouble maintaining my weight because of my swallowing problem $\begin{array}{lllllllllllll}\text { None } & 0 & 1 & 2 & 3 & 4 & 5 & 6 & 7 & 8 & 9 & 10 & \text { A lot }\end{array}$

7. I have trouble eating certain solid foods (like hard to chew, crumbly, or sticky foods)

$\begin{array}{lllllllllllll}\text { None } & 0 & 1 & 2 & 3 & 4 & 5 & 6 & 7 & 8 & 9 & 10 & \text { A lot }\end{array}$

8. I have trouble drinking thin liquids (like water, tea and Ensure ${ }^{\circledR}$ )

$\begin{array}{lllllllllllll}\text { None } & 0 & 1 & 2 & 3 & 4 & 5 & 6 & 7 & 8 & 9 & 10 & \text { A lot }\end{array}$

9. Food gets stuck in my mouth

$\begin{array}{lllllllllllll}\text { Never } & 0 & 1 & 2 & 3 & 4 & 5 & 6 & 7 & 8 & 9 & 10 & \text { Always }\end{array}$

10. Food gets stuck in my throat

$\begin{array}{lllllllllllll}\text { Never } & 0 & 1 & 2 & 3 & 4 & 5 & 6 & 7 & 8 & 9 & 10 & \text { Always }\end{array}$

11. I choke or strangle on liquids

$\begin{array}{lllllllllllll}\text { Never } & 0 & 1 & 2 & 3 & 4 & 5 & 6 & 7 & 8 & 9 & 10 & \text { Always }\end{array}$

12. I choke or strangle on solid foods

$\begin{array}{lllllllllllll}\text { Never } & 0 & 1 & 2 & 3 & 4 & 5 & 6 & 7 & 8 & 9 & 10 & \text { Always }\end{array}$

13. I cough after I swallow

$\begin{array}{lllllllllllll}\text { Never } & 0 & 1 & 2 & 3 & 4 & 5 & 6 & 7 & 8 & 9 & 10 & \text { Always }\end{array}$

(Continued) 
14. Swallowing takes great effort

$\begin{array}{lllllllllllll}\text { Never } & 0 & 1 & 2 & 3 & 4 & 5 & 6 & 7 & 8 & 9 & 10 & \text { Always }\end{array}$

15. It takes me longer to eat because of my swallowing problem

$\begin{array}{lllllllllllll}\text { Never } & 0 & 1 & 2 & 3 & 4 & 5 & 6 & 7 & 8 & 9 & 10 & \text { Always }\end{array}$

16. I have problems with dry mouth

$\begin{array}{lllllllllllll}\text { None } & 0 & 1 & 2 & 3 & 4 & 5 & 6 & 7 & 8 & 9 & 10 & \text { Severe }\end{array}$

17. Problems with dry mouth make chewing and swallowing difficult

$\begin{array}{lllllllllllll}\text { Never } & 0 & 1 & 2 & 3 & 4 & 5 & 6 & 7 & 8 & 9 & 10 & \text { Always }\end{array}$

18. I have thick mucous / phlegm

$\begin{array}{lllllllllllll}\text { Never } & 0 & 1 & 2 & 3 & 4 & 5 & 6 & 7 & 8 & 9 & 10 & \text { Always }\end{array}$

19. Mucous causes me to choke or gag

$\begin{array}{lllllllllllll}\text { Never } & 0 & 1 & 2 & 3 & 4 & 5 & 6 & 7 & 8 & 9 & 10 & \text { Always }\end{array}$

20. I have difficulty chewing because of my teeth or dentures

$\begin{array}{lllllllllllll}\text { None } & 0 & 1 & 2 & 3 & 4 & 5 & 6 & 7 & 8 & 9 & 10 & \text { Severe }\end{array}$

21. I have sores in my mouth or throat that cause pain

$\begin{array}{lllllllllllll}\text { No pain } & 0 & 1 & 2 & 3 & 4 & 5 & 6 & 7 & 8 & 9 & 10 & \text { Severe }\end{array}$ pain

22. My average overall pain level over the last week has been...

$\begin{array}{lllllllllllll}\text { No pain } & 0 & 1 & 2 & 3 & 4 & 5 & 6 & 7 & 8 & 9 & 10 & \text { Severe }\end{array}$ pain

23. My worst overall pain level over the last week has been...

$\begin{array}{lllllllllllll}\text { No pain } & 0 & 1 & 2 & 3 & 4 & 5 & 6 & 7 & 8 & 9 & 10 & \text { Severe }\end{array}$ pain

24. The average relief from my pain medication is...

$\begin{array}{llllllllllllll}\text { None } & 0 & 1 & 2 & 3 & 4 & 5 & 6 & 7 & 8 & 9 & 10 & \text { Total }\end{array}$

relief

25. My voice is hoarse

$\begin{array}{lllllllllllll}\text { Not at all } & 0 & 1 & 2 & 3 & 4 & 5 & 6 & 7 & 8 & 9 & 10 & \text { Very }\end{array}$

Hoarse

26. I have trouble being understood because of my hoarse voice

$\begin{array}{lllllllllllll}\text { Never } & 0 & 1 & 2 & 3 & 4 & 5 & 6 & 7 & 8 & 9 & 10 & \text { Always }\end{array}$

27. I have trouble with my hearing

$\begin{array}{lllllllllllll}\text { None } & 0 & 1 & 2 & 3 & 4 & 5 & 6 & 7 & 8 & 9 & 10 & \text { Severe }\end{array}$

28. The top three problems bothering me today are:

1.

2.

3. 


\section{APPENDIX I}

\section{HOSPITAL ANXIETY AND DEPRESSION SCALE (HADS)}

This questionnaire is designed to help your healthcare professionals to know how you feel. Please Read each item and circle the one which comes closest to how you have been feeling in the past week. Don't take too long over your replies; your immediate reaction to each item will probably be more accurate than a long thought out response.

\section{I feel tense or "wound up":}
A. Most of the time
B. A lot of the time
C. From time to time, occasionally
D. Not at all

\section{I still enjoy the things I used to enjoy:}
A. Definitely as much
B. Not quite so much
C. Only a little
D. Hardly at all

3. I feel a sort of frightened feeling as if something awful is about to happen:
A. Very definitely and quite badly
B. Yes, but not too badly
C. A little, but it doesn't worry me
D. Not at all

\section{I can laugh and see the funny side of things:}
A. As much as I always could
B. Not quite so much now
C. Definitely not so much now
D. Not at all

\section{Worrying thoughts go through my mind:}
A. A great deal of the time
B. A lot of the time
C. From time to time, but not too often
D. Only occasionally

\section{I feel cheerful:}
A. Not at all
B. Not often
C. Sometimes
D. Most of the time

7. I can sit at ease and feel relaxed:
A. Definitely
B. Usually
C. Not often
D. Not at all 


\section{I feel as if I am slowed down:}
A. Nearly all the time
B. Very often
C. Sometimes
D. Not at all

9. I get a sort of frightened feeling like "butterflies" in the stomach:
A. Not at all
B. Occasionally
C. Quite often
D. Very Often

10. I have lost interest in my appearance:
A. Definitely
B. I don't take as much care as I should
C. I may not take quite as much care
D. I take just as much care as ever

11. I feel restless as I have to be on the move:
A. Very much indeed
B. Quite a lot
C. Not very much
D. Not at all

12. I look forward with enjoyment to things:
A. As much as I ever did
B. Rather less than I used to
C. Definitely less than I used to
D. Hardly at all

13. I get sudden feelings of panic:
A. Very often indeed
B. Quite often
C. Not very often
D. Not at all

14. I can enjoy a good book or radio or TV program:
A. Often
B. Sometimes
C. Not often
D. Very seldom 


\section{APPENDIX J}

\section{BODY IMAGE SCALE (BIS)}

In this questionnaire you will be asked how you feel about your appearance, and about any changes that may have resulted from your disease or treatment. Please read each item carefully, and circle the one choice which comes closest to the way you have been feeling about yourself,

\section{during the past week.}

1. Have you been feeling self-conscious about your appearance?
A. Not at all
B. A little
C. Quite a bit
D. Very much
E. Not Applicable

2. Have you felt less physically attractive as a result of your disease or treatment?
A. Not at all
B. A little
C. Quite a bit
D. Very much
E. Not Applicable

3. Have your been dissatisfied with your appearance when dressed?
A. Not at all
B. A little
C. Quite a bit
D. Very much
E. Not Applicable

4. Have you been feeling less feminine/masculine as a result of your disease or treatment?
A. Not at all
B. A little
C. Quite a bit
D. Very much
E. Not Applicable

5. Did you find it difficult to look at yourself naked?
A. Not at all
B. A little
C. Quite a bit
D. Very much
E. Not Applicable

6. Have you been feeling less sexually attractive as a result of your disease or treatment?
A. Not at all
B. A little
C. Quite a bit
D. Very much
E. Not Applicable

7. Did you avoid people because of the way you felt about your appearance?
A. Not at all
B. A little
C. Quite a bit
D. Very much
E. Not Applicable

8. Have you been feeling the treatment has left your body less whole?
A. Not at all
B. A little
C. Quite a bit
D. Very much
E. Not Applicable

9. Have you felt dissatisfied with your body?
A. Not at all
B. A little
C. Quite a bit
D. Very much
E. Not Applicable

10. Have you been dissatisfied with the appearance of your scar?
A. Not at all
B. A little
C. Quite a bit
D. Very much
E. Not Applicable 
APPENDIX K

WHISPERED VOICE TEST

Whispered Voice Test Results

Fail (0)

Pass (1)

- The examiner stands arm's length $(0.6 \mathrm{~m})$ behind the seated patient and whispers a combination of numbers and letters (for example, 4-K-2) and then asks the patient to repeat the sequence.

- The examiner should quietly exhale before whispering to ensure as quiet a voice as possible.

- If the patient responds correctly, hearing is considered normal; if the patient responds incorrectly, the test is repeated using a different number/letter combination.

- The patient is considered to have passed the screening test if they repeat at least three out of a possible six numbers or letters correctly.

- The examiner always stands behind the patient to prevent lip reading.

- Each ear is tested individually, starting with the ear with better hearing, and during testing the non-test ear is masked by gently occluding the auditory canal with a finger and rubbing the tragus in a circular motion.

- The other ear is assessed similarly with a different combination of numbers and letters. 


\section{APPENDIX L TRISMUS GRADING CRITERIA}

Definition of Trismus: difficulty, restriction or pain when opening mouth

Please check the one that best applies based upon your knowledge of the participant.

Grade 1-- Decreased range of motion without impaired eating

Grade 2--Decreased range of motion requiring small bites, soft foods or purees

Grade 3--Decreased range of motion with inability to adequately aliment or hydrate orally 


\section{CERVICAL RANGE OF MOTION (CROM)}

The participant's CROM parameters:

(1) Forward flexion degrees

(2) Extension degrees

(3) Left lateral flexion degrees

(4) Right lateral flexion degrees

(5) Left lateral rotation degrees

(6) Right lateral rotation____ degrees

Signs in their head/neck/shoulder area:

Elicited Pain

Tenderness

Postural abnormalities

Fixed deformity 


\section{APPENDIX N}

\section{FACT- H\&N (Version 4)}

Below is a list of statements that other people with your illness have said are important. By circling one (1) number per line, please indicate how true each statement has been for you during the past 7 days.

\section{PHYSICAL WELL-BEING}

I have a lack of energy.

I have nausea.

Because of my physical condition, I have trouble meeting the needs of my family...

I have pain. .

I am bothered by side effects of treatment....

GP5

GP6

GP7

I am forced to spend time in bed.

\section{SOCIAL/FAMILY WELL-BEING}

I feel close to my friends

I get emotional support from my family....

I get support from my friends...

My family has accepted my illness.

I am satisfied with family communication about my illness

I feel close to my partner (or the person who is my main support)

Regardless of your current level of sexual activity, please answer the following question. If you prefer not to answer it, please check this box $\square$ and go to the next section.$$
\text { . } 0
$$

0

$$
\begin{array}{lclll}
\text { Not } & \text { A little } & \begin{array}{l}
\text { Some- } \\
\text { at all }
\end{array} \quad \text { bit } & \begin{array}{l}
\text { Quite } \\
\text { what }
\end{array} \text { a bit } & \text { much }
\end{array}
$$

$\begin{array}{lllll}0 & 1 & 2 & 3 & 4 \\ 0 & 1 & 2 & 3 & 4\end{array}$

$\begin{array}{lllll}0 & 1 & 2 & 3 & 4\end{array}$

$\begin{array}{lllll}0 & 1 & 2 & 3 & 4\end{array}$

$\begin{array}{lllll}0 & 1 & 2 & 3 & 4\end{array}$

$\begin{array}{lllll}0 & 1 & 2 & 3 & 4\end{array}$

$\begin{array}{lllll}0 & 1 & 2 & 3 & 4\end{array}$

1

2


By circling one (1) number per line, please indicate how true each statement has been for you during the past 7 days.

EMOTIONAL WELL-BEING

I feel sad.

I am satisfied with how I am coping with

my illness...

I am losing hope in my fight against my illness. $\begin{array}{llllll}0 & 1 & 2 & 3 & 4\end{array}$

I feel nervous............................... $0 \quad 1 \quad 4 \quad 3$

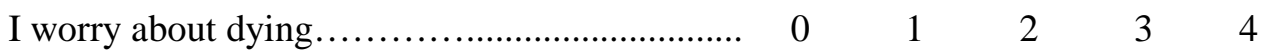

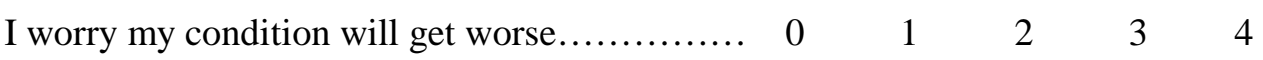

$$
\begin{array}{lclll}
\text { Not } & \text { A little } & \text { Some- } & \text { Quite } & \text { Very } \\
\text { at all } & \text { bit } & \begin{array}{l}
\text { what } \\
\text { a bit }
\end{array} \text { much }
\end{array}
$$

$\begin{array}{lllll}0 & 1 & 2 & 3 & 4\end{array}$

$\begin{array}{lllll}0 & 1 & 2 & 3 & 4\end{array}$

\section{FUNCTIONAL WELL-BEING}

I am able to work (include work at home)

My work (include work at home) is fulfilling....

I am able to enjoy life

I have accepted my illness.

I am sleeping well

I am enjoying the things I usually do for fun.....

I am content with the quality of my life

right now. 
By circling one (1) number per line, please indicate how true each statement has been for you during the past 7 days.

\section{ADDITIONAL CONCERNS}

$\begin{array}{lclll}\text { Not A little } & \begin{array}{l}\text { Some- } \\ \text { at all }\end{array} \text { bit } & \begin{array}{l}\text { Quite } \\ \text { what a bit }\end{array} & \text { much }\end{array}$

\begin{tabular}{|c|c|c|c|c|}
\hline $\mathrm{H} \& \mathrm{~N} 1$ & I am able to eat foods I like...................... 0 & 1 & 2 & 3 \\
\hline $\mathrm{H} \& \mathrm{~N} 2$ & My mouth is dry.............................. 0 & 1 & 2 & 3 \\
\hline $\mathrm{H} \& \mathrm{~N} 3$ & I have trouble breathing........................ 0 & 1 & 2 & 3 \\
\hline $\mathrm{H} \& \mathrm{~N} 4$ & My voice has its usual quality and strength........ 0 & 1 & 2 & 3 \\
\hline H\&N 5 & I am able to eat as much food as I want............ 0 & 1 & 2 & 3 \\
\hline H\&N 6 & I am unhappy with how my face and neck looks... 0 & 1 & 2 & 3 \\
\hline $\mathrm{H} \& \mathrm{~N} 7$ & I can swallow naturally and easily................ 0 & 1 & 2 & 3 \\
\hline $\mathrm{H} \& \mathrm{~N} 8$ & I smoke cigarettes and tobacco products........... 0 & 1 & 2 & 3 \\
\hline H\&N 9 & I drink alcohol (e.g. beer, wine, etc.)............... & 1 & 2 & 3 \\
\hline $\mathrm{H} \& \mathrm{~N} 10$ & I am able to communicate with others............ 0 & 1 & 2 & 3 \\
\hline H\&N11 & I can eat solid foods............. & 1 & 2 & 3 \\
\hline H\&N12 & I have pain in my mouth, throat or neck........... 0 & 1 & 2 & 3 \\
\hline
\end{tabular}




\section{APPENDIX O}

\section{QUALITY OF LIFE SCALE (LINEAR ANALOG SELF ASSESSMENT)}

Directions: Please circle the number (0-10) best reflecting your response to the following that describes your feelings during the past week, including today.

1. How would you rate your physical well being over the past week?

This question refers to such things as fatigue, activity, etc.

$\begin{array}{lllllllllc}\begin{array}{c}0 \\ \begin{array}{l}\text { As bad as } \\ \text { can be }\end{array}\end{array} & 1 & 2 & 3 & 4 & 5 & 6 & 7 & 8 & 9 \begin{array}{c}10 \\ \text { As good as it } \\ \text { it can be }\end{array}\end{array}$

2. How would you rate your emotional well being over the past week?

This question refers to such things as depression, anxiety, stress, etc.

$\begin{array}{ccccccccccc}\begin{array}{c}0 \\ \begin{array}{l}\text { As bad as } \\ \text { can be }\end{array}\end{array} & 1 & 2 & 3 & 4 & 5 & 6 & 7 & 8 & 9 \begin{array}{c}10 \\ \text { As good as it } \\ \text { it can be }\end{array} \\ \end{array}$

3. How would you rate your spiritual well being over the past week?

This question refers to such things as a sense of meaning and purpose, relationship with God, etc.

$\begin{array}{ccccccccccc}\begin{array}{c}0 \\ \text { As bad as } \\ \text { can be }\end{array} & 1 & 2 & 3 & 4 & 5 & 6 & 7 & 8 & 9 \begin{array}{c}10 \\ \text { As good as it } \\ \text { it can be }\end{array}\end{array}$

4. How would you rate your intellectual well being over the past week?

This question refers to such things as the ability to think clearly, to concentrate, to remember, etc.

$\begin{array}{lllllllllll}0 & 1 & 2 & 3 & 4 & 5 & 6 & 7 & 8 & 9 & 10\end{array}$

As bad as

can be

As good as it

it can be

5. How would you rate your overall well being over the past week?

$\begin{array}{lllllllllll}0 & 1 & 2 & 3 & 4 & 5 & 6 & 7 & 8 & 9 & 10\end{array}$

As bad as

can be

As good as it

it can be 


\section{REFERENCES}

About Lymphedema Sleeves/Garments. (2008). Retrieved October 10, 2008, from http://www.simmsmanncenter.ucla.edu/reflections/section/lymphedema.asp

Air Travel \& Lymphedema. (2008). Retrieved July 4, 2008, from http://www.lymphnet.org/pdfDocs/nlnairtravel.pdf

American Academic of Otolaryngology-Head and Neck Surgery [AAO-HNS]. (2008). Head and neck cancer. Retrieved March 10, 2008, from http://www.entnet.org/healthinfo/tobacco/cancer.cfm

American Cancer Society [ACS]. (2006). Lymphedema: Understanding and managing lymphedema after cancer treatment. Atlanta, GA: American Cancer Society.

American Cancer Society [ACS]. (2007). Signs and symptoms. Retrieved March 10, 2008, from http://www.cancer.org/docroot

American Cancer Society [ACS]. (2008). Cancer facts \& figures 2008. Retrieved April 16, 2008, from http://www.cancer.org/docroot/PRO/content/PRO_1_1_Cancer_Statistics_2008

American Cancer Society [ACS]. (2009). Cancer facts \& figures 2009. Retrieved May 12, 2009, from http://www.cancer.org/downloads/STT/500809web.pdf

Argiris, A., Karamouzis, M.V., Raben, D., \& Ferris, R.L. (2008). Head and neck cancer. Lancet, 371, 1695-1709.

Armer, J. M., \& Whitman, M. (2002). The problem of lymphedema following breast cancer treatment: Prevalence, symptoms, and self-management. Lymphology, 35(Suppl), 153-159.

Armer, J.M., Radina, M.E., Porock, D., \& Culbertson, S.D. (2003). Predicting breast cancer-related lymphedema using self-reported symptoms. Nursing Research, 52(6), 370-379.

Augustin, M., Bross, F., Foldi, E., Vanscheidt, W., \& Zschocke, I. (2005). Development, validation and clinical use of the FLQA-l, a disease-specific quality of life questionnaire for patients with lymphedema. Vasa, 34(1), 31-35.

Avraham,T., Yan, A., Zampell, J.C., Daluvoy, S.V., Haimovitz-Friedman, A., Cordeiro, A.P., et al. (2010). Radiation therapy causes loss of dermal lymphatic vessels and interferes with lymphatic function by TGF- $\beta 1$ mediated tissue fibrosis. American Journal of Physiology. Cell Physiology, [Epub ahead of print]. 
Avraham, T., Clavin, N.W., Daluvoy, S.V., Fernandez, J., Soares, M.A., Cordeiro, A.P., et al. (2009). Fibrosis is a key inhibitor of lymphatic regeneration. Plastic and Reconstructive Surgery, 124(2), 438-450.

Basch, E., Lasonos, A., McDonoough, T., Barz, A. Culkin, A., Kris, M.G., et al. (2006). Patient versus clinician symptom reporting using the National Cancer Institute Common Terminology Criteria for adverse events: Results of a questionnaire-based study. Lancet Oncology, 7, 903-900.

Bensadoun, R.J., Riesenbeck, D., Lockhart, P.B., Elting, L.S., Spijkervet, F.K., \& Brennan, M.T. (2010). A systematic review of trismus induced by cancer therapies in head and neck cancer patients. Supportive Care in Cancer, [Epub ahead of print].

Bentzen, S.M., Dörr, W., Anscher, M.S., Denham, J.W., Hauer-Jensen, M., Marks, L.B., et al. (2003). Normal tissue effects: Reporting and analysis. Seminars in Radiation Oncology,13(3), 189-202.

Biology-online. (2005). Function. Retrieved March 10, 2008, from http://www.biology-online.org/dictionary/Function

Bjelland, I., Dahl, A.A., Haug, T.T., \& Neckelmann, D. (2002).The validity of the Hospital Anxiety and Depression Scale. An updated literature review. Journal of Psychosomatic Research, 52(2), 69-77.

Bjordal, K., Hammerlid, E., Ahlner-Elmqvist, M., de Graeff, A., Boysen, M., Evensen, J.F., et al. (1999). Quality of life in head and neck cancer patients: Validation of the European Organization for Research and Treatment of Cancer Quality of Life Questionnaire-H\&N35. Journal of Clinical Oncology, 17(3), 1008-1019.

Bruner, L.H., Carr, G.J., Curren, R.D., \& Chamberlain, M. (1998). Validation of alternative methods for toxicity testing. Environmental Health Perspectives, 106 (Suppl 2), 477-484.

Bruns, F., Micke, O., \& Bremer, M. (2003). Current status of selenium and other treatments for secondary lymphedema. Journal of Supportive Oncology, 1(2), 121-130.

Bruns, F., Buntzel, J., Mucke, R., Schonekaes, K., Kisters, K., \& Micke, O. (2004). Selenium in the treatment of head and neck lymphedema. Medical Principles and Practice, 13(4), 185-190.

Buntzel, J., Glatzel, M., Mucke, R., Micke, O., \& Bruns, F. (2007). Influence of amifostine on late radiation-toxicity in head and neck cancer-a follow-up study. Anticancer Research, 27(4A), 1953-1956.

Carter, B.J. (1997). Women’s experiences of lymphedema. Oncology Nursing Forum, 
24, 875-882.

Casey, P., Maracy, M., Kelly, B.D., Lehtinen, V., Ayuso-Mateos, J-L., Dalgard, O.S., et al. (2006). Can adjustment disorder and depressive episode be distinguished? Results from ODIN. Journal of Affective Disorders, 92, 291-297.

Cash, T.F., \& Pruzinsky, T. (2002). Body image: A handbook of theory, research, and clinical practice. New York: Guilford Press.

Center for Disease Control and Prevention [CDC]. (2009). Alcohol use. Retrieved June 28, 2010, from http://www.cdc.gov/nchs/fastats/alcohol.htm

Cheville, A.L., McGarvey, C.L., Petrek, J.A., Russo, S.A., Thiadens, S.R.J., \& Taylor, M.E. (2003). The grading of lymphedema in oncology clinical trials. Seminars in Radiation Oncology, 13, 214-225.

Chopra, R.R., \& Bogart, J.A. (2010). Radiation therapy-related toxicity (including pneumonitis and fibrosis). Hematology/Oncology Clinics of North America, 24(3), 625-642.

Clark, B., Sitzia, J., \& Harlow, W. (2005). Incidence and risk of arm oedema following treatment for breast cancer: A three-year follow-up study. The Quarterly Journal of Medicine, 98, 343-348.

Code of Ethics for Nurses. (2008). Retrieved March 10, 2008, from http://www.nursingworld.org/MainMenuCategories/ThePracticeofProfessional Nursing/EthicsStandards/CodeofEthics.aspx

Coopee, R. (2008). Use of “elastic taping” in the treatment of head and neck lymphedema. National Lymphedema Network Lymph Link, 20(4), 3-4.

Coreil, J., Wilke, J., \& Pintado, I. (2004). Cultural models of illness and recovery in breast cancer support groups. Qualitative Health Research, 14, 905-923.

Coward, D. (1999). Lymphedema prevention and management knowledge in women treated for breast cancer. Oncology Nursing Forum, 26, 1047-1053.

CTCAE v3.0. (2006). Retrieved December 15, 2008, from http://ctep.cancer.gov/protocolDevelopment/electronic_applications/docs/ctcaev 3.pdf

D’Antonio, L.L., Zimmerman, G.J., Cella, D.F., \& Long, S.A. (1996). Quality of life and functional status measures in patients with head and neck cancer. Archives of Otolaryngology - Head \& Neck Surgery, 122, 482-487. 
Davis, A., Dische, S., Gerber, L., Saunders, M., Leung, S., \& O’Sulliven, B. (2003). Measuring postirradiation subcutaneous soft-tissue fibrosis: State-of-the-art and future directions. Seminars in Radiation Oncology, 13(3), 203-213.

De Koning C.H., van den Heuvel S.P., Staal, J.B., Smits-Engelsman, B.C., \& Herdriks, E.J. (2008). Clinimetric evaluation of active range of motion measures in patients with non-specific neck pain: A systemic review. European Spine Journal, 17(7), 905-921.

Deimling, G.T., Bowman, K.F., Sterns, S., Wagner, L.J., \& Kahana, B. (2006). Cancer-related health worries and psychological distress among older adult, long-term cancer survivors. Psycho-Oncology, 15, 306-320.

Dennert, G., \& Horneber, M. (2007). Selenium for alleviating the side effects of chemotherapy radiotherapy and surgery in cancer patients (Review). The Cochrane Library, 3, 1-19.

Deo, S.V., Ray, S., Rath, G.K., Shukla, N.K., Kar, M., Asthana, S., et al. (2004). Prevalence and risk factors for development of lymphedema following breast cancer treatment. Indian Journal of Cancer, 41, 8-12.

Derogatis, L.R., Morrow, G.R., Fetting, D., Penman, S., Piasetsky, A.M., Schmale, M., et al. (1983). The prevalence of psychiatric disorders among cancer patients. Journal of the American Medical Association, 49, 751-756.

Dietz, A., Rudat, V., Nollert, J., Helbig, M., Vanselow, B., \& Weidauer, H. (1998). Chronic laryngeal edema as a late reaction to radiochemotherapy. HNO, 46(8):731-738.

Dijkstra, P.U., Kalk, W.W., \& Roodenburg, J.L. (2004). Trismus in head and neck oncology: A systematic review. Oral Oncology, 40(9), 879-889.

Dirix, P., Nuyts, S., Vander Poorten, V., Delaere, P., \& Van den Bogaert ,W. (2008). The influence of xerostomia after radiotherapy on quality of life: Results of a questionnaire in head and neck cancer. Support Care in Cancer,16(2), 171-179.

Donatelli-Lassig, A. A., Duffy, S. A., Fowler, K. E., Ronis, D. L., Chepeha, D. B., \& Terrell, J. E. (2008). The effect of neck dissection on quality of life after chemoradiation. Otolaryngology-Head and Neck Surgery, 139(4), 511-518.

Dos, J., Gorska-Dos, M., \& Szuba, A. (2005). The integrated and interdisciplinary treatment of chronic lymphedema. Roczniki Akademii Medycznej w Bialymstoku, 50(Suppl 1), 141-144.

Eisbruch, A., Schwartz, M., Rasch, C., Vineberg, K., Damen, E., Van As, C. J., et al. (2004). Dysphagia and aspiration after chemoradiotherapy for head-and-neck 
cancer: Which anatomic structures are affected and can they be spared by IMRT? International Journal of Radiation Oncology, Biology, Physics, 60(5), 14251439.

Eisele, D.W., Koch, D.G., Tarazi, A.E., \& Jones, B. (1991). Case report: Aspiration from delayed radiation fibrosis of the neck. Dysphagia, 6(2), 120-122.

El-Deiry, M. W., Futran, N. D., McDowell, J. A., Weymuller, E. A.Jr., \& Yueh, B. (2009). Influences and predictors of long-term quality of life in head and neck cancer survivors. Archives of Otolaryngology-Head \& Neck Surgery, 135(4), 380-384.

Fadol, A., Mendoza, T., Gning, I., Kernicki, J., Symes, L., Cleeland, C.S., et al. (2008). Psychometric testing of the MDASI-HF: A symptom assessment instrument for patients with cancer and concurrent heart failure. Journal of Cardiac Failure, 14(6), 497-507.

Ferlito, A., Johnson, J.T., Rinaldo, A., Pratt, L.W., Fagan, J.J., Weir, N., et al. (2007). European surgeons were the first to perform neck dissection. Laryngoscope, 117, 797-802.

Fix, J.D. (2002). Neuroanatomy ( $3^{\text {rd }}$ ed.). Philadelphia: Lippincott Williams \& Wilkins.

Foldi, M. (2001). Lymphology in the second millennium. Lymphology, 34(1), 12-21.

Foldi, M., Foldi, E., \& Kubik, S. (2003). Textbook of Lymphology. Muchen, Germany: Urban \& Fischer.

Foldi, M., Foldi, E., Strobenreuther, R.H.K., \& Kubik, S. (2006). Foldi's textbook of lymphology $\left(2^{\text {nd }}\right.$ ed.). Muchen, Germany: Urban \& Fischer.

Funk, G.F., Karnell, L.H., Christensen, A.J., Moran, P.J., \& Ricks, J. (2003). Comprehensive head and neck oncology health status assessment. Head \& Neck, 7, 561-575.

Geller, B.M., Vacek, P.M., O’Brien, P., \& Secker-Walker, R.H. (2003). Factors associated with arm swelling after breast cancer surgery. Journal of Women's Health, 12(9), 921-930.

Gourin, C.G., \& Podolsky, R.H. (2006). Racial disparities in patients with head and neck squamous cell carcinoma. Laryngoscope, 116(7), 1093-1106.

Gourin, C.G., Boyce, B.J., Vaught, C.C., Burkhead, L.M., \& Podolsky, R.H. (2009). Effect of comorbidity on post-treatment quality of life scores in patients with head and neck squamous cell carcinoma. Laryngoscope, 119(5), 907-914. 
Graeff, A., Leeuw, J.R., Ros, W.J., Hordijk, G.J., Blijham, G.H., \& Winnubst, J.A. (2000). Long-term quality of life of patients with head and neck cancer. Laryngoscope, 110(1), 98-106.

Graham, P.H. (2002). Compression prophylaxis may increase the potential for flightassociated lymphoedema after breast cancer treatment. Breast, 11, 66-71.

Hadamitzky, C., \& Pabst, R. (2008). Acquired lymphedema: An urgent need for adequate animal models. Cancer Research, 68(2), 343-345.

Hammond, T. (2007). Symptoms of head and neck edema. Retrieved January 10, 2008, from http://www.lymphnotes.com/article.php/id/378/

Hapner, E.R., \& Wise, J.C. (2010). Results of a large-scale head and neck cancer screening of an at-risk population. Journal of Voice, [Epub ahead of print].

Hashibe, M., Brennan, P., Benhamou, S., Castellsague, X., Chen, C., Curado, M. P., et al. (2007). Alcohol drinking in never users of tobacco, cigarette smoking in never drinkers, and the risk of head and neck cancer: Pooled analysis in the international head and neck cancer epidemiology consortium. Journal of the National Cancer Institute, 99(10), 777-789.

Hassan, S.J., \& Weymuller, E.A. Jr. (1993). Assessment of quality of life in head and neck cancer patients. Head \& Neck, 15(6), 485-496.

Hayes, S.C., Janda, M., Cornish, B., Battistutta, D., \& Newman, B. (2008). Lymphedema after breast cancer: Incidence, risk factors, and effect on upper body function. Journal of Clinical Oncology, 26, 3536-3542.

Head and Neck Cancer. (2008). Retrieved October 10, 2008, from http://www.oncologychannel.com/headneck/index.shtml

Healthy People 2010. (2000). Retrieved November 20, 2007, from http://www.healthy people.gov

Heppner, P.P., Tierney, C.G., Wang, Y.W., Armer, J.M., Whitlow, N.M., \& Reynolds, A. (2009). Breast cancer survivors coping with lymphedema: What all counselors need to know. Journal of Counseling \& Development, 87(3), 327338.

Herd-Smith, A., Russo, A., Muraca, M.G., Turco, M.R.D., \& Cardona, G. (2001). Prognostic factors for lymphedema after primary treatment of breast carcinoma. Cancer, 92, 1783-1787.

Hettrick, H., Nof, L., Ward, S., \& Echernach, J. (2004). Incidence and prevalence of lymphedema in patients following burn injury: A five-year retrospective and three-month prospective study. Lymphatic Research and Biology, 2(1), 11-24. 
Hinrichs, C.S., Watroba, N.L., Rezaishiraz, H., Giese, W., Hurd, T., Fassl, K.A., et al. (2004). Lymphedema secondary to postmastectomy radiation: Incidence and risk factors. Annals of Surgical Oncology, 11(6), 573-580.

Hitchcock, Y.J., Tward, J.D., Szabo, A., Bentz, B.G., \& Shrieve, D.C. (2009). Relative contributions of radiation and cisplatin-based chemotherapy to sensorineural hearing loss in head-and-neck cancer patients. International Journal of Radiation Oncology, Biology, Physics, 73(3),779-788.

Holcomb, S.S. (2006). Identification and treatment of different types of lymphedema. Advances in Skin and Wound Care, 19, 103-108.

Hopwood, P., Fletcher, I., Lee, A., \& Ghazal, S. A. (2001). A body image scale for use with cancer patients. European Journal of Cancer, 37, 189-197.

Hormes, J.M., Lytle, L.A., Gross, C.R., Ahmed, R.L., Troxel, A.B., \& Schmitz, K.H. (2008). The body image and relationships scale: Development and validation of a measure of body image in female breast cancer survivors. Journal of Clinical Oncology, 26(8), 1269-1274.

Hsiung, C.Y., Huang, E.Y., Ting, H.M., \& Huang, H.Y. (2008). Intensity-modulated radiotherapy for nasopharyngeal carcinoma: The reduction of radiationinduced trismus. The British Journal of Radiology, 81(970), 809-814.

Huth, M.M., \& Broome, M. E. (2007). A snapshot of children’s postoperative tonsillectomy outcomes at home. Journal for Specialists in Pediatric Nursing, 12(3), 186-195.

Itano, J., \& Taoka, K.N. (2005). Core curriculum for oncology nursing (4 $4^{\text {th }}$ ed.). W.B. Saunders Company.

Jager, G., Doller, W., \& Roth, R. (2006). Quality-of-life and body image impairments in patients with lymphedema. Lymphology, 39(4), 193-200.

Jager-Wittenaar, H., Dijkstra, P.U., Vissink, A., van der Laan, B.F.A.M., van Oort, R.P., \& Roodenburg, J.L.N. (2007). Critical weight loss in head and neck cancer-prevalence and risk factors at diagnosis: An explorative study. Support Care Cancer, 15, 1045-1050.

Jemal, A., Siegel, R., Ward, E., Murray, T., Xu, J., \& Thun, M.J. (2007). Cancer statistics 2007. A Cancer Journal for Clinicians, 57(1), 43-66.

Jereczek-Fossa, B.A., Zarowski, A., Milani, F., \& Orecchia, R. (2003). Radiotherapyinduced ear toxicity. Cancer Treatment Reviews, 29(5), 417-430.

Jung, H.M., \& Cho, M.O. (2006). Factors influencing the emotional state of patients 
with lymphedema. Taehan Kanho Kakhoe Chi, 36(5), 845-852.

Kangas, M., Henry, J.L., \& Bryant, R.A. (2002). Posttraumatic stress disorder following cancer: A conceptual and empirical review. Clinical Psychology Review, 22, 499-524.

Kangas, M., Henry, J.L., \& Bryant, R.A. (2005). The course of psychological disorders in the $1^{\text {st }}$ year after cancer diagnosis. Journal of Consulting and Clinical Psychology, 73(4), 763-768.

Kinney, C.K., Rodgers, D.M., Nash, K.A., \& Bray, C.O. (2003). Holistic health for women with breast cancer through a mind, body, and spirit self-empowerment program. Journal of Holistic Nursing, 21, 260-279.

Kosir, M. A., Rymal, C., Koppolu, P., Hryniuk, L., Darga, L., Du, W., et al. (2001). Surgical outcomes after breast cancer surgery: Measuring acute lymphedema. Journal of Surgical Research, 95(2), 147-151.

Kroenke, K. (2003). The interface between physical and psychological symptoms. Primary Care Companion to the Journal of Clinical Psychiatry, 5(Suppl 7), 11-18.

Langendijk, J. A., Doornaert, P., Verdonck-de Leeuw, I. M., Leemans, C. R., Aaronson, N. K., \& Slotman, B. J. (2008). Impact of late treatment-related toxicity on quality of life among patients with head and neck cancer treated with radiotherapy. Journal of Clinical Oncology, 26(22), 3770-3776.

Launois, R. Mègnigbêto, A.C., Pocquet, K., \& Alliot, F. (2002). A specific quality of life scale in upper limb lymphedema : The ULL-27 questionnaire, Lymphology 35(Suppl), 181-187.

Lenz, E.R., Suppe, F., Gift, A.G., Pugh, L.C., \& Milligan, R.A. (1995). Collaborative development of middle-range theory: Toward a theory of unpleasant symptoms. Advances in Nursing Science, 17(3), 1-13.

Lenz, E., Pugh, L., Milligan, R., Gift, A., \& Suppe, F. (1997).The middle-range theory of unpleasant symptoms: An update. Advances in Nursing Science, 19(3), 14-27.

Lewis, M., \& Morgan, K. (2008). Managing chronic oedema: A collaborative community approach. British Journal of Community Nursing, 13(4), S25-26, S2832.

Liehr, P. (2005). Looking at symptoms with a middle-range theory lens. Advanced Studies in Nursing, 3(5), 152-157.

List, M.A., D’Antonio, L.L., Cella, D.F., Siston, A., Mumby, P., Haraf, D., et al. 
(1996). The performance status scale for head and neck cancer patients and the functional assessment of cancer therapy-Head and neck scale. A study of utility and validity. Cancer, 77(11), 2294-2301.

Liu, H.E. (2006). Fatigue and associated factors in hemodialysis patients in Taiwan. Research in Nursing \& Health, 29(1), 40-50.

Locke, D.E., Decker, P.A., Sloan, J.A., Brown, P.D., Malec, J.F., Clark, M.M., et al. (2007). Validation of single-item linear analog scale assessment of quality of life in neuro-oncology patients. Journal of Pain and Symptom Management, 34(6), 628-638.

Lymphoedema Framework (2006). Best practice for the management of lymphoedema. International consensus. London: MEP Ltd.

Machtay, M., Rosenthal, D.I., Chalian, A.A., Lustig, R., Hershock, D., Miller, L., et al. (2004). Pilot study of postoperative reirradiation, chemotherapy, and amifostine after surgical salvage for recurrent head-and-neck cancer. International Journal of Radiation Oncology, Biology, Physics, 59(1), 72-77.

Machtay, M., Moughan, J., Trotti, A., Garden, A.S., Weber, R.S., Cooper, J.S., et al. (2008). Factors associated with severe late toxicity after concurrent chemoradiation for locally advanced head and neck cancer: An RTOG analysis. Journal of Clinical Oncology, 26(21), 3582-3589.

Mallick, I., \& Waldron, J.N. (2009). Radiation therapy for head and neck cancers. Seminars in Oncology Nursing, 25(3), 193-202.

Manikantan, K., Khode, S., Sayed, S.I., Roe, J., Nutting, C.M., Rhys-Evans, P., et al. (2009). Dysphagia in head and neck cancer. Cancer Treatment Reviews, 35(8), 724-732.

Marrs, J. (2007). Lymphedema and implications for oncology nursing practice. Clinical Journal of Oncology Nursing, 11(1), 19-21.

Matorin, P.A. (1994). Lymphatic malformations of the head and neck. Retrieved January 10, 2008, from http://www.bcm.edu/oto/grand/61694.html

Mayerson, H.S. (1969). Three centuries of lymphatic history-an outline. Lymphology, 2, 143-150.

McLaughlin, S.A., Wright, M.J., Morris, K.T., Giron, G.L., Sampson, M.R., Brockway, J.P., et al. (2008). Prevalence of lymphedema in women with breast cancer 5 years after sentinel lymph node biopsy or axillary dissection: Objective measurements. Journal of Clinical Oncology, 26, 5213-5219.

Meeske, K.A., Sullivan-Halle, J., Smith, A.W., McTiernan, A., Baumgartner, K.B., 
Harlan, L.C., et al. (2009). Risk factors for arm lymphedema following breast cancer diagnosis in Black women and White women. Breast Cancer Research and Treatment, 113, 383-391.

Merriam-Webster Dictionary. (2007). Lymphedema. Retrieved March 10, 2008, from http://www.merriam-webster.com/dictionary/lymphedema

Merriam-Webster's Medical Dictionary. (2008). Sign. Retrieved October 6, 2008, from http://medical.merriam-webster.com/medical/sign

Micke, O., Bruns, F., Mucke, R., Schafer, U., Glatzel, M., DeVries, A.F., et al. (2003). Selenium in the treatment of radiation-associated secondary lymphedema. International Journal of Radiation Oncology, Biology, Physics, 56(1), 40-49.

Miracle, V.A. (2008). The life and impact of Florence Nightingale. Dimensions of Critical Care Nursing, 27(1), 21-23.

Moorey, S., Greer, S., Watson, M., Gorman, C., Rowden, L., Tunmore, R., et al. (1991). The factor structure and factor stability of the Hospital Anxiety and Depression Scale in patients with cancer. British Journal of Psychiatry, 158, 255-259.

Morgan, P.A., Franks, P.J., \& Moffatt, C.J. (2005). Health-related quality of life with lymphoedema: A review of the literature. International Wound Journal, 2(1), 4762.

Morton, R.P., Davis, A.D., Baker, J., Baker, G.A., \& Stell, P.M. (1984). Qualify of life in treated head and neck cancer patients: A preliminary report. Clinical Otolaryngology, 9, 181-185.

Mouth Cancer Foundation [MCF]. (2008). Mouth cancer and the human papilloma virus. Retrieved March 10, 2008, from http://www.rdoc.org.uk/hpv.html

Murphy, B.A., Wells, N.L., Cmelak, A.J., Netterville, J.L., Burkey, B.B., \& Smith, K.Z. (2004). Reliability and validity for the Vanderbilt Head and Neck Symptom Survey (VHNSS): A new tool to assess symptom burden in patients undergoing chemoradiation. Journal of Clinical Oncology, 22(14S), 5569.

Murphy, B.A., Gilbert, J., \& Ridner, S.H. (2007a). Systemic and global toxicities of head and neck treatment. Expert Review of Anticancer Therapy, 7(7), 1043-1053.

Murphy, B.A., Ridner, S., Wells, N., \& Dietrich, M. (2007b). Quality of life research in head and neck cancer: A review of the current state of the science. Clinical Review in Oncology Hematology, 62, 251-267.

Murphy, B.A., \& Gilbert, J. (2009). Dysphagia in head and neck cancer patients treated with radiation: Assessment, sequelae, and rehabilitation. Seminars in Radiation Oncology, 19(1), 35-42. 
Murphy, B.A., Beaumont, J.L., Isitt, J., Garden, A.S., Gwede, C.K., Trotti, A.M., et al. (2009). Mucositis-related morbidity and resource utilization in head and neck cancer patients receiving radiation therapy with or without chemotherapy. Journal of Pain and Symptom Management, 38(4), 522-532.

Murphy, B.A., Dietrich, M.S., Wells, N., Dwyer, K., Ridner, S.H., Silver, H.J., et al. (2010). Reliability and validity of the Vanderbilt Head and Neck Symptom Survey: A tool to assess symptom burden in patients treated with chemoradiation. Head \& Neck, 32(1), 26-37.

Nakamura, K., Radhakrishnan, K., Wong, Y.M., \& Rockson, S.G. (2009). Antiinflammatory pharmacotherapy with ketoprofen ameliorates experimental lymphatic vascular insufficiency in mice. PLoS One, 4(12), e8380.

National Anemia Action Council [NAAC]. (2008). Quality of life. Retrieved October 20, 2008, from http://www.anemia.org/patients/glossary/

National Cancer Institute [NCI]. (2007a). Lymphedema. Retrieved March 10, 2008, from http://www.cancer.gov/cancertopics/pdq/supportivecare/lymphedema/Patient

National Cancer Institute [NCI]. (2007b). Head and neck cancer. Retrieved March 10, 2008, from http://www.cancer.gov/cancertopics/factsheet/sites-types/head-andneck

National Cancer Institute [NCI]. (2007c). Head and neck cancer. Retrieved June 16, 2010, from http://seer.cancer.gov/csr/1975_2007/results_merged/topic_survival.pdf

National Cancer Institute [NCI]. (2008a). Psychosocial distress. Retrieved April 15, 2008, from

http://www.cancer.gov/cancertopics/pdq/supportivecare/adjustment/HealthProfes sional/page4

National Cancer Institute [NCI]. (2008b). Mood disturbance. Retrieved April 15, 2008, from

http://www.cancer.gov/cancertopics/pdq/supportivecare/adjustment/HealthProfes sional /page5

National Cancer Institute [NCI]. (2008c). Risk factor. Retrieved April 15, 2008, from http://www.cancer.gov/dictionary/?searchTxt=risk+factor\&sgroup=

National Cancer Institute [NCI]. (2010). Snapshot of head and neck cancer. Retrieved June 15, 2010 from http://www.cancer.gov/aboutnci/servingpeople/snapshots/head-neck.pdf 
National Lymphedema Network [NLN]. (2005a). Training of lymphedema therapists. Retrieved April 15, 2008, from http://www.lymphnet.org/lymphedemaFAQs/positionPapers.htm

National Lymphedema Network [NLN]. (2005b). Change to medicare reimbursement ruling. Retrieved April 15, 2008, from http://www.lymphnet.org/lymphedemaFAQs/legislation/actionAlert/legMedicare .$h t m$

Nielsen, I., Gordon, S., \& Selby, A. (2008). Breast cancer-related lymphoedema risk reduction advice: A challenge for health professionals. Cancer Treatment Reviews, 34, 621-628.

Oates, J., Clark, J.R., Read, J., Reeves, N., Gao, K., \& O'Brien, C.J. (2008). Integration of prospective quality of life and nutritional assessment as routine components of multidisciplinary care of patients with head and neck cancer. ANZ Journal of Surgery, 78(1-2), 34-41.

Oishi, K.J. (2007). New paradigms in the treatment of head and neck cancers. Continuing education regional symposium for oncology nurses. Retrieved January 10, 2008, from http://www.imeronline.com/2007_regional_tour/247_symposia.html

ONS Research Agenda (2009-2013). Retrieved March 15, 2010, from http://www.ons.org/media/ons/docs/research/20092013onsresearchagendaexecutivesummary.pdf

O’Sullivan, B., \& Levin, W. (2003). Late radiation-related fibrosis: Pathogenesis, manifestations, and current management. Seminars in Radiation Oncology, 13, 274-289.

Park, J.H., Lee, W.H., \& Chung, H.S. (2008). Incidence and risk factors of breast cancer lymphoedema. Journal of Clinical Nursing, 17(11), 1450-1459.

Paskett, E.D., Naughton, M.J., McCoy, T.P., Case, L.D., \& Abbott, J.M. (2007). The epidemiology of arm and hand swelling in premenopausal breast cancer survivors. Cancer Epidemiology Biomarkers \& Prevention, 16(4), 775-782.

Passik, S.D., Newman, M.L., Brennan, M., \& Tunkel, R. (1995). Predictors of psychological distress, sexual dysfunction and physical functioning among women with upper extremity lymphedema related to breast cancer. PsychoOncology, 4, 255-263.

Patterson, J.M., Hildreth, A., \& Wilson, J.A. (2007). Measuring edema in irradiated head and neck cancer patients. Annuals of Otology, Rhinology \& Laryngology, 116(8), 559-564. 
Pearson, S.E., Meyer, A.C., Adams, G.L., \& Ondrey, F.G. (2006). Decreased hearing after combined modality therapy for head and neck cancer. American Journal of Otolaryngology, 27(2), 76-80.

Pirozzo, S., Papinczak, T., \& Glasziou, P. (2003). Whispered voice test for screening for hearing impairment in adults and children: Systematic review. British Medical Journal, 327, 1-5.

Piso, D.U., Eckardt, A., Liebermann, A., Gutenbrunner, C., Schafer, P., \& Gehrke, A. (2001). Early rehabilitation of head-neck edema after curative surgery for orofacial turmors. American Journal Physical Medicine \& Rehabilitation, 80, 261-269.

Piso, D.U., Eckardt, A., Liebermann, A., \& Gehrke, A. (2002). Reproducibility of sonographic soft-tissue measurement of the head and neck. American Journal Physical Medicine \& Rehabilitation, 81, 8-12.

Polit, D.F., \& Beck, C. T. (2004). Nursing research: Principles and methods $\left(7^{\text {th }}\right.$ ed.). Philadelphia, PA: Lippincott Williams and Wilkins.

Powell, S.N., Taghian, A.G., Kachnic, L.A., Coen, J.J., \& Assaad, S.I. (2003). Risk of lymphedema after regional nodal irradiation with breast conservation therapy. International Journal of Radiation Oncology, Biology, Physics, 55(5), 12091215.

Pryor, D.I., Porceddu, S.V., Burmeister, B.H., Guminski, A., Thomson, D.B., Shepherdson, K., et al. (2009). Enhanced toxicity with concurrent cetuximab and radiotherapy in head and neck cancer. Radiotherapy and Oncology, 90(2), 172176.

Pusic, A., Liu, J.C., Chen, C.M., Cano, S., Davidge, K., Kalassen, A., et al. (2007). A systematic review of patient-reported outcome measures in head and neck cancer surgery. Otolaryngology-Head and Neck Surgery, 136, 525-535.

Radina, M.E., \& Armer, J.M. (2001). Post breast cancer lymphedema and their family: A qualitative investigation of families coping with chronic illness. Journal of Family Nursing, 7(3), 281-299.

Razavi, D., Delvaux, N., Bredart, A., Paesmans, M., Debusscher, L., Bron, D., et al. (1992). Screening for psychiatric disorders in a lymphoma out-patient population. European Journal of Cancer, 28A(11), 1869-1872.

Reichent, F.L., \& Mathes, M.E. (1936). Experimental lymphedema of the intestinal tract and its relation to regional cicatrizing enteritis. Annals of Surgery, 104(4), 601-616.

Reishtein, J.L. (2005). Relationship between symptoms and functional performance in COPD. Research in Nursing \& Health, 28(1), 39-47. 
Ridner, S. H. (2004). Psychological distress: Concept analysis. Journal of Advanced Nursing, 45(5), 536-545.

Ridner, S. H. (2005). Quality of life and a symptom cluster associated with breast cancer treatment- related lymphedema. Supportive Care in Cancer, 13(11), 904911.

Ridner, S. H. (2008). Lymphedema of the head and neck: An overview. National Lymphedema Network Lymph Link, 20(4), 1-3.

Ridner, S.H. (2009). The psycho-social impact of lymphedema. Lymphatic Research and Biology, 7(2), 109-112.

Rockson, S.G. (2001). Lymphedema. The American Journal of Medicine, 110, 288295.

Rockson, S.G. (2009). The unique biology of lymphatic edema. Lymphatic Research and Biology, 7(2), 97-100.

Rockson, S.G., \& Rivera, K.K. (2008). Estimating the population burden of lymphedema. Annals of the New York Academy of Sciences, 1131, 147-154.

Rudat, V., Dietz, A., Nollert, J., Conradt, C., Weber, K.J., Flentje, M., et al. (1999). Acute and late toxicity, tumor control and intrinsic radiosensitivity of primary fibroblasts in vitro of patients with advanced head and neck cancer after concomitant boost radiotherapy. Radiotherapy Oncology, 53, 233-245.

Rychnovsky, J.D. (2007). Postpartum fatigue in the active-duty military woman. Journal of Obstetric, Gynecologic and Neonatal Nursing, 36(1), 38-46.

Sanguineti, G., Adapala, P., Endres, E.J., Brack, C., Fiorino, C., Sormani, M.P., et al. (2007). Dosimetric predictors of laryngeal edema. International Journal of Radiation Oncology, Biology, Physics, 68(3), 741-749.

Savard, J., Laberge, B., Gauthier, J.G., Ivers, H., \& Bergeron, M.G. (1998). Evaluating anxiety and depression in HIV-infected patients. Journal of Personality Assessment, 71(3), 349-367.

Schiefke, F., Akdemir, M., Weber, A., Akdemir, D., Singer, S., \& Frerich, B. (2009). Function, postoperative morbidity, and quality of life after cervical sentinel node biopsy and after selective neck dissection. Head \& Neck, 31(4), 503-512.

Shih, Y-C.T., Xu, Y., Cormier, J.N., Giordano, S., Ridner, S.H., Buchholz, T.A., et al. (2009). Incidence, treatment costs, and complications of lymphedema after breast cancer among women of working age: A two-year follow-up study. Journal of Clinical Oncology, 27, 1-8. 
Shuman, A.G., Duffy, S.A., Ronis, D.L., Garetz, S.L., McLean, S.A., Fowler, K.E., et al. (2010). Predictors of poor sleep quality among head and neck cancer patients. Laryngoscope, 120(6), 1166-1172.

Smith, B.G., \& Lewin, J.S. (2010). Lymphedema management in head and neck cancer. Current Opinion of Otolaryngology \& Head and Neck Surgery, 18(3), 153-158.

Snaith, R.P. (2003). The Hospital Anxiety and Depression Scale. Health and Quality of Life Outcomes, 1, 1-4.

Sneddon, M.C., \& Lewis, M. (2007). Lymphoedema: A female health issue with implications for self care. British Journal of Nursing, 16(2), 76-81.

Soran, A., D’Angelo, G., Begovic, M., Ardic, F., Harlak, A., Wieand, H.S., et al. (2006). Breast cancer-related lymphedema-what are the significant predictors and how they affect the severity of lymphedema? The Breast Journal, 12(6), 536-543.

Speck, R.M., Gross, C.R., Hormes, J.M., Ahmed, R.L., Lytle, L.A., Hwang, W.T., et al. (2010). Changes in the Body Image and Relationship Scale following a oneyear strength training trial for breast cancer survivors with or at risk for lymphedema. Breast Cancer Research and Treatment, 121(2), 421-430.

Stein, K.D., Syrjala, K.L., \& Andrykowski, M.A. (2008). Physical and psychological long-term and late effects of cancer. Cancer Supplement, 112(11), 2577-2592.

Tabibiazar, R., Cheung, L., Han, J., Swanson, J., Beilhack, A., An A., et al. (2006). Inflammatory manifestations of experimental lymphatic insufficiency. PLoS Medicine, 3(7), e264.

Taylor, J.C., Terrell, J.E., Ronis, D.L., Fowler, K.E., Bishop, C., Lambert, M.T., et al. (2004). Disability in patients with head and neck cancer. Archives of Otolaryngology-Head and Neck Surgery, 130, 764-769.

Terrell, J.E., Nanavati, K.A., Esclamado, R.M., Bishop, J.K., Bradford, C.R., \& Wolf, G.T. (1997). Head and neck cancer-specific quality of life: Instrument validation. Archives of Otolaryngology - Head \& Neck Surgery, 122, 1125-1132.

Terrell, J.E., Ronis, D.L., Fowler, K.E., Bradford, C.R., Chepeha, D.B., Prince, M.E., et al. (2004). Clinical predictors of quality of life in patients with head and neck cancer. Archives of Otolaryngology-Head and Neck Surgery, 130(4), 401-408.

Teymoortash, A., Hoch, S., Eivazi, B., \& Werner, J.A. (2010). Postoperative morbidity after different types of selective neck dissection. Laryngoscope, 120(5), 924-929. 
Trochim, W.M.K. (2001). The research methods knowledge base ( ${ }^{\text {nd }}$ ed.). Cincinnati: Atomic Dog Publishing.

Trotti, A., Colevas, A.D., Setser, A., Rusch, V., Jaques, D., Budach, V., et al. (2003). CTCAE v3.0: Development of a comprehensive grading system for the adverse effects of cancer treatment. Seminars in Radiation Oncology, 13(3), 176-181.

Trotti, A., Colevas, D., Setser, A., \& Basch, E. (2007). Patient-reported outcomes and the evolution of adverse event reporting in oncology. Journal of Clinical Oncology, 25, 5121- 5127.

Twycross, R., Jenns, K., \& Todd, J. (2000). Lymphoedema. Oxford: Radcliffe Medical Press Ltd.

U.S. Census Bureau (2000). Population: Estimates and projections--states, metropolitan areas, cities. Retrieved June 10, 2010, from http://www.census.gov/compendia/statab/cats/population/estimates_and_projecti ons--states_metropolitan_areas_cities.html

U.S. Census Bureau (2006-2008). 2006-2008 American community survey 3-year estimates. Retrieved June 10, 2010, from

http://factfinder.census.gov/servlet/ACSSAFFFacts?_event=Search\&_state $=040$ 00US47\&_lang $=$ en $\& \_s s e=$ on

Uzarski, J., Drelles, M.B., Gibbs, S.E., Ongstad, E.L., Goral, J.C., McKeown, K.K., et al. (2008). The resolution of lymphedema by interstitial flow in the mouse tail skin. American Journal of Physiology: Heart and Circulatory Physiology, 294(3), H1326-1334.

van Bokhorst-de van der Schueren, M.A., van Leeuwen, P.A., Sauerwein, H.P., Kuik, D.J., Snow, G.B., \& Quak, J.J. (1997). Assessment of malnutrition parameters in head and neck cancer and their relation to postoperative complications. Head \& Neck, 19(5), 419-425.

van Wilgen, C.P., Dijkstra, P.U., van der Laan, B.F., Plukker, J.T., \& Roodenburg, J.L. (2004). Morbidity of the neck after head and neck cancer therapy. Head \& Neck, 26(9), 785-791.

Varricchio, C.G., \& Sloan, J.A. (2002). The need for and characteristics of randomized, phase III trials to evaluate symptom management in patients with cancer. Journal of the National Cancer Institute, 94, 1184-1185.

Vokes, E.E., Kies, M.S., Haraf, D.J., Stenson, K., List, M., Humerickhouse, R., et al. (2000). Concomitant chemoradiotherapy as primary therapy for locoregionally advanced head and neck cancer. Journal of Clinical Oncology, 18(8), 1652-1661.

Wade, D.T., \& Halligan, P.W. (2004). Do biomedical models of illness make for good healthcare system? British Medical Journal, 329, 1398-1401. 
Warren, A.G., Brorson, H., Borud, L., \& Slavin, S.A. (2007). Lymphedema: A comprehensive review. Annals of Plastic Surgery, 59(4), 464-472.

Warren, A.G., \& Slavin, S. A. (2007). Scar lymphedema: Fact or fiction? Annals of Plastic Surgery, 59, 41-45.

Weber, C., Dommerich, S., Pau, H.W., \& Kramp, B. (2010). Limited mouth opening after primary therapy of head and neck cancer. Oral and Maxillofacial Surgery, [Epub ahead of print].

Werner, J.A., \& Davis, R.K. (2004). Metastases in head and neck cancer. Berlin Heidelberg, Germany: Springer.

Wolff, H.A., Overbeck, T., Roedel, R.M., Hermann, R.M., Herrmann, M.K., Kertesz, T., et al. (2009). Toxicity of daily low dose cisplatin in radiochemotherapy for locally advanced head and neck cancer. Journal of Cancer Research and Clinical Oncology, 135(7), 961-967.

Zigmond, A.S., \& Snaith, R.P. (1983). The Hospital Anxiety and Depression Scale. Acta Psychiatrica Scandinavica, 67, 361-370.

Zimmermann, T., Leonhardt, H., Kersting, S., Albercht, S., Range, U., \& Eckelt, U. (2005). Reduction of postoperative lymphedema after oral tumor surgery with sodium selenite. Biological Trace Element Research, 106(3), 193-203. 